\title{
Modeling Watershed-Wide Bioretention Stormwater Retrofits to Achieve Thermal Pollution Mitigation Goals
}

\author{
Helen Y. Chen
}

Thesis submitted to the faculty of the Virginia Polytechnic Institute and State University in partial fulfillment of the requirements for the degree of

Master of Science

In

Civil Engineering

\author{
Randel L. Dymond, Chair \\ Clayton C. Hodges \\ Kevin D. Young
}

February 17, 2020

Blacksburg, VA

Keywords: stormwater management, best management practice (BMP), bioretention, temperature, thermal pollution, thermal mitigation, modeling, MINUHET 


\title{
Modeling Watershed-Wide Bioretention Stormwater Retrofits to Achieve Thermal Pollution Mitigation Goals
}

\author{
Helen Y. Chen
}

\section{ACADEMIC ABSTRACT}

Stream ecosystems are increasingly at risk for thermal impairment as urbanization intensifies, resulting in more heated runoff from impervious cover that is less likely to be cooled naturally. While several best management practices, including bioretention filters, have been able to reduce thermal pollution, success has been limited. The extent of thermal mitigation required to prevent ecological damage is unknown. A calibrated runoff temperature model of a case study watershed in Blacksburg, VA was developed to determine the cumulative treatment volume of bioretention filters required to reduce thermal impacts caused by runoff from development in the watershed to biologically acceptable levels. A future build out scenario of the study watershed was also analyzed. Results from this study established that runoff thermal pollution cannot be fully reduced to goal thresholds during all storms using bioretention filter retrofits. While retrofitting significantly decreased temperatures and heat exports relative to the controls, increasing treatment volumes did not really enhance mitigation. Alternate thermal mitigation methods which actively remove runoff volume should be considered where more thermal mitigation is required. 


\title{
Modeling Watershed-Wide Bioretention Stormwater Retrofits to Achieve Thermal Pollution Mitigation Goals
}

\author{
Helen Y. Chen
}

\section{GENERAL AUDIENCE ABSTRACT}

Stream temperature is a significant ecological, biological, and chemical property affecting the long-term health of streams. However, as development intensifies, stream ecosystems are increasingly at risk of being damaged by thermal pollution, which causes warmer and less stable temperatures that distress aquatic organisms. While several stormwater management methods that reduce runoff-related pollution, known as best management practices (BMPs), were found to also decrease thermal pollution, their success has been limited. Furthermore, the extent of thermal mitigation required to prevent ecological damage is unclear. This study aimed to determine how much treatment by a popular BMP, the bioretention filter, was necessary across a watershed in Blacksburg, VA to adequately reduce thermal pollution to protect stream health. Mitigation impacts were tested on both existing and predicted future development conditions through model simulations. Results from this study established that thermal pollution from runoff cannot be fully reduced to goal thresholds consistently using bioretention filter retrofits. While retrofitting significantly decreased thermal pollution, increasing treatment volume did not considerably enhance mitigation. Results suggested that bioretention filters are not an effective method, and alternate thermal mitigation practices which actively remove runoff volume should instead be considered where intensive reductions in thermal pollution are necessary. 


\section{Acknowledgements}

This thesis would never have been possible without the professors of classes I took during my time here at Virginia Tech; inspirations sparked while I was sitting in some of those classrooms. I would also like to acknowledge my gratitude towards my research committee for their advice and support. Thank you to Dr. Randy Dymond for encouraging me to think more critically and with perspective; I also learned a lot from you while assisting with hydrology class. Thank you to Kevin Young for providing meaningful feedback during meetings. I am especially grateful for having Dr. Clay Hodges help with this research process; he supported me through all the bumps and holes along the way (and there were countless).

This research involved a few unexpectedly specific topics in meteorology and biological systems, and I would like to thank everyone who assisted with those, especially Dr. Tess Thompson, who provided invaluable insight. I would also like to thank everyone from the Town of Blacksburg who helped provide essential data and facts. Additionally, without the guidance of Dr. Bill Herb, the MINUHET model may never have been constructed successfully.

Last but not least, I would like to thank my friends and family for their unwavering support and encouragement. Friends from the Fishbowl and Patton 310, thank you for making grad school enjoyable; you all were like families and I am glad to have been a part of them. Carlos, thanks for being a caring mentor. Liam, thanks for reassuring me that breaks are good whenever they were necessary, and more. And finally, huge thanks to my parents for always supporting me and my aspirations, especially Mom; words are not enough. 


\section{Table of Contents}

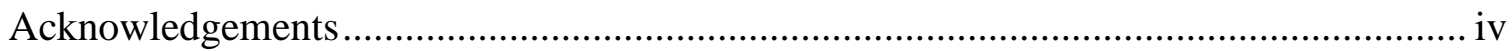

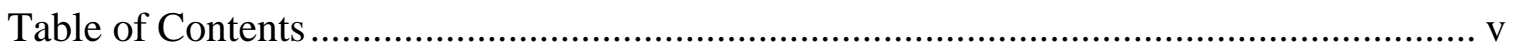

List of Figures ........................................................................................................ vii

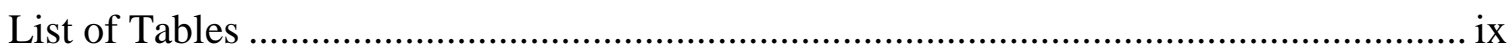

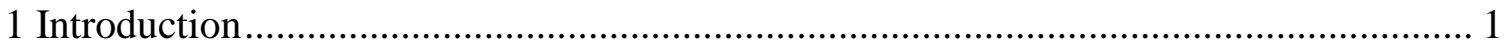

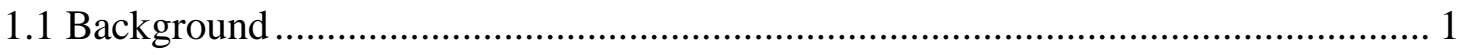

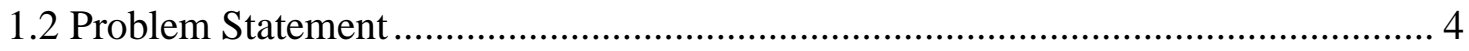

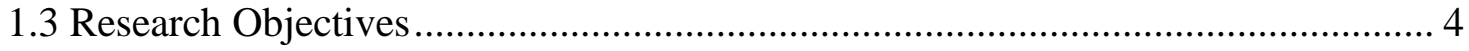

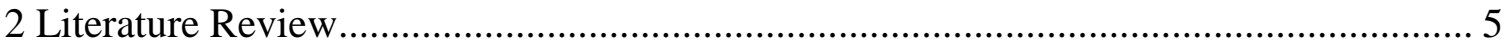

2.1 Factors of Stream Temperature (.......................................................................... 5

2.2 Mechanisms of Runoff Heat Transfer............................................................... 7

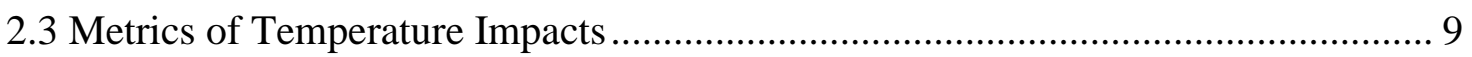

2.4 Runoff Temperature Modeling .......................................................................... 11

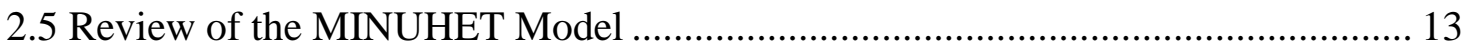

2.6 Thermal Mitigation Methods …………………….............................................. 15

2.7 Thermal Properties of Bioretention Basins ............................................................. 16

2.8 Topics Requiring More Research ........................................................................ 18

3 Modeling Watershed-Wide Bioretention Stormwater Retrofits to Achieve Thermal

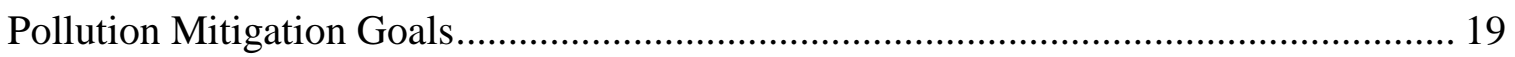

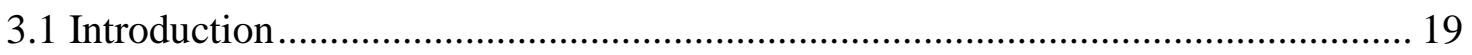

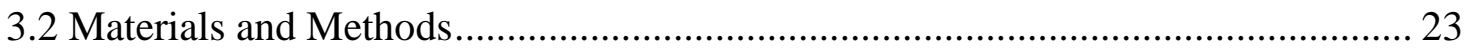

3.2.1 Study Area ………………………………………................................. 24

3.2.2 Study Storm Conditions ........................................................................... 24

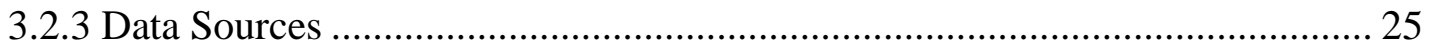




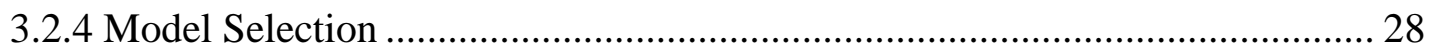

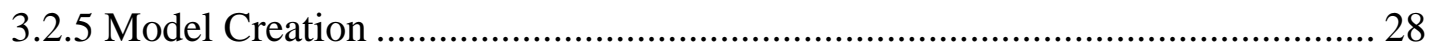

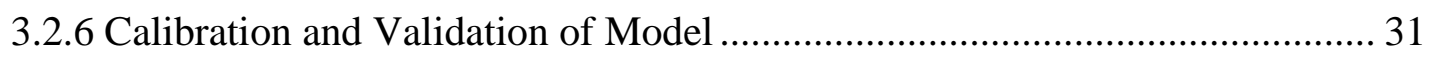

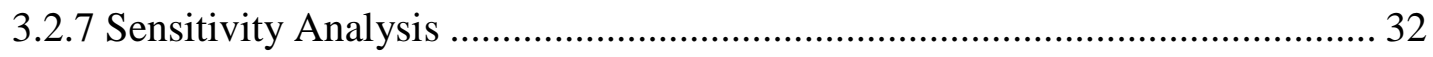

3.2.8 Future Build Out Scenario ......................................................................... 33

3.2.9 Bioretention Filter Retrofit Design .......................................................... 33

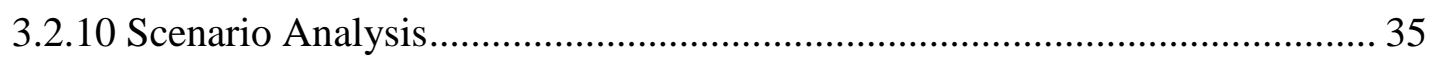

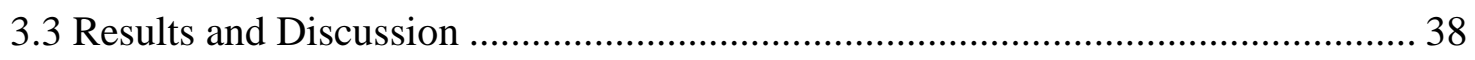

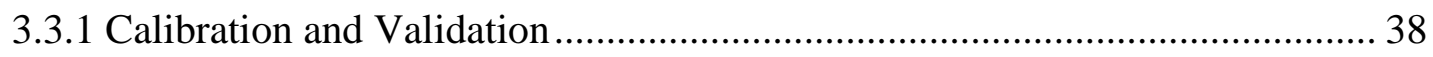

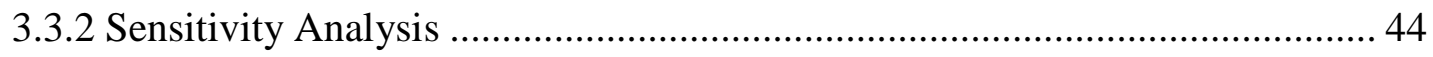

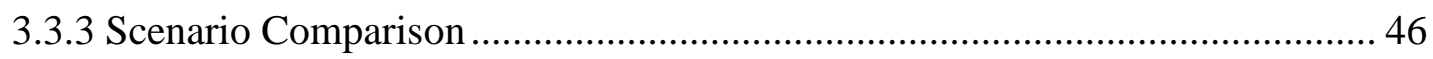

3.3.4 Retrofit Implementation Analysis .................................................................. 47

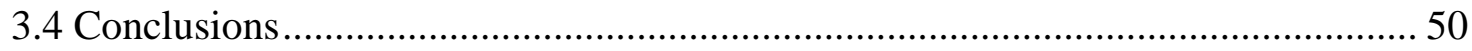

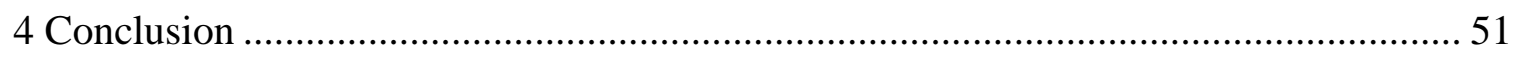

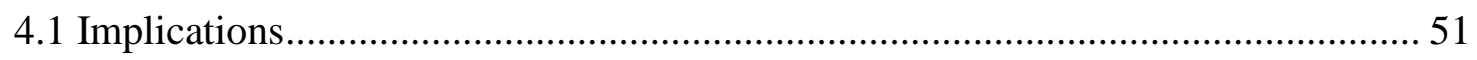

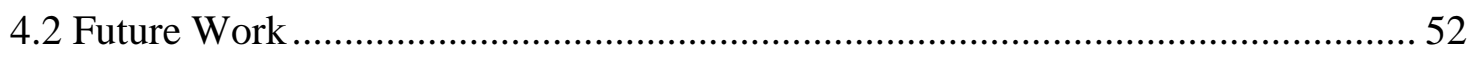

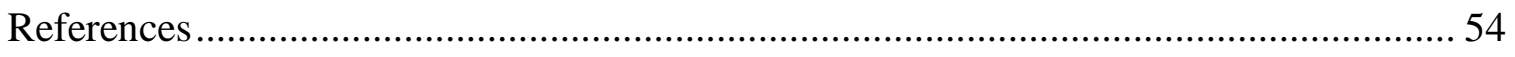

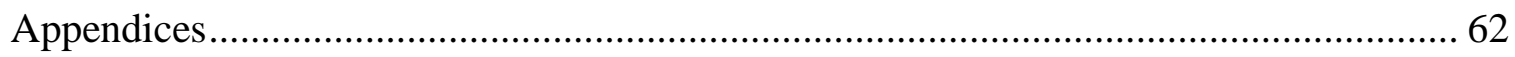

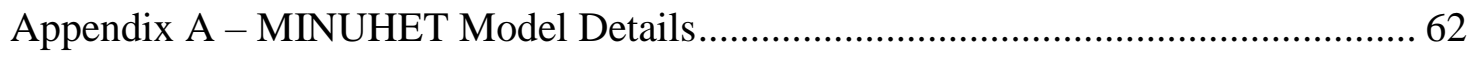

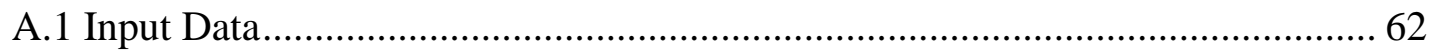

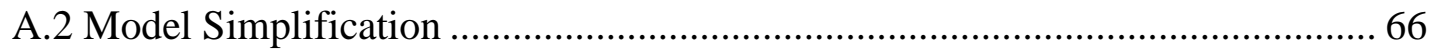

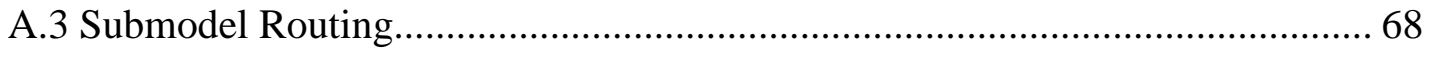

A.4 Simulation Instabilities of Bioretention Filter Facilities..................................... 69

Appendix B - Calibration and Validation Results..................................................... 70

B.1 Calibration and Validation Figures Not Included in Research Paper ................ 70 
B.2 Additional Storms Simulated by Model..................................................... 71

Appendix C - Supplemental Results .............................................................. 74

Appendix D - Design Storm Input Files........................................................... 77 


\section{List of Figures}

Figure 1. Diagram of Flow (Blue Arrows) and Heat Flux (Red Arrows) Balance in a System, from Herb et al. (2010b)............................................................................ 7

Figure 2. Locations of Observed Data Sensors Relative to Study Watershed ................. 26

Figure 3. Layout of Existing Condition Watershed ........................................................ 29

Figure 4. Layout of Future Build Out Watershed ...................................................... 33

Figure 5. Proposed Locations of Bioretention Filter Retrofits for Existing Conditions .. 37

Figure 6. Proposed Locations of Bioretention Filter Retrofits for Future Build Out Conditions

Figure 7. Discharge and Temperature Profiles of Select Calibration and Validation Simulations; Calibrated: (a) July 27, 2017 Storm, (b) August 7, 2017 Storm; Validated:

(c) July 31, 2017 Storm.

Figure 8. Relative Sensitivities of Runoff Volume and Max. Temperature to Model

Parameters; Runoff Volume: (a) June 19, 2017 Storm, (b) July 27, 2017 Storm; Max.

Temp.: (c) June 19, 2017 Storm, (d) July 27, 2017 Storm

Figure 9. Relative Sensitivities of Runoff Volume and Max. Temperature to Bioretention

Filter Properties; Runoff Volume: (a) June 19, 2017 Storm, (b) July 27, 2017 Storm;

Max. Temp.: (c) June 19, 2017 Storm, (d) July 27, 2017 Storm

Figure 10. Effects of Retrofit Analysis on Runoff Properties: (a) Volume, (b) Peak

Discharge 48

Figure 11. Effect of Retrofit Analysis on Temperature Metrics: (a) Max. Temperature,

(b) Event Mean Temperature, (c) Total Heat Export 48 


\section{List of Tables}

Table 1. Relevant Characteristics of Select Models Able to Determine Runoff

Temperatures (Listed in Reverse Chronology) .......................................................... 12

Table 2. Characteristics of Observed Summer Storm Events Used for Model Calibration,

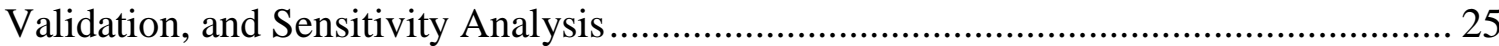

Table 3. Characteristics of Synthetic Design Storms Used for Scenario Modeling

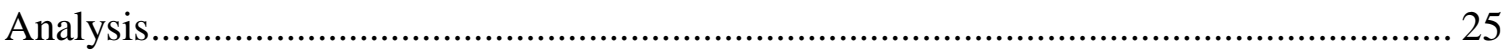

Table 4. Descriptions and Uncertainties of Sensors Measuring Observed Data.............. 27

Table 5. Characteristics of Drainage Areas of Bioretention Filters Used in Sensitivity

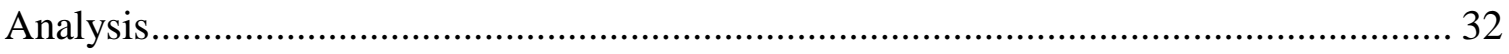

Table 6. Constant Properties of Bioretention Filter Retrofits ........................................... 35

Table 7. Calibrated Values of Parameters Used to Calibrate Flow Rate and Accepted

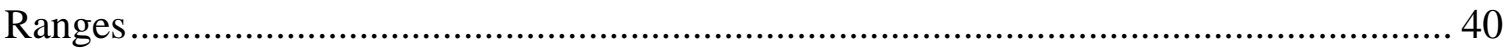

Table 8. Calibrated Values of Parameters Used to Calibrate Temperature and Accepted Ranges

Table 9. Calibration and Validation Goodness-of-fit Results for Runoff Flow Rates and

Temperatures.

Table 10. Summary of Control Scenario Runoff Characteristics and Temperature Metrics

Table 11. Required Bioretention Filter Surface Areas for Select Facilities 50 


\section{Introduction}

\subsection{Background}

Stormwater management in the United States has come a long way since the first version of the Clean Water Act (CWA) was passed in 1948 (Federal Water Pollution Control Act, 33 U.S.C. 1251 et seq. (1972) (amended 2002)). Formerly only addressing water quantity issues, contemporary stormwater regulations and land development practices have expanded to consider many aspects of water quality as well. Mitigation is becoming more crucial because the degradation of receiving waters is intensifying with continued development. Increases in stormwater runoff cause major ecological degradation, but stream temperature changes play a significant role as well. Those impacts have been uncovered through increased research and more advanced data collection technologies (Steel et al. 2017). Stream thermal regimes define riparian habitats ecologically, biologically, and chemically.

Similar to flow regimes, temperature regimes also impact biology (Steel et al. 2017). For instance, occurrence frequency of different temperatures impacts growth and metabolic rates in organisms, and rates of change influence species composition by causing the disappearance of species with low temperature tolerance (Steel et al. 2017). Trout, other salmonid fishes, and benthic macroinvertebrates are just a few examples of thermally sensitive organisms that have disappeared under changes to such temperature characteristics (Virginia Citizen Water Quality Monitoring Program 2007). Temperature magnitude, which has more widespread impacts, can also determine life cycle timing and other behavioral patterns in addition to the previously listed consequences (Steel et al. 2017). Although continuously uncharacteristic temperatures tend to be more harmful than short term abnormalities (Wardynski et al. 2014), organisms get stressed, become more vulnerable to disease, and may even die if water temperatures undergo extreme fluctuations (Steel et al. 2017). Moreover, water temperature impacts photosynthesis, $\mathrm{pH}$ values, chemical solubility, and dissolved oxygen content (Clark 2017; Ophardt 2015; Virginia Citizen Water Quality Monitoring Program 2007), among other chemical processes, of which long term deviations would further exacerbate ecological damage. 
Recognizing the ecological significance of temperature, the CWA requires state regulations to define allowable temperature thresholds (33 U.S.C. 1251 et seq. (1972)). These thresholds often vary according to a water body's designated use and are based on critical biological temperature thresholds for native organisms (33 U.S.C. 1251 et seq. (1972); Webster 2011). Temperature standards are often set as daily or weekly mean or maximum allowable temperatures (Webster 2011). In Virginia, water bodies are divided into seven classes, four of which have specific allowable maximum temperature criteria (Virginia Administrative Code, 9VAC25 ch. $260 \S 50$ (2017)). Trout waters have the strictest standards. Virginia regulations also restrict temperature fluctuations. In general, temperatures are not allowed to stray more than $3^{\circ} \mathrm{C}$ from the natural temperature, the predevelopment temperature unaffected by any point source discharges (Virginia Administrative Code, 9VAC25 ch. $260 \S 60$ (1992)). If temperatures surpass such thresholds, streams can be designated as impaired for temperature issues (National Research Council 2009). In the US, most identified issues occur in coldwater environments or where fishery industries are located (EPA 2012).

Thermal pollution results from both point and nonpoint sources. While point source thermal pollution is regulated by the National Pollutant Discharge Elimination System (NPDES), nonpoint sources are currently not strictly regulated in most of the US. One exception is Wisconsin, where water temperature impacts are considered during the land development process (Roa-Espinosa et al. 2003). Virginia, however, does not require stormwater management practices to control runoff temperature. Regardless, anthropogenic land changes inherently contribute to thermal impairment and therefore, the impacts should be acknowledged. In a pioneering study of anthropogenic impacts on stream temperature, Pluhowski (1970) compared urbanized streams with an undeveloped stream and found that development caused more extreme temperature fluctuations and magnitudes. Later studies revealed that urbanization increases impervious areas, runoff volumes, surface impoundment, point discharges, and deforestation, which lead to decreased runoff infiltration, less vegetation shading, and smaller baseflow to runoff ratios. Such impacts disrupt the natural thermal regime. 
Motivated by the need to fix temperature impairments, ways to reduce non-point source thermal pollution were investigated. Substituting traditional pavement and roof materials with less heat absorbent materials and increasing tree canopy cover are effective (Ketabchy et al. 2019). Other research revealed that certain stormwater best management practices (BMPs) are also able to lower temperature spikes in addition to reducing runoff and pollutants, including infiltration devices, rock cribs, and bioretention basins (Arrington et al. 2004; Jones and Hunt 2009; Long and Dymond 2013; Roa-Espinosa et al. 2003).

Bioretention basins are depressions filled with modified soils or filter media, a combination of "sand, soil, and organic material" (VA DEQ 2013). Vegetation grows on a mulch layer on the surface and helps remove pollutants and nutrients in the runoff collected (VA DEQ 2013). Bioretention basins are designed to treat small highly impervious drainage areas (less than $0.01 \mathrm{~km}^{2}$ ) on site (VA DEQ 2013), and are adept at controlling pollution from the first flush, which is the initial 1.27 to $2.54 \mathrm{~cm}(0.5$ to $1 \mathrm{in}$.) of runoff (Li, Dvorak, and Sung 2010). The BMP varies in size and process depending on drainage area characteristics. Small scale basins, mostly found on residential properties, are commonly called rain gardens (VA DEQ 2013). In Virginia, infiltration capability is a major process differentiator. In areas where karst geology and clayey soils restrict the infiltration of runoff, non-infiltrating bioretention facilities known as bioretention filters are typically used (VA DEQ 2013). Bioretention filters have an underdrain system consisting of perforated pipes sitting in a gravel layer below the filter media, which routes treated outflow into the stormwater network (VA DEQ 2013). While infiltration enhances temperature reduction capabilities of bioretention basins, non-infiltrating facilities were determined to still be effective (Long and Dymond 2013). Since bioretention facilities are recommended for stormwater management by Leadership in Energy and Environmental Design (LEED) and Sustainable Sites Initiative (SSI) (Li, Dvorak, and Sung 2010) and are also one of the most popular BMPs used in urban watersheds (Long and Dymond 2013), they are convenient stormwater control methods (SCMs) to implement for thermal pollution mitigation. 


\subsection{Problem Statement}

The thermal mitigation potential of bioretention basins and the other BMPs were largely demonstrated at the local scale. Since thermal pollution from runoff is a watershedwide issue (Long and Dymond 2013), more research on potential mitigation methods must be performed at the watershed level. Most practices studied were also not specifically designed for thermal pollution mitigation. Furthermore, existing studies suggested that individual mitigation efforts inadequately reduce downstream temperatures both locally (Booth, Kraseski, and Jackson 2014; Cockerill et al. 2017; Herb 2008; Long and Dymond 2013; Natarajan and Davis 2010; Winston, Hunt, and Lord 2011) and across a watershed (Ketabchy et al. 2019), in order to always meet desired temperature thresholds. Still, there is potential for mitigation success, as Ketabchy et al. (2019) suggested that thermal pollution in less impervious watersheds may be easier to treat, but how much thermal mitigation effort would be required is uncertain.

Evidently, a knowledge gap exists regarding the quantity of treatment necessary to meet thermal mitigation goals at the watershed level. This study endeavors to fill that gap by attempting to determine the cumulative treatment volume of bioretention filters required to reduce thermal impacts caused by runoff from development in target watersheds to acceptable levels using calibrated thermal models.

\subsection{Research Objectives}

Runoff temperature modeling of a case study was performed to meet the stated goal of this research, as modeling facilitates the investigation of various hypothetical scenarios. The objectives of this research were as follows:

1. Conduct literature review to compile existing information on the processes associated with stream and runoff temperatures, temperature mechanisms in bioretention filters, and thermal pollution modeling.

2. Obtain data necessary for developing a stormwater temperature model of the study watershed. Prepare and format the data for model input. 
3. Develop, calibrate, and validate a model of an urbanized watershed based on existing conditions to simulate stormwater discharges and temperatures at the outlet.

4. Perform a sensitivity analysis on critical parameters of the model.

5. Modify the calibrated model to represent proposed future build out conditions of the watershed.

6. Add bioretention basin retrofits to both the existing condition and future build out scenario models, designed and adjusted for various treatment volumes to:

a. Evaluate temperature impacts of bioretention filter retrofits on the existing watershed and how impacts varied with future development,

b. Determine whether the thermal mitigation method could adequately reduce thermal pollution to acceptable levels and if so, how much treatment volume would be required, and

c. Assess if implementation of the method would be practical.

\section{Literature Review}

\subsection{Factors of Stream Temperature}

Many parameters influence stream temperature. Meteorological factors are the most important influences on stream temperatures because they dictate heat exchange at the water-air interface (Janke et al. 2009; Mayer 2012; Thompson et al. 2008). For example, solar radiation on a water body is a major heat source (Edinger, Duttweiler, and Geyer 1968). Since stream temperatures follow the daily and seasonal cyclic trends exhibited by air temperatures (Watson and Chang 2017), stream ecosystems are most vulnerable to thermal degradation during the summer when air temperatures are the warmest. Landscape characteristics such as aspect, or directional orientation, and the amount of vegetation shading influence how much solar radiation the land is exposed to (Booth, Kraseski, and Jackson 2014; Dugdale, Bergeron, and St-Hilaire 2013; Mayer 2012; Pluhowski 1970; Watson and Chang 2017). More abundant shading promotes cooler stream temperatures. Also, elevation and slope affect runoff paths, including travel and ponding times, as well as how flow from various sources mix (Dugdale, Bergeron, and StHilaire 2013; Mayer 2012; Watson and Chang 2017). Martin, Hodges, and Dymond (2019) 
confirmed that land cover type and travel time were significant factors of runoff temperatures. More direct runoff into a stream more powerfully influences stream temperatures (Hathaway et al. 2016; Somers et al. 2013; Watson and Chang 2017). In contrast, larger catchment sizes tend to help buffer and decrease flow temperatures when contiguous pervious areas are present (Hathaway et al. 2016). Pervious surfaces allow for infiltration, which is one of the most effective processes for runoff heat mitigation (Chapman, Wawiernia, and Kieweg 2008) because water is cooled as it travels through colder soils. Infiltration also replenishes groundwater, contributing to baseflow, which has cooling benefits (Dugdale, Bergeron, and St-Hilaire 2013; Ketabchy et al. 2018; LeBlanc, Brown, and FitzGibbon 1997). Baseflow helps buffer thermal fluctuations.

With so many different factors, stream thermal regimes are expected to vary temporally and spatially under natural circumstances. In undeveloped watersheds, storms have been found to cause flow temperature decreases or only slight increases (Brown and Hannah 2007). On the other hand, storm events in developed watersheds cause flow temperatures to increase (Somers et al. 2013) since larger runoff to baseflow ratios allow external influences to more strongly impact stream temperatures (Arrington et al. 2004). Studies have also shown that climate change plays a role in increasing overall stream temperatures (Nelson and Palmer 2007; Selbig 2015). Climate change is predicted to exacerbate temperature-related consequences of urbanization; however, the thermal pollution from development is currently considered more critical (Nelson and Palmer 2007).

Urbanization is often correlated with deforestation, increased surface water impoundment, impervious areas, discharges from man-made sources, decreased infiltration, and more runoff volume. These changes cause stream temperatures to increase and have more extreme fluctuations. For instance, deforestation results in less shading, less evapotranspiration, and higher soil temperatures (Nelson and Palmer 2007; Risley, Roehl, and Conrads 2003). Impervious surfaces are major sources of thermal pollution. Impervious cover adds heat to stormwater flowing across the surface (Janke et al. 2009; Jones, Hunt, and Winston 2012), reduces infiltration, hindering the ability of baseflow to 
buffer streams from temperature fluctuations (Arrington et al. 2004; Nelson and Palmer 2007), and increases runoff volumes, which then causes stream incision and widening, increasing the flow surface area and thus allowing more atmospheric energy exchange (Klein 1979; LeBlanc, Brown, and FitzGibbon 1997). Shallow flows are more easily heated than deeper water (Nelson and Palmer 2007). Additionally, high intensity land uses close to watershed outlets have high thermal pollution potential (TPP) (Martin, Hodges, and Dymond 2019). Accordingly, surface runoff going directly into streams is one of the worst thermal pollution sources (Hathaway et al. 2016). Other urban infrastructures also produce thermal pollution, such as wastewater treatment plants which discharge treated wastewater (Kinouchi, Yagi, and Miyamoto 2007; Walker 1989). Even traditional stormwater management such as shallow lakes (Booth, Kraseski, and Jackson 2014; Pluhowski 1970) and detention basins (Jones and Hunt 2010) cause downstream temperatures to increase.

\subsection{Mechanisms of Runoff Heat Transfer}

Heat exchange processes shape runoff temperatures during overland flow, channel and pipe flow, and pond storage. Similar to flow balancing, energy balance is shaped by sources and sinks of heat (Figure 1). Heat exchange is dictated by three fundamental processes: conduction, convection, and radiation (Geankoplis, Hersel, and Lepek 2018).

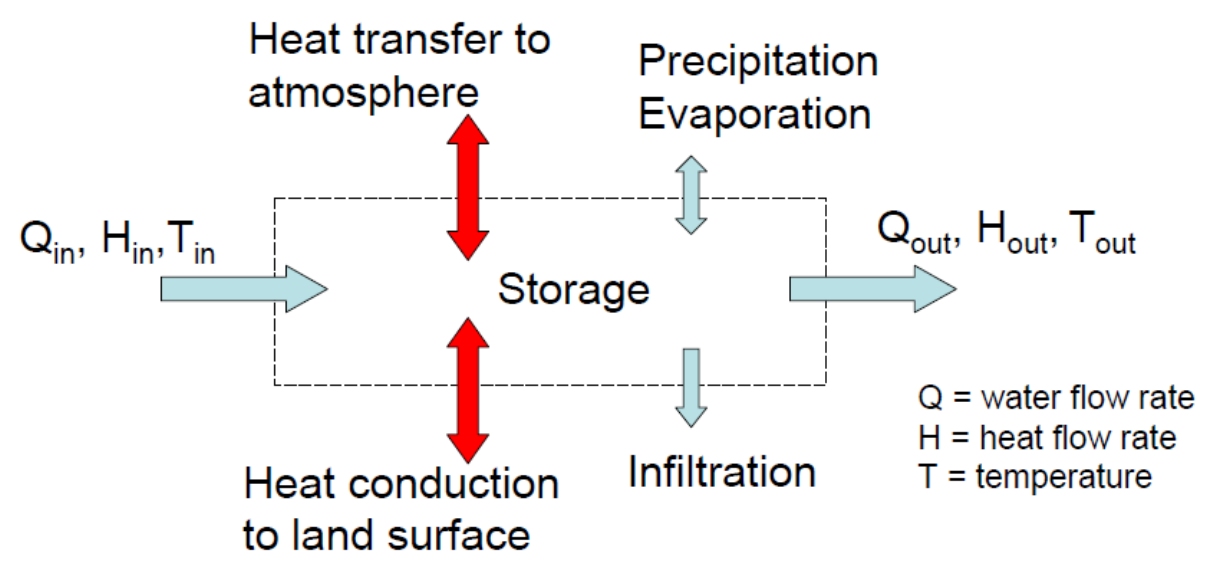

Figure 1. Diagram of Flow (Blue Arrows) and Heat Flux (Red Arrows) Balance in a System, from Herb et al. (2010b) 
At the water surface, heat transfer is impacted by meteorological conditions (Janke et al. 2009):

$\frac{\partial\left(y T_{R o}\right)}{\partial t} \rho C_{p}=-\frac{\partial\left(q T_{R o}\right)}{\partial x} \rho C_{p}+h_{\text {rain }}+h_{f}+h_{c o n d, p v}+h_{\text {rad }}+h_{\text {evap }}+h_{c o n v, a t m}$

where $T_{R O}$ is the temperature of runoff on the pavement $\left({ }^{\circ} \mathrm{C}\right), y$ is runoff depth $(\mathrm{m}), t$ is time (s), $\rho$ and $C_{p}$ are the density $\left(\mathrm{kg} / \mathrm{m}^{3}\right)$ and specific heat $(\mathrm{J} / \mathrm{kgK})$ of water, $q$ is the runoff flow rate per unit width $\left(\mathrm{m}^{2} / \mathrm{s}\right)$, and $x$ is the distance along pavement slope $(\mathrm{m})$. The heat flux from rainfall, infiltration, conduction between pavement and runoff water, net solar and long wave radiation, evaporation, and atmosphere are respectively represented by the variables $h_{\text {rain }}, h_{f}, h_{\text {cond,pv }}, h_{\text {rad }}, h_{\text {evap }}$, and $h_{\text {conv, atm, }}$ all in $\mathrm{W} / \mathrm{m}^{2}$. Radiation, in the forms of short wave solar radiation and long wave atmospheric radiation, plays a significant role. Net solar radiation is the heat directly from sunlight that is absorbed by a material minus the reflected radiation lost (Edinger, Duttweiler, and Geyer 1968). Net atmospheric radiation encompasses the radiation emitted by the gases that make up the atmosphere, again with the loss of reflected radiation accounted for (Edinger, Duttweiler, and Geyer 1968). Atmospheric convection is dependent on ambient air temperature (Edinger, Duttweiler, and Geyer 1968; Janke et al. 2009). Heat is also lost through emitted radiation from the water and through evaporation, which is dependent on the heat of vaporization, density of water, wind speed, and water movement (Edinger, Duttweiler, and Geyer 1968). During dry conditions, land surface temperatures are also influenced by radiation and conduction (Thompson et al. 2008; Van Buren et al. 2000).

The concept of equilibrium temperature states that heat exchange is driven by the temperature difference between a substance's temperature and the temperature at a steadied state (Edinger, Duttweiler, and Geyer 1968). By transferring heat energy from the warmer substance to the cooler substance, flow and pavement attempt to balance each other's temperatures during runoff over pavement (Edinger, Duttweiler, and Geyer 1968). Right where the liquid meets the solid surface, a thin layer exists where velocity can be assumed zero, referred to as the no-slip condition (Geankoplis, Hersel, and Lepek 2018). At this transitional layer, heat transfer occurs through conduction (Janke et al. 2009), driving both pavement and water temperatures to a state of equilibrium over time. The rate of heat 
exchange depends on the magnitude of the temperature difference (Edinger, Duttweiler, and Geyer 1968). Additionally, since runoff over rough pavement is considered turbulent flow (Geankoplis, Hersel, and Lepek 2018), complete mixing can be assumed for the thin layer of runoff water, which allows a uniform temperature to be assumed though the full depth (Edinger, Duttweiler, and Geyer 1968; Janke et al. 2009). Runoff heat transfer results are advected in the direction of movement (Janke et al. 2009).

During pipe flow, convective and conductive heat transfer occurs perpendicular to the pipe wall between the wall and runoff (Geankoplis, Hersel, and Lepek 2018). Pipe wall temperature is impacted by surrounding soil temperatures through conduction, and because pipes are buried, atmospheric and solar radiation effects may be neglected (Herb et al. 2010b). Empirical relationships are used to estimate heat transfer in turbulent regions of pipe flow, which experience greater transfer rates due to increased velocity (Geankoplis, Hersel, and Lepek 2018).

More factors influence temperature in ponds because the water is exposed to the atmosphere. Thermal energy in a pond is determined by water-air interface heat exchanges at the surface, heat flux of inflows and outflows, and pond bathymetry (Herb, Mohseni, and Stefan 2009). Sediment temperature may also impact water temperature at the bottom (Herb, Mohseni, and Stefan 2009). While wind works to mix water near the surface, vertical stratification occurs at deeper depths due to differences in water density and temperature (Herb, Mohseni, and Stefan 2009). The presence of vertical temperature profiles in ponds causes outflow temperatures to change as a function of exiting depth (Herb, Mohseni, and Stefan 2009).

\subsection{Metrics of Temperature Impacts}

Wardynski et al. (2014) provide thorough descriptions of several metrics recommended for assessing stormwater management impacts on stream thermal regimes. The metrics can be categorized into comparisons with three main threshold types: biological thresholds, flow reductions, and healthy reference conditions. Biological thresholds are derived from the critical conditions at which the biological processes of 
organisms of concern start to decline (Eaton et al. 1995). Such thresholds are often reflected in regulatory standards and represent acute or chronic temperature thresholds to which metrics are compared (Wardynski et al. 2014). Acute impacts are captured by short term metrics while responses to more chronic exposure are assessed with long term metrics. Metrics that work with biological thresholds include measurements of maximum and event mean temperatures as well as temperature-duration plots, which determine the frequency of temperature threshold exceedances (Wardynski et al. 2014).

An alternative metric focuses on measuring flow reductions, derived from knowledge that excess runoff causes environmental degradation (Wardynski et al. 2014). Also, temperature reductions were found to correlate with flow reductions (Jones and Hunt 2009). A 95\% runoff reduction is considered adequate to prevent thermal impacts (Wardynski et al. 2014). Thermal load, or heat export, computations combine both temperature and flow related metrics and are one of the most common methods used in studies of stormwater thermal impacts (Janke et al. 2009; Kieser et al. 2004; Long and Dymond 2013; Wardynski et al. 2014; Winston, Hunt, and Lord 2011). One advantage of using heat export is the inclusion of runoff volume impacts (Wardynski et al. 2014), which are significant in developed watersheds. A disadvantage of heat export is that the metric is highly dependent on the point of interest, as locations too upstream may not consider the mixing of multiple flow sources (Wardynski et al. 2014). By setting a biological threshold as the reference temperature, heat export quantifies the thermal energy added to a stream by runoff.

Comparison of uniform continuous above-threshold (UCAT) patterns between study and reference data offers long term, statistical probability analysis of thermal impacts on a stream (Wardynski et al. 2014). Use of a reference stream as reference data provides more holistic interpretations of thermal impacts than single-value biological thresholds (Wardynski et al. 2014). Reference streams used should be unaffected by development, hydrologically and physically similar to the study stream, and representative of the draining watershed (Wardynski et al. 2014). Alternatively, groundwater temperature is a more conservative reference threshold, but effectively provides an estimation of baseflow 
temperature since groundwater is a significant contributor to baseflow, a major flow source under undeveloped conditions (Wardynski et al. 2014). Regardless of the methods and thresholds used, a combination of different types of metrics is necessary to capture a wide scope of thermal impacts (Wardynski et al. 2014). Furthermore, metrics should be feasible within study constraints and available reference data, and threshold values should reflect the goals of a study (Wardynski et al. 2014).

\subsection{Runoff Temperature Modeling}

Many water temperature models, both stochastic and deterministic, have been developed and applied. Most of the existing models focus on simulating in-stream water temperatures or heat energy, including Qual2K (EPA 2009), HFLUX (Glose, Lautz, and Baker 2017), BasinTEMP (Allen et al. 2007), and various statistical models which relate air temperatures, flow, and equilibrium temperatures with stream temperatures to form predictions (Bogan, Mohseni, and Stefan 2003; Laanaya, St-Hilaire, and Gloaguen 2017; Mohseni, Stefan, and Erickson 1998; Morrill, Bales, and Conklin 2005), but do not explicitly calculate surface runoff temperatures. Several comprehensive hydrologic and/or hydraulic models with water temperature capabilities can calculate surface runoff heat exchanges. However, unless heat fluxes across impervious land cover are considered, such calculations are typically simplified and determined in order to supplement the computation of in-stream temperatures. These integrated models are able to analyze watershed-scale meteorological, landscape, and hydrological influences on stream thermal regimes (Ficklin et al. 2012; James and Xie 1999; St-Hilaire et al. 2015). There are also models which, in contrast, solely determine thermal impacts of runoff over impervious surfaces. Table 1 provides an overview of select water temperature models which account for the thermal effects of surface runoff. 
Table 1. Relevant Characteristics of Select Models Able to Determine Runoff

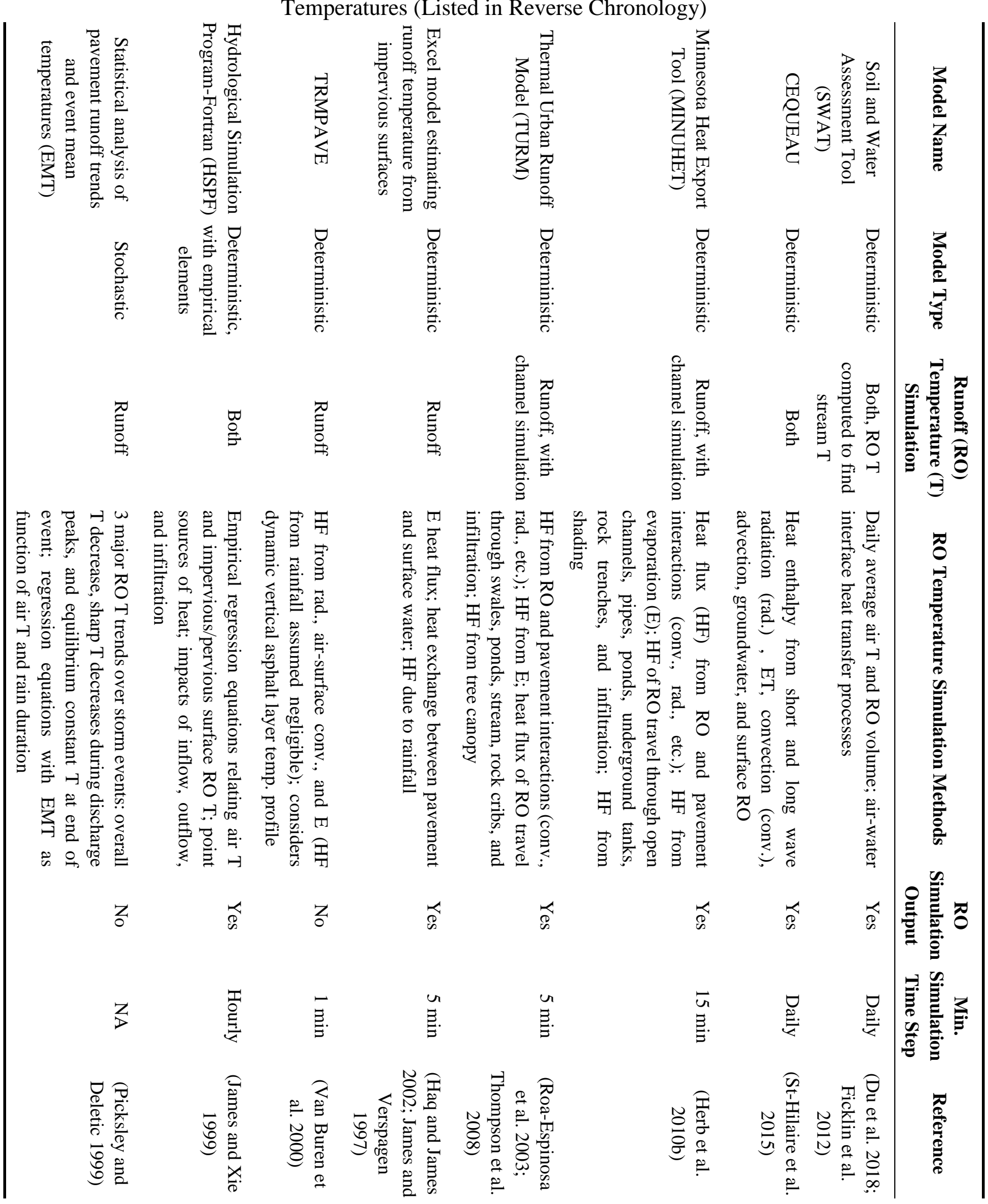


When modeling urban watersheds, it is beneficial for a model to be able to simulate both runoff discharge and temperature, because of the significant ecological impacts of runoff and heat export from urban areas, and consider the flow and thermal processes of runoff traveling through urban infrastructures. Thermal Urban Runoff Model (TURM) and Minnesota Heat Export Tool (MINUHET) are two deterministic runoff temperature models which explicitly consider multiple land cover types, model stormwater management infrastructure, and also simulate runoff discharge. While TURM has several strengths including applicability to a large range of watershed sizes and small computational time steps, rain intensity is assumed to be uniform and there is no mechanism built-in to consider pipe systems (Roa-Espinosa et al. 2003). The lack of pipe modeling ability is a major limitation, as heat transfer processes in pipe systems can be significant (Sabouri et al. 2013). In one study, differences between modeled and measured runoff temperatures were attributed to ignoring pipe cooling impacts (Van Buren et al. 2000). Therefore, a model which can model heat exchange in pipes is preferred.

\subsection{Review of the MINUHET Model}

MINUHET considers pipe heat transfer (Herb et al. 2010a). MINUHET, an eventbased, runoff temperature model applicable to urban watersheds, uniquely models heat transfer processes in underground stormwater detention tanks and infiltration ponds. However, this model also has limitations. MINUHET has no point source discharge input, assumes spatially uniform meteorological inputs, has inflexible component property requirements, produces less accurate results of modeled watersheds larger than $0.1 \mathrm{~km}^{2}$, and compared to more robust hydrologic and hydraulic models such as SWMM, lacks hydraulically relevant structural details (Herb et al. 2010a; Ketabchy et al. 2018). Limitations aside, the model provides valuable outputs of flow rate, water temperature, and heat export profiles at various nodes of a modeled network (Herb et al. 2010a). The model requires time-series input of storm event meteorological data: air temperature, wind speed, relative humidity, solar radiation, cloud cover, and precipitation depth (Herb et al. 2010a).

The MINUHET model is divided into three main subprograms which utilize flow and heat flux balancing: surface runoff, routing, and pond programs. Overland flow 
temperature is calculated through a heat transfer model considering radiation, convection, and evaporation (Herb et al. 2010a), fundamental mechanisms involved during the heat exchange of water (Edinger, Duttweiler, and Geyer 1968; Janke et al. 2009). The surface runoff program differentiates between pervious and impervious area and considers impervious area connectivity, vegetation density, and surface shading (Herb et al. 2010a). Discharge is simulated with Manning's equation and the conservation of mass for steady and unsteady flow, and infiltration is modeled based on the Green-Ampt equation (Herb et al. 2010a). The routing program calculates channel and pipe flow with the kinematic wave equation and corresponding flow temperatures with heat balance considering conduction with conveyance walls (Herb et al. 2010b). Atmospheric heat exchange at the water surface of channels are currently not considered by the model, limiting the accuracy of modeling flow temperatures through open channels with travel times greater than 1 hour (Herb et al. $2010 \mathrm{~b}$ ). The pond program is derived from one-dimensional lake models from MINLAKE (Ford and Stefan 1980; Hondzo and Stefan 1993) and can model detention, retention, and infiltration ponds (Herb et al. 2010b). Vertical pond temperature profiles are calculated over time for horizontal pond layers using heat diffusion and conduction, flow mixing, and surficial atmospheric heat transfer (Herb, Mohseni, and Stefan 2009). The volume of stored water is determined through flow balance considering flow flux, infiltration, evaporation, and rainfall, with outflows defined through outlet structures (Herb, Mohseni, and Stefan 2009).

MINUHET has been validated with several case studies since the model was first developed, for each individual subprogram and for the complete coupled model. The surface temperature model was verified for various pervious and impervious land covers (Herb et al. 2008) and subbasin runoff model results were compared to other similar models (Herb et al. 2006a). Validation of the coupled surface runoff and temperature model was also performed (Herb et al. 2009). The pond component of MINUHET was verified with field data to accurately estimate outflow temperatures (Herb et al. 2006b). However, more studies to validate the routing program for pipes and open channels are needed. 
Additional case studies evaluated MINUHET performance for various sized mixeduse watersheds: a $0.05 \mathrm{~km}^{2}$ residential watershed in Plymouth, Minnesota (Janke et al. 2013), a $0.13 \mathrm{~km}^{2}$ commercial site in Hastings, Minnesota (Herb 2008), and a $75 \%$ developed $14.1 \mathrm{~km}^{2}$ watershed in Blacksburg, Virginia (Ketabchy et al. 2018). Dew point temperature and soil saturated hydraulic conductivity were the recurring parameters that produced the greatest model sensitivities (Herb 2008; Janke et al. 2013; Ketabchy et al. 2018). Dew point temperatures significantly influence initial runoff temperatures because MINUHET assumes that precipitation temperatures are equal to dew point temperatures, especially during lighter storms (Janke et al. 2013; Ketabchy et al. 2018). Additionally, simulated runoff for scenarios with large amounts of pervious areas is highly sensitive to soil hydraulic conductivity because the property is a significant variable in the Green-Ampt method for infiltration (Janke et al. 2013). The case studies also revealed that modeled results were also impacted by the spatial resolution of the model, the delineation of subbasins in the modeled watershed, effective impervious areas, and thermal properties of pavement (Janke et al. 2013; Ketabchy et al. 2018). More spatial discretization improved the simulation of incremental output details (Janke et al. 2013). Subbasin surface roughness was a property determined to not significantly impact output results (Janke et al. 2013). Differences in model parameter sensitivity among the case study results were due to differences in characteristics of the storms simulated and in land cover composition. Furthermore, the case studies indicated that discharge simulations were more similar to results from models such as SWMM for small watersheds, and temperature simulation errors were smaller than discharge simulation errors for larger watersheds, although water temperature tends to be under-predicted by MINUHET (Janke et al. 2013; Ketabchy et al. 2018). The latter observation may be problematic where temperature threshold exceedances exist.

\subsection{Thermal Mitigation Methods}

Studies revealed the effectiveness of certain SCMs at mitigating thermal pollution. Storm sewer pipe networks help cool runoff (Jones, Hunt, and Winston 2012; Sabouri et al. 2013). Some specific BMPs were also tested to effectively reduce runoff temperatures, including level spreaders (Winston, Hunt, and Lord 2011), rock cribs (Roa-Espinosa et al. 
2003), thermal swales (Arrington et al. 2004), permeable pavement (Wardynski et al. 2014), underground detention (Natarajan and Davis 2010), infiltration devices, and bioretention basins (Jones and Hunt 2009; Long and Dymond 2013). Infiltrating bioretention basins are particularly effective at reducing runoff temperatures (Hunt, Davis, and Traver 2012; Long and Dymond 2013). Wetlands may also be effective if adequate shading is present (Kieser et al. 2004). Most studies on the SCMs were performed at the local scale and focused on inflow and outflow comparisons.

Ketabchy et al. (2019) were one of the first to evaluate thermal mitigation practices at the watershed level. The study investigated the effects of "cool" pavements and roofs, forest canopy coverage, and bioretention basins. Replacement of pavements and roofs with less heat absorbent materials resulted in the greatest total heat load reduction as an individual method, while bioretention basin retrofitting, in the form of infiltration ponds, was the least effective individual method (Ketabchy et al. 2019). Combination of the best performing variations of the different mitigation methods to form a comprehensive mitigation plan resulted in the overall lowest total heat loads and mean temperatures (Ketabchy et al. 2019). Nonetheless, the frequency that simulated temperature stayed above the study's established temperature threshold was still exceeded by $26 \%$ under the comprehensive plan, demonstrating that thermal pollution was not able to be fully mitigated under the study scenario (Ketabchy et al. 2019). Likewise, other previous studies on various thermal mitigation methods have also argued that meeting temperature regulations may not be possible (Booth, Kraseski, and Jackson 2014; Cockerill et al. 2017; Herb 2008; Long and Dymond 2013; Natarajan and Davis 2010; Winston, Hunt, and Lord 2011). It is unclear how much thermal mitigation must be implemented to fully reduce thermal pollution from runoff to ecologically harmless thresholds.

\subsection{Thermal Properties of Bioretention Basins}

Filter media thickness is a critical property controlling temperature reduction because thicker media ensures that deeper soils are far enough away from the surface to not be impacted by atmospheric temperature changes, warmed by sunlight, or significantly affected by vegetation shading (Hunt, Davis, and Traver 2012; Jones and Hunt 2007). 
Deeper conditions encourage runoff temperatures to equilibrate with surrounding soil temperatures of a facility (Jones and Hunt 2009). Accordingly, increasing runoff retention time may help decrease runoff temperatures by providing time for temperatures to equilibrate. Moreover, Long and Dymond (2013) confirmed that bioretention cooling did not have strong correlation with air temperatures, indicating that the filter media is well insulated. In fact, soil temperatures at least $1.2 \mathrm{~m}$ below the surface of bioretention basins seem to be coolest and stabilized (Jones and Hunt 2007), while soil temperatures within the top $0.6 \mathrm{~m}$ were measured to be relatively warm (Jones and Hunt 2009).

Flow temperatures in a bioretention facility are also effected by the amount of vegetal shading over surficial mulch and the filter media underneath, especially in shallower facilities (Hunt, Davis, and Traver 2012; Jones and Hunt 2007). Broad leaf vegetation can supply more complete coverage, providing the most cooling (Hunt, Davis, and Traver 2012; Jones and Hunt 2007). Light colored mulch also helps deflect solar radiation (Jones and Hunt 2007). Therefore, the selection of vegetation and plant substrate is important for thermal mitigation.

Bioretention facilities also reduce thermal pollution through runoff discharge reduction (Jones and Hunt 2009). Greater storage volume allows discharge to be decreased through increased exfiltration, evapotranspiration, and other abstractions (Brown, Skaggs, and Hunt 2013; Hunt, Davis, and Traver 2012). Therefore, by increasing bioretention cell storage volume through constructing larger surface areas or thicker filter media layers, temperature reduction potential can be increased. Internal water storages (IWS) at least $0.9 \mathrm{~m}$ below the surface were predicted to enhance thermal mitigation potential by increasing retention and heat transfer contact times, increasing exfiltration, and increasing runoff storage (Hunt, Davis, and Traver 2012; Jones and Hunt 2007). However, IWS systems are not recommended for $\mathrm{C}$ and $\mathrm{D}$ type soils, as use of IWS in low soil permeability increases the overflow potential of a bioretention basin (Brown and Hunt 2010).

Design and construction limitations must also be considered. Many design regulations have depth limitations due to concerns about vegetation health, sediment 
compaction potential, safety, adequate hydraulic head, and water table separation (Hunt, Davis, and Traver 2012; VA DEQ 2013). Bioretention filter dimensions are restricted by the area of buildable pervious surfaces. Long and Dymond (2013) predicted that bioretention basins will be most effective at cooling smaller volumes of runoff and Jones and Hunt (2009) found that larger bioretention areas do not improve temperature mitigation. Overall, few studies on the thermal impacts of specific bioretention basin properties have been conducted, so more research on this topic, especially field experiments, are needed.

\subsection{Topics Requiring More Research}

Much is known about stream temperature factors, both natural and anthropogenic. The physics behind heat transfer along routes that runoff typically follows are also well documented. Moreover, despite a lack of standardization in the research methods used to evaluate thermal pollution (Wardynski et al. 2014), existing methods are justified. Therefore, more research is needed in topics stemming from foundational information, such as how specific properties of runoff temperature reducing SWM methods effect each method's effectiveness. The determination of optimal properties for thermal mitigation would facilitate thermal pollution reduction in the future. Bioretention basin properties in particular, both with and without exfiltration, should be analyzed with more experiments focusing on individual properties. Furthermore, most existing studies investigated thermal mitigation at the local level, but because stream temperature is impacted at the watershed scale, it is important to assess each method's impacts when implemented at a larger scale. A single BMP may not significantly alter the temperature of a stream several kilometers downstream. Finally, the cumulative amount of mitigation necessary to meet temperature thresholds has not been determined for any tested thermal mitigation method reviewed. 


\section{Modeling Watershed-Wide Bioretention Stormwater Retrofits to Achieve Thermal Pollution Mitigation Goals}

\subsection{Introduction}

As development continues, increasing impervious land areas will exacerbate not only stormwater runoff quantities, but also stormwater temperatures. Rises in average stream temperature due to development has caused accelerated degradation of the aquatic habitats in receiving streams, negatively affecting wildlife, aquatic plants, and the ability for many of these waters to be used for recreation. Temperature is a significant ecological, biological, and chemical property affecting the long-term health of streams (Steel et al. 2017; Virginia Citizen Water Quality Monitoring Program 2007). Aquatic organism health, growth, birth, and survivability are heavily impacted by increasing average temperatures and their more extreme fluctuations (Steel et al. 2017). Since many aquatic organisms such as benthic macroinvertebrates and trout are thermally sensitive, species diversity is also impacted (Steel et al. 2017). Additionally, water temperature affects dissolved oxygen content and other water quality properties, further jeopardizing the survivability of aquatic species in the altered environment (Thompson et al. 2008; Virginia Citizen Water Quality Monitoring Program 2007). Stormwater management (SWM) in response to the eroding ecological health of streams has led to broad interest in reducing urbanization's thermal impacts.

Guides for stream health, thermal thresholds are often defined by the acute or chronic biological tolerances of sensitive species, and are typically reflected in regulations. For instance, Virginia water quality standards impose a maximum temperature of $21^{\circ} \mathrm{C}$ for stocked trout waters (Virginia Administrative Code, 9VAC25 ch. $260 \S 50$ (2017)). Such thresholds are benchmarks to which various metrics are compared in order to quantify thermal pollution. Short term metrics include measurements of maximum or mean temperatures and heat export (Wardynski et al. 2014). Heat export computations are especially advantageous in urbanized watersheds because they also consider runoff volume impacts. For longer term assessments, the frequency of threshold exceedances over time is analyzed (Wardynski et al. 2014). 
During the summer when air and rainfall temperatures are warmest, stream ecosystems are most at risk for elevated temperatures. Meteorological factors are the most important influences on stream temperature because they dictate heat exchange processes at the water-air interface (Janke et al. 2009; Mayer 2012; Thompson et al. 2008). For example, direct solar radiation heats water bodies (Edinger, Duttweiler, and Geyer 1968). Besides weather, many other natural factors also influence ultimate stream temperature, including watershed characteristics and flow behavior. Catchment size can act as a buffering mechanism to help decrease flow temperatures if contiguous pervious areas are present (Hathaway et al. 2016). Land cover, elevation, slope, and aspect, or directional orientation, are surficial landscape features affecting stream temperature (Dugdale, Bergeron, and St-Hilaire 2013; Mayer 2012; Nelson and Palmer 2007; Watson and Chang 2017). In particular, high amounts of vegetation shading help decrease runoff temperatures (Booth, Kraseski, and Jackson 2014).

Under the surface, geology influences how flow migrates through a watershed (Nelson and Palmer 2007). Water is cooled as it travels through colder soils, resulting in infiltration being one of the most effective processes for mitigating runoff heat and replenishing groundwater (Chapman, Wawiernia, and Kieweg 2008). Groundwater and its contribution to baseflow aids the cooling of streams through buffering (Dugdale, Bergeron, and St-Hilaire 2013; Ketabchy et al. 2018; LeBlanc, Brown, and FitzGibbon 1997). Since infiltration is a significant flow cooling mechanism, areas with limited infiltration have more difficulty mitigating thermal pollution caused by development.

There have been a number of research studies of anthropogenic impacts on stream temperature within the last 50 years. Comparison of urbanized streams with an undeveloped stream revealed that development caused more extreme temperature fluctuations and magnitudes (Pluhowski 1970). Deforestation eliminates natural cooling from shading and evapotranspiration (Nelson and Palmer 2007; Risley, Roehl, and Conrads 2003). Impervious surfaces contribute significantly to stream warming by reducing infiltration (Nelson and Palmer 2007) and adding heat to stormwater as it flows across those surfaces (Janke et al. 2009; Jones, Hunt, and Winston 2012). As land use becomes more intensive, those areas will have higher thermal pollution potential (TPP) (Martin, Hodges, and Dymond 2019), especially closer to outlet points since the directness of 
runoff entry into a stream increases surface flow's impacts on the stream's temperature (Hathaway et al. 2016; Somers et al. 2013; Watson and Chang 2017). Greater impervious cover also causes higher runoff volumes, which change stream morphology in ways that allow more energy exchange with the atmosphere (Klein 1979; LeBlanc, Brown, and FitzGibbon 1997; Nelson and Palmer 2007). Supporting infrastructure for urbanization also causes negative thermal impacts. A direct source of thermal pollution is wastewater treatment plant discharge from standard treatment practices (Kinouchi, Yagi, and Miyamoto 2007; Walker 1989). Even traditional SWM practices such as shallow lakes (Booth, Kraseski, and Jackson 2014; Pluhowski 1970) and detention basins (Jones and Hunt 2010) increase downstream temperatures due to heat absorption during impoundment. Storm sewer pipe networks are exceptions, and actually help cool runoff temperatures by conveying water underground (Natarajan and Davis 2010; Sabouri et al. 2013), although they contribute to stream degradation in other ways (Walsh et al. 2005).

Fortunately, newer types of stormwater management that treat smaller quantities of runoff on site, known as best management practices (BMPs), were found to be effective at reducing water contamination and decreasing the temperature of runoff, perhaps since water is not impounded above ground for long periods of time. Such BMPs include level spreaders (Winston, Hunt, and Lord 2011), rock cribs (Roa-Espinosa et al. 2003), thermal swales (Arrington et al. 2004), underground detention (Natarajan and Davis 2010), permeable pavement (Wardynski et al. 2014), bioretention basins (Jones and Hunt 2009; Long and Dymond 2013), and any management technique involving infiltration (Arrington et al. 2004; Jones, Hunt, and Winston 2012). Effective at treating both water quality and quantity, bioretention basins are one of the most popular BMP methods used in urban watersheds (Long and Dymond 2013).

Bioretention basins are depressions filled with filter media or amended soils, have vegetation growing at the surface, and are designed to treat small highly impervious drainage areas on site (VA DEQ 2013). Bioretention basins vary in size and process, with a main differentiator being infiltrative capability. Non-infiltrating bioretention facilities, or "bioretention filters," are typically used in areas where karst geology and clayey soils inhibit the effectiveness of runoff infiltration (VA DEQ 2013). Bioretention filters have an underdrain system consisting of 
perforated pipes sitting in a gravel layer below the filter media (VA DEQ 2013). The underdrain routes treated runoff from the BMP to the storm sewer network.

Thermal cooling capabilities of bioretention filters stem mainly from the filter media component, where heat is dissipated through conduction with cooler substrate (Long and Dymond 2013). Deeper soils are protected from atmospheric temperature changes, sunlight warming, and influences of vegetation shading (Hunt, Davis, and Traver 2012; Jones and Hunt 2007; Long and Dymond 2013). Accordingly, thicker and deeper filter media cools runoff more effectively (Brown and Hunt 2010; Jones and Hunt 2009), but bioretention facility depths are often limited by design regulations due to safety and facility integrity concerns (Hunt, Davis, and Traver 2012; VA DEQ 2013). Planted vegetation facilitates thermal mitigation by shading the mulch and filter media from solar radiation, especially broad leaf plants which can provide full coverage (Hunt, Davis, and Traver 2012; Jones and Hunt 2007). Using light colored mulch also helps deflect solar radiation from the facility (Jones and Hunt 2007).

Although few studies on the thermal impacts of bioretention facilities have been conducted, decreases in thermal loading were linked to reductions in discharge (Jones and Hunt 2009; Long and Dymond 2013). Bioretention basin runoff reduction mechanisms are better established. Thus, bioretention facilities allowing exfiltration and greater runoff storage, through thicker media and internal water storage (IWS), have more temperature reduction potential (Brown and Hunt 2010; Hunt, Davis, and Traver 2012; Jones and Hunt 2007; Li et al. 2009). Long and Dymond (2013) predicted that bioretention basins are most effective at cooling smaller volumes of runoff, but further research about bioretention basin applications for thermal mitigation would be beneficial.

Use of stormwater models can aid in determining the most efficient methods for tackling thermal pollution. Most existing water temperature models focus on in-stream temperatures and only consider runoff thermal processes implicitly (Bogan, Mohseni, and Stefan 2003; Glose, Lautz, and Baker 2017; Laanaya, St-Hilaire, and Gloaguen 2017; Mohseni, Stefan, and Erickson 1998; Morrill, Bales, and Conklin 2005). However, comprehensive hydrologic and/or hydraulic models with water temperature simulation capabilities are able to analyze watershed-scale meteorological, landscape, and hydrological influences on stream thermal regimes, and do 
compute runoff temperatures, albeit with simplified heat exchanges (Ficklin et al. 2012; James and Xie 1999; St-Hilaire et al. 2015). On the other side of the spectrum, several stochastic and deterministic temperature models focus solely on the impacts of runoff over impervious surfaces (Haq and James 2002; Picksley and Deletic 1999; Van Buren et al. 2000), and cannot model watersheds with variable land cover. Perhaps the most useful for devising thermal pollution solutions are models that account for both flow rate and heat transfer through various stormwater infrastructures, as runoff volume and heat export in urban environments can be critical.

Although several studies suggested that meeting target temperatures set by regulatory guidance may not be possible (Booth, Kraseski, and Jackson 2014; Cockerill et al. 2017; Herb 2008; Ketabchy et al. 2019; Long and Dymond 2013; Natarajan and Davis 2010; Winston, Hunt, and Lord 2011), no research testing how much mitigation would be necessary for successful thermal mitigation was found. This study attempted to clarify the uncertainty surrounding thermal mitigation requirements at the watershed scale and determine the cumulative treatment volume of bioretention filters required to reduce thermal impacts caused by runoff from development in target watersheds to acceptable levels using calibrated thermal models.

\subsection{Materials and Methods}

To meet the stated goal of this study, a case study application was developed and divided into the following tasks:

1. Develop, calibrate, and validate a model of the case study watershed based on existing conditions and add future development to the calibrated model. These act as control scenarios.

2. Perform a sensitivity analysis on critical parameters of the model.

3. Add bioretention basin retrofits, designed and modified for various treatment volumes, to both control scenario models to evaluate retrofit impacts on the controls, determine whether this mitigation method could adequately reduce thermal pollution to acceptable levels and the quantity of treatment volume required, and if implementation of this method would be practical. 


\subsubsection{Study Area}

The case study site is a $0.8 \mathrm{~km}^{2}$ watershed in Blacksburg, located in southwest Virginia, which has karst. The watershed's outlet has been monitored for flow, velocity, and temperature. The study watershed is part of the Toms Creek - Poverty Creek watershed (HUC12: 050500011804) (VA DCR 2020). Toms Creek has an unresolved temperature impairment and is designated as a stocked rainbow trout stream (VA DEQ 2018; VA DGIF 2020). The study watershed is $84 \%$ developed, containing approximately $34 \%$ impervious land cover and consists of mainly residential areas and open space, with some civic, commercial, and industrial land uses. The watershed's stormwater management infrastructure consists of approximately $7.2 \mathrm{~km}$ of storm sewer pipes, 11 detention ponds, 2 retention ponds, 8 bioretention filters, and 1 underground detention facility.

\subsubsection{Study Storm Conditions}

This study focused on summer storms (June to August) because temperature issues are most critical during warm weather (Nelson and Palmer 2007). Observed data was used for calibration and validation of the model (Table 2), while synthetic design storms were used for scenario analysis to ensure more consistent inputs (Table 3). The design storms were developed from conditions which maximized temperature issues, based on a study deriving design storms from heat export potential by Herb, Mohseni, and Stefan (2007). Accordingly, short duration, summer evening storms were used as model inputs. The design storm was set on the day with the highest temperature within the observed data period. Preliminary testing determined that rainfall beginning at 18:00 produced the warmest runoff temperatures. Observed air temperature, relative humidity, wind speed, and cloud cover data were used for the design storms. Ideal solar radiation values were computed with the Cosine Law of Illumination using geographic elevation angle values (Gronbeck 2009; Honsberg and Bowden 2019). Design storm precipitation depths were computed with National Oceanic and Atmospheric Administration (NOAA) Atlas 14 point precipitation frequency estimates for Station 44-0765 (NOAA 2017) following the Natural Resources Conservation Service (NRCS) Type II Distribution (NRCS 1986). A range of return periods which would unlikely be bypassed by bioretention basins were analyzed because stream temperatures have been found to vary inversely with storm intensity (Jones and Hunt 2009). 
Table 2. Characteristics of Observed Summer Storm Events Used for Model Calibration, Validation, and Sensitivity Analysis

\begin{tabular}{ccccccc}
\hline Storm Event & $\begin{array}{c}\text { Event } \\
\text { Distribution } \\
\text { (hr) }\end{array}$ & $\begin{array}{c}\text { Start } \\
\text { Time } \\
(\mathbf{h h : m m})\end{array}$ & $\begin{array}{c}\text { Duration } \\
(\mathbf{h r})\end{array}$ & $\begin{array}{c}\text { Total } \\
\text { Rainfall } \\
\text { Depth }(\mathbf{m m})\end{array}$ & $\begin{array}{c}\text { Intensity } \\
(\mathbf{m m} / \mathbf{h r})\end{array}$ & $\begin{array}{c}\text { Air } \\
\text { Temperature } \\
\text { Right Before } \\
\text { Storm }\left({ }^{\circ} \mathbf{C}\right)\end{array}$ \\
\hline June 6, 2017 & 1.25 & $13: 00$ & 1.25 & 21.8 & 17.44 & 23.72 \\
July 4, 2017 & 47.00 & $18: 15$ & 8.50 & 41.9 & 4.93 & 22.65 \\
July 27, 2017 & 34.25 & $13: 15$ & 7.00 & 28.7 & 4.1 & 26.33 \\
July 31, 2017 & 1.75 & $17: 15$ & 1.75 & 8.6 & 4.91 & 24.92 \\
August 7, 2017 & 19.25 & $4: 30$ & 6.25 & 25.4 & 4.06 & 17.65 \\
\hline
\end{tabular}

Table 3. Characteristics of Synthetic Design Storms Used for Scenario Modeling Analysis

\begin{tabular}{ccccccc}
\hline $\begin{array}{c}\text { Storm } \\
\text { Return } \\
\text { Period, } \mathbf{T}_{\mathbf{R}}\end{array}$ & Date & $\begin{array}{c}\text { Start } \\
\text { Time } \\
(\mathbf{h h : m m})\end{array}$ & $\begin{array}{c}\text { Duration } \\
\mathbf{( h r )}\end{array}$ & $\begin{array}{c}\text { Total } \\
\text { Rainfall } \\
\text { Depth }(\mathbf{m m})\end{array}$ & $\begin{array}{c}\text { Intensity } \\
(\mathbf{m m} / \mathbf{h r})\end{array}$ & $\begin{array}{c}\text { Air Temp. } \\
\text { Right Before } \\
\text { Storm }\left({ }^{\circ} \mathbf{C}\right)\end{array}$ \\
\hline 1-year & July 22, 2017 & $18: 00$ & 1.00 & 25.7 & 25.7 & 31.12 \\
2-year & July 22, 2017 & $18: 00$ & 1.00 & 31.2 & 31.2 & 31.12 \\
5-year & July 22, 2017 & $18: 00$ & 1.00 & 39.6 & 39.6 & 31.12 \\
\hline
\end{tabular}

\subsubsection{Data Sources}

Study watershed stormwater infrastructure information was taken from the Town of Blacksburg's stormwater infrastructure Geographical Information System (GIS) database (Blacksburg 2019). Land cover, elevation, and soil survey data were from the Detailed Land Cover Database (DLCD) and aerial imagery, LiDAR survey data, and Soil Survey Geographic Data (SSURGO), respectively, all obtained from the Town of Blacksburg (Blacksburg 2019). Available design plans of developments and stormwater facilities from the Town of Blacksburg supplemented GIS data.

Observed streamflow level, velocity, and temperature were obtained from the Town's ISCO 2150 area-velocity sensor (Blacksburg 2017, unpublished data) located inside a $1.83 \mathrm{~m}$ (72”) concrete culvert at the watershed outlet. Streamflow rate was calculated with the continuity equation. Runoff was derived from streamflow using the constant baseflow method (McCuen 2017), assuming baseflow as the average baseflow prior to the storm event. Precipitation, air temperature, wind speed, net solar radiation, and cloud cover datasets were required to run the model. While most meteorological datasets were from the StREAM Lab weather station (StREAM 
Lab 2019), cloud cover was not measured at that site. Cloud cover data was obtained from local climatological data (LCD) at the Virginia Tech Airport NOAA station. Shenandoah rain gage precipitation data (Blacksburg 2018), maintained by Town of Blacksburg, was used because the gage was located inside the study watershed and recorded at smaller time intervals. Sensor details are listed in Table 4. See Figure 2 for sensor locations relative to the study site.

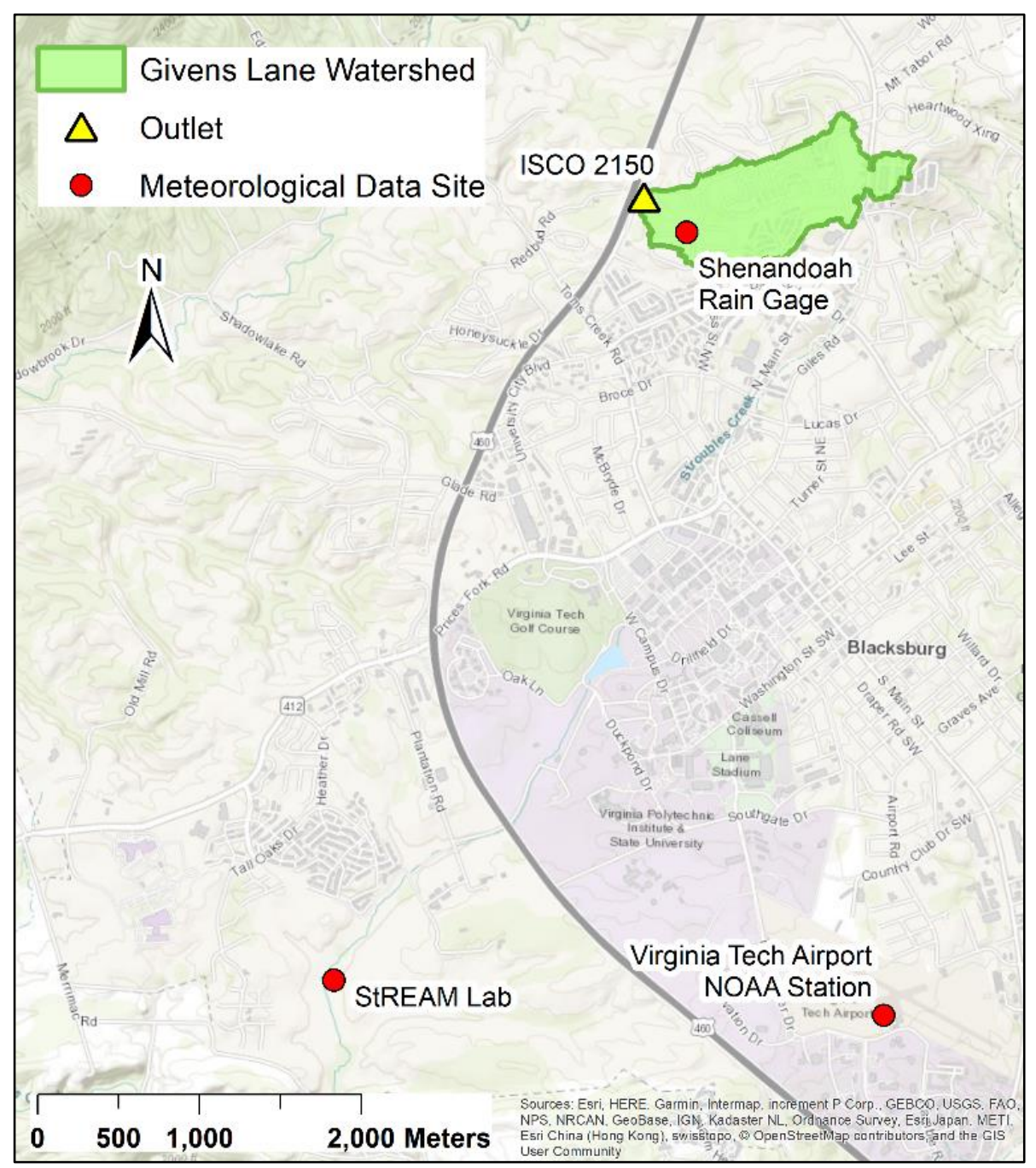

Figure 2. Locations of Observed Data Sensors Relative to Study Watershed 
Table 4. Descriptions and Uncertainties of Sensors Measuring Observed Data

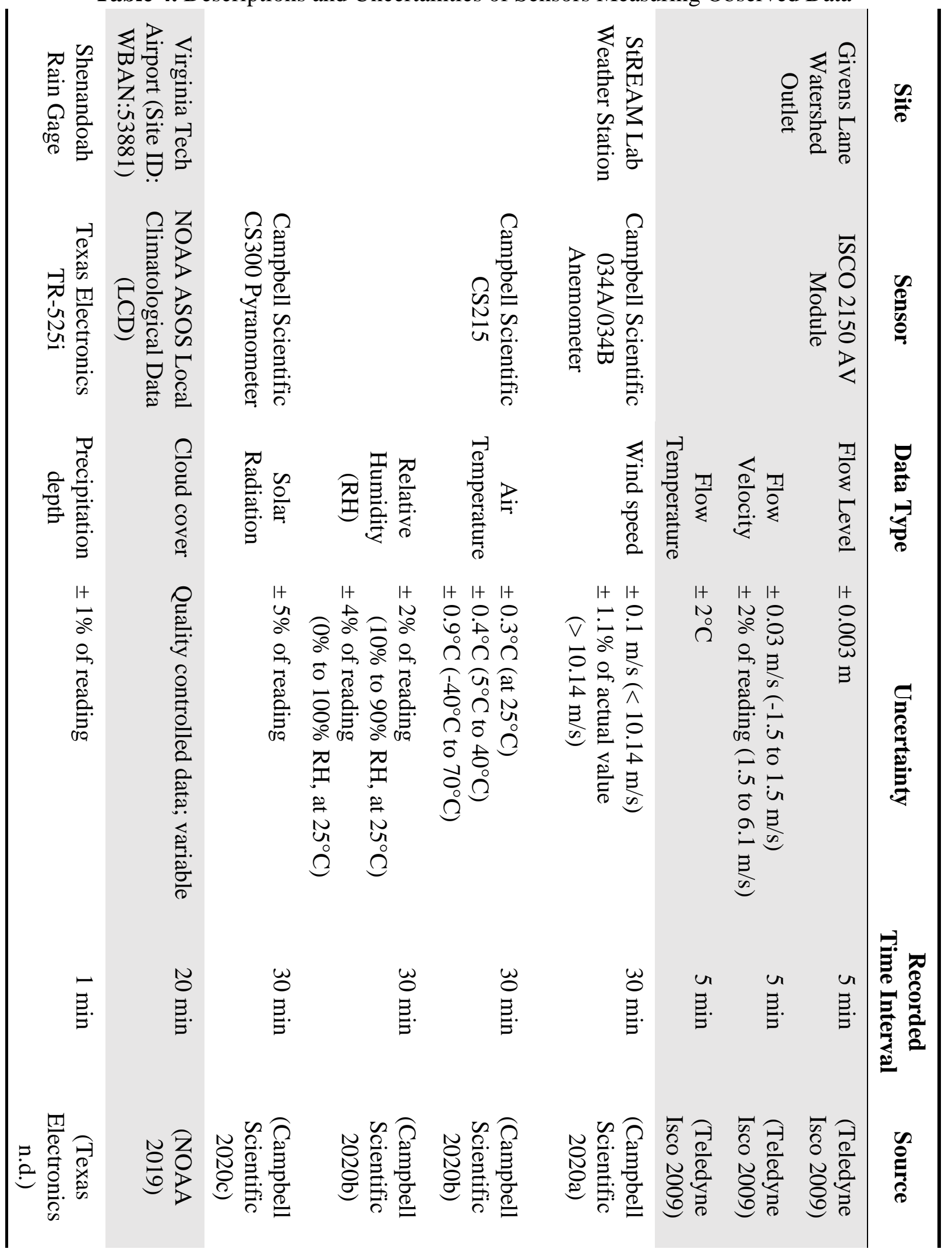




\subsubsection{Model Selection}

The Thermal Urban Runoff Model (TURM) (Roa-Espinosa et al. 2003; Thompson et al. 2008) and Minnesota Urban Heat Export Tool (MINUHET) (Herb et al. 2010b) are two wellknown deterministic models which account for multiple land covers and explicitly consider infrastructure unique to urban watersheds. With more comprehensive inclusion of temperature and flow processes within storm sewer pipes and other infrastructure, including underground tanks, rock cribs, and ponds, MINUHET seemed more versatile than TURM. TURM does not model heat exchange in pipes (Roa-Espinosa et al. 2003), which is significant in systems with long and dense storm sewer networks (Sabouri et al. 2013), as is the case with this study. Therefore, MINUHET was selected to be used in this case study.

MINUHET is a lumped model for event-based analysis. The model requires input of continuous storm meteorological data and outputs water temperature, discharge, and heat export profiles at 15 minute intervals (Herb et al. 2010a). Flow rate and temperature are calculated through flow and heat flux balancing within individual components of the model (Herb et al. 2010a). Several case studies validated MINUHET performance for the individual model components (Herb et al. 2010b; Herb, Mohseni, and Stefan 2009) as well as for comprehensive modeling of various sized mixed-use watersheds and results were most accurate for small watersheds less than $0.1 \mathrm{~km}^{2}$ (Herb 2008; Janke et al. 2013; Ketabchy et al. 2018). Identified limitations of MINUHET include inaccurate modeling of long channel reaches through which surface-water thermal interactions are not considered (Herb et al. 2010a), no input for point source discharges (Ketabchy et al. 2018), and inflexible component property requirements (Herb et al. 2010a).

\subsubsection{Model Creation}

A model based on existing conditions of the study watershed (Figure 3) was developed using MINUHET. The constructed model represented a skeletonized version of the watershed delineated into 130 subbasins based on major sewer network intersections, stormwater facility configurations, runoff temperature research, and in anticipation of retrofit implementation, Virginia bioretention filter design standards. BMP drainage area (DA) is limited to no more than $10,117 \mathrm{~m}^{2}$ (2.5 ac) of impervious area (VA DEQ 2013). Also, smaller DAs tend to have greater 
temperature mitigation potential (Jones and Hunt 2009). Since pipe length affects runoff cooling (Sabouri et al. 2013; Watson and Chang 2017), maximum network lengths were maintained in areas with highly linear drainage networks, such as along major roads. Inflow sources into ponds were kept distinct to allow mixing of inflow at the appropriate layers because pond stratification is thermally significant, since pond outflow temperature is dependent on a pond's vertical temperature profiles (Herb, Mohseni, and Stefan 2009).

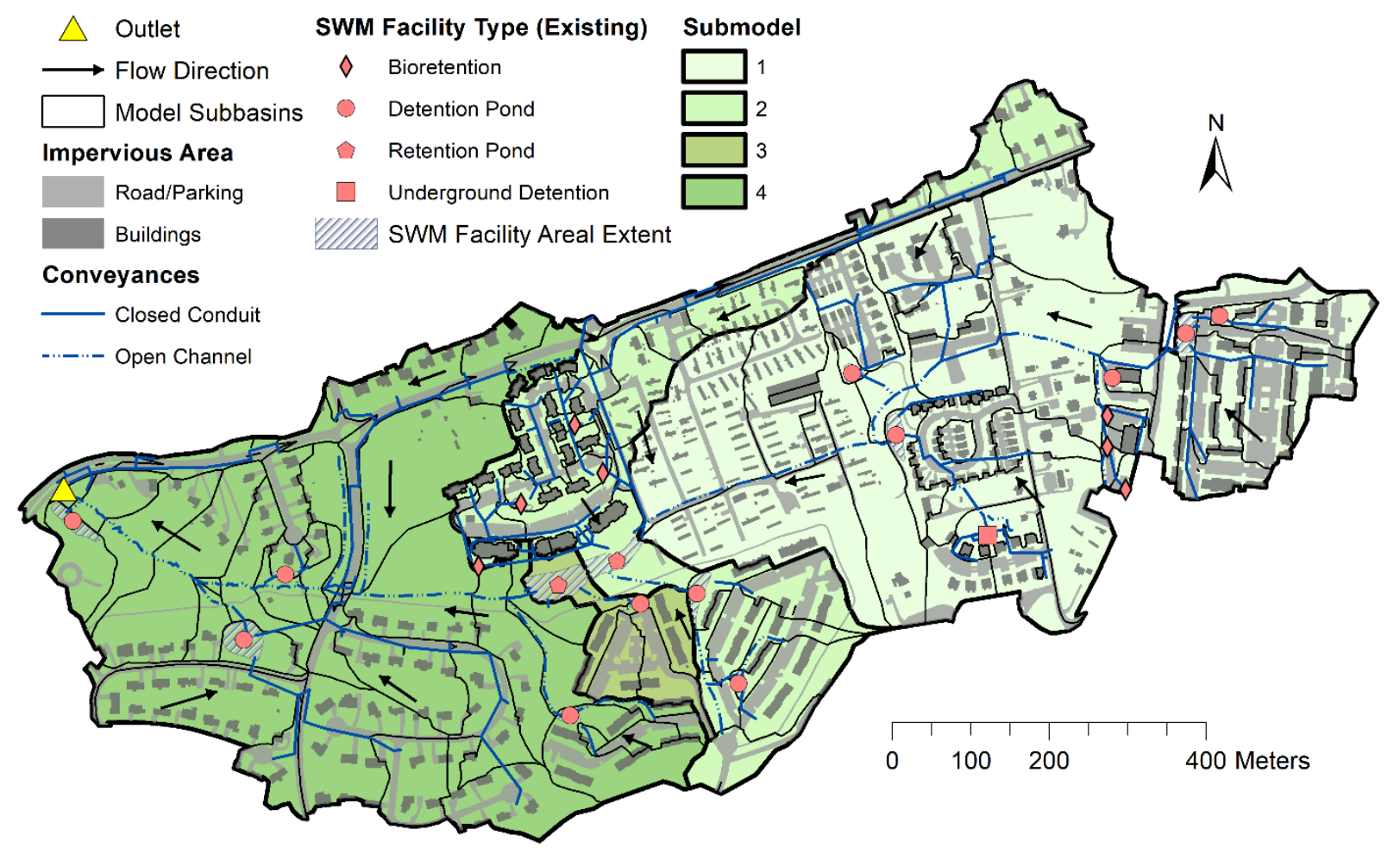

Figure 3. Layout of Existing Condition Watershed

While standard practice to use skeletonized hydrologic models, detailed and simplified model versions of the study watershed were compared to verify the validity of simplifying the runoff and temperature models of MINUHET. Very small differences between the model versions determined that use of the simplified watershed model was acceptable for this study. Also, in order to avoid modeling errors, the watershed model was divided into four separate submodels because the MINUHET routing program uses a maximum of 256 routing elements (Herb et al. 2010a). The submodels were then routed together. 
Pervious and impervious areas in each subbasin were determined with the DLCD. Subbasin land use was represented by the dominant land use of pervious and impervious areas. Initial values of connected impervious areas were estimated based on contiguous impervious areas' observed locations relative to corresponding outlet points. Disconnected roofs were considered disconnected impervious areas, but in order to utilize roof heat transfer computations, connected roofs were represented by distinct impervious subbasins. Canopy shading percentages were estimated using the DLCD and aerial imagery. Vegetation density was assumed to be $90 \%$ for all pervious areas. Soil type was defined as the most abundant type in each subbasin, as determined by the SSURGO GIS layer. Initial soil moisture was not a significant input since an antecedent period was simulated before each storm event of concern, so the value was set at "normal," representing moderate saturation conditions. For representative estimation, the runoff path lengths and slopes of subbasins made up of multiple catch basin DAs were defined by the averages of the respective properties of the smaller DAs. The maximum runoff path length for each DA was determined geometrically in GIS, defined as the longest path length of overland flow (both sheet and concentrated) in order to account for conductive heat transfer occurring along the path. Average slopes along runoff paths were estimated with elevation data.

MINUHET assumes circular pipes. Pipe properties were obtained from the Town of Blacksburg infrastructure GIS. The average pipe burial depth was determined as the average buried depth of the upstream and downstream inverts. MINUHET assumes trapezoidal channels. Channel dimensions, roughness, slopes, and shading amounts were derived from GIS and aerial imagery data. Estimated translations of natural channel shape dimensions to trapezoidal dimensions were used where applicable. In channel segments with baseflow, groundwater inflow rates and temperature were estimated from observed streamflow data and adjusted during calibration. However, a minimum rate that could be entered restricted where baseflow was added. Lateral inflow of $0.001 \mathrm{~m}^{2} / \mathrm{s}$ over $2 \mathrm{~m}$ of open channel was assumed for modeling purposes, but in reality, approximately $0.002 \mathrm{~m}^{3} / \mathrm{s}$ was spread over about $180 \mathrm{~m}$ of open channel. Groundwater temperature was calibrated individually per storm event to match simulated base temperature profiles to observed data. For the synthetic storms, the observed average summer baseflow temperature of $15.5^{\circ} \mathrm{C}$ was used. 
SWM facilities were modeled with representative elements available in MINUHET. Pond elements modeled detention and retention ponds using bathymetry data based on elevation contours and design plan specifications. Outflows were defined via rating curves generated using the Storm QC program (Land Design Technologies 2019) from outlet structures based on design plan information. Infiltration rates were defined based on underlying soil types, with B soils and $\mathrm{C}$ soils having an average rate of $24 \mathrm{~cm} /$ day and $2 \mathrm{~cm} /$ day, respectively (NRCS 2009). Underground detention tanks were modeled based on design plan dimensions, storage, and outlet structures. Due to model limitations, bioretention filters were also modeled using the underground tank element, but with properties adjusted to represent bioretention filter properties. Outflows were defined by perforated underdrains, assumed as circular orifices, and overflow grates, assumed as sharp-crested weirs. The 3.2.9 Bioretention Filter Retrofit Design section elaborates on the modeling of bioretention filters.

\subsubsection{Calibration and Validation of Model}

The existing condition watershed model was calibrated with several observed summer 2017 storm events for runoff discharge and stream temperature, as both properties are essential to thermal pollution analysis. The June 19, July 27, and August 7 storms were selected for calibration due to their differences in intensity and event time. Runoff was calibrated first by adjusting hydrologic properties. Then, thermal properties of asphalt were adjusted to calibrate stream temperature. Previous studies have determined that temperature results were most thermally impacted by the properties of asphalt (Janke et al. 2013; Ketabchy et al. 2018). After calibration, the model was validated with the remaining observed storms. As recommended for single event analysis, the Nash Sutcliffe Efficiency Coefficient (NSE) (Nash and Sutcliffe 1970), percent bias (PBIAS) (ASCE 1993; Moriasi et al. 2007), or percent error in volume for flow rate, and percent error in peak (PEP) (ASCE 1993) were used as goodness-of-fit metrics during the calibration and validation process. NSE values greater than 0.50 are considered satisfactory and values above 0.75 indicate excellent fit (Moriasi et al. 2007). For flow, PBIAS and PEP values under $\pm 10 \%$ demonstrate excellent fit, while values between $\pm 10 \%$ and $\pm 25 \%$ are still acceptable (Moriasi et al. 2007). These percentage error ranges are typically more lax for water quality properties (Moriasi et al. 2007), but temperature error values were also compared to the described ranges for a more conservative evaluation. 


\subsubsection{Sensitivity Analysis}

A sensitivity analysis was conducted for the hydrologic and thermal parameters adjusted during model calibration, meteorological input parameters, and bioretention filter properties to assess how much each parameter impacted model results. Rainfall amount was not analyzed because it was already known to be highly sensitive (Janke et al. 2013) and is considered an independent variable in this study. Parameters were varied $\pm 10 \%$ and $\pm 20 \%$, except air temperature, which was varied $\pm 1^{\circ} \mathrm{C}$ and $\pm 2{ }^{\circ} \mathrm{C}$. Bioretention filter property variations were defined based on design characteristics. Both increases and decreases were analyzed because many parameters were calibrated to equilibrium points, suggesting that directionality may impact sensitivity. Relative sensitivity $\left(R_{S}\right)$ was computed:

$$
R_{s}=\frac{\Delta F_{0}}{F_{0}} / \frac{\Delta F_{i}}{F_{i}}
$$

where $F_{0}$ is the original output parameter, $\Delta F_{0}$ is change in output parameter, $F_{i}$ is the original input parameter, and $\Delta F_{i}$ is change in input parameter (McCuen 1973). A negative value indicates inverse correlation. The June 19 and July 27 storms used during calibration were again simulated for sensitivity analysis. Different storm intensities and distributions were considered in case such properties impacted sensitivity results.

The output properties analyzed were runoff volume and maximum event temperature, which are straightforward indicators of how changes to the model affected temperature and runoff results. For the hydrologic, thermal, and meteorological parameters, outputs were evaluated at the watershed outlet. In contrast, the bioretention filter properties were analyzed locally at various retrofitted bioretention filters with a range of drainage area characteristics (Table 5). The same output properties were evaluated, but at the outlet of each bioretention filter discharge pipe.

Table 5. Characteristics of Drainage Areas of Bioretention Filters Used in Sensitivity Analysis

\begin{tabular}{ccc}
\hline Bioretention Filter & Drainage Area, DA $\left(\mathbf{m}^{\mathbf{2}}\right)$ & Treatment \\
\hline $1-17$ & 21,800 & 110 \\
$1-31$ & 1,010 & 11 \\
$1-66$ & 8,340 & 147 \\
$1-81$ & 9,710 & 198 \\
$1-90$ & 3,320 & 74 \\
\hline
\end{tabular}

${ }^{1}$ Bioretention filter naming convention: [submodel \#]-[\% impervious cover] 


\subsubsection{Future Build Out Scenario}

A future build out scenario model was developed for the calibrated existing condition model. The altered areas are outlined in Figure 4. The three "designed" areas were based on design plans of new developments constructed after the time period the existing condition model was calibrated for. The "proposed" areas were identified as parcels with proposed land use changes in the future, and were redeveloped based on existing sites in Blacksburg with the same zoning as proposed and similar size. New SWM infrastructure was designed to tie-in to the existing infrastructure network. Relative to the existing condition model, the completed future build out model had an additional $1 \mathrm{~km}$ of pipes, 3 bioretention filters, and 1 underground detention facility. The proposed conditions resulted in a 93\% developed watershed with 36\% impervious area.

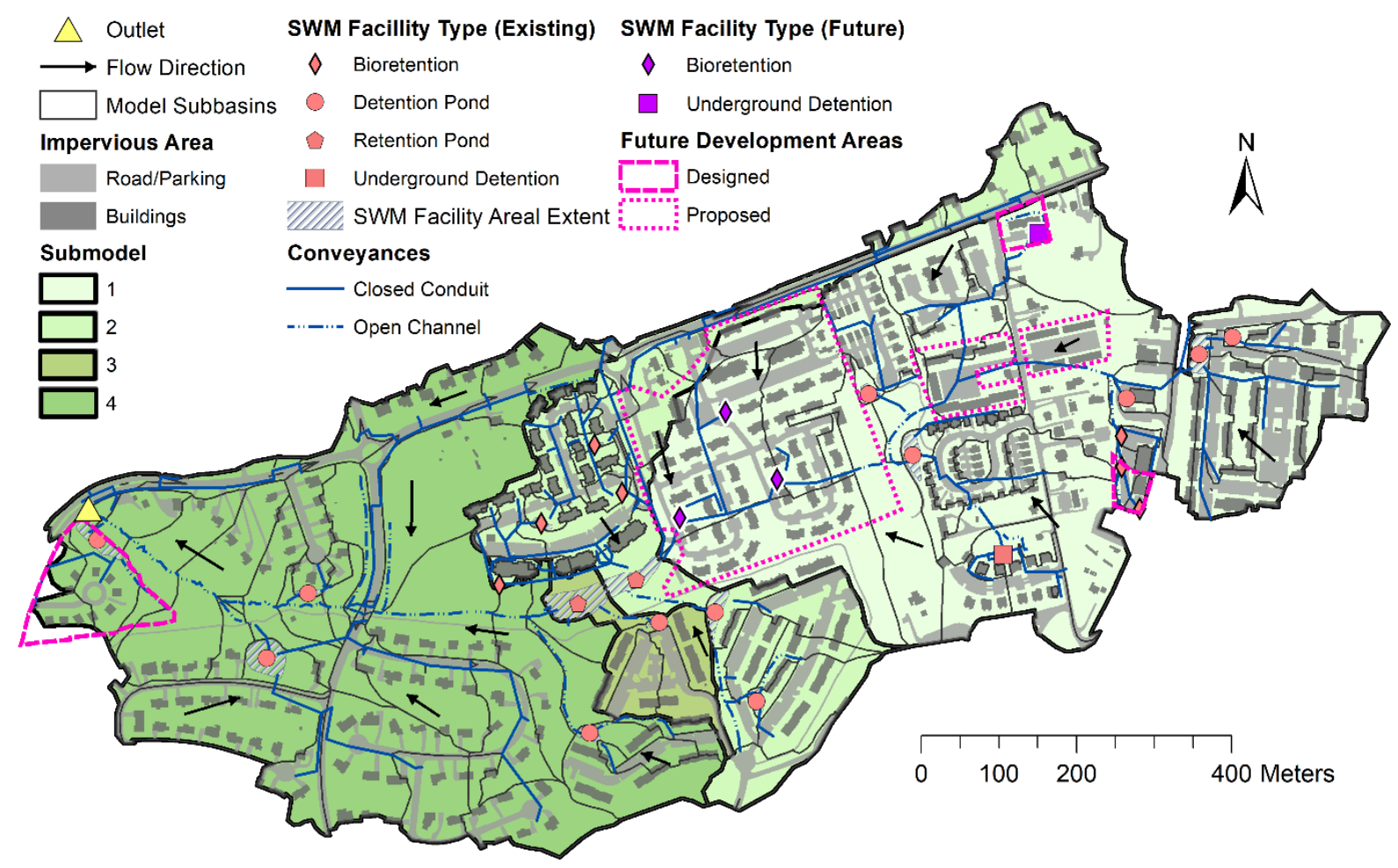

Figure 4. Layout of Future Build Out Watershed

\subsubsection{Bioretention Filter Retrofit Design}

MINUHET does not have a bioretention filter element built in. The infiltration pond element could not be used because the element allows exfiltration. Instead, the underground tank element was substituted to represent bioretention filters because the underground tank is modeled 
with heat transfer processes very similar to what occurs through filter media. Heat transfer is calculated based on the temperatures of water in the tank, of the rock or sediment, and of the surrounding soil, assuming good mixing inside the tank (Herb et al. 2010b):

$$
\begin{gathered}
\frac{\partial}{\partial t}\left(V_{w} T_{w}\right)=T_{\text {in }} Q_{\text {in }}-T_{\text {out }} Q_{\text {out }}+\frac{h_{r} A_{r w}\left(T_{r}-T_{w}\right)}{\left(\rho c_{p}\right)_{w}}+\frac{h_{s} A_{w s}\left(T_{s}-T_{w}\right)}{\left(\rho c_{p}\right)_{w}} \\
V_{r} \frac{\partial T_{r}}{\partial t}=\frac{h_{r} A_{r w}\left(T_{w}-T_{r}\right)}{\left(\rho c_{p}\right)_{r}}+\frac{h_{s} \theta A_{w}\left(T_{s}-T_{r}\right)}{\left(\rho c_{p}\right)_{r}}
\end{gathered}
$$

where $V_{x}$ is volume of $x$ in tank $\left(\mathrm{m}^{3}\right), T_{x}$ is temperature of $x$ in tank $\left({ }^{\circ} \mathrm{C}\right), T_{\text {in }}$ is inflow temperature $\left({ }^{\circ} \mathrm{C}\right), T_{\text {out }}$ is outflow temperature $\left({ }^{\circ} \mathrm{C}\right), Q_{\text {in }}$ is inflow rate $\left(\mathrm{m}^{3} / \mathrm{s}\right), Q_{\text {out }}$ is outflow rate $\left(\mathrm{m}^{3} / \mathrm{s}\right), h_{x}$ is heat transfer coefficient of $x\left(\mathrm{~W} / \mathrm{m}^{2} \mathrm{~K}\right), A_{r w}$ is media particle surface area in contact with water $\left(\mathrm{m}^{2}\right), A_{w s}$ is wetted area at tank wall $\left(\mathrm{m}^{2}\right), \theta$ is volume fraction of media, $A_{w}$ is tank wall area $\left(\mathrm{m}^{2}\right)$, $\left(\rho c_{p}\right)_{x}$ is heat capacity of $x\left(\mathrm{~J} / \mathrm{m}^{3} \mathrm{~K}\right)$, and $t$ is time (hr), with $x$ subscripts denoting $w$ as water, $r$ as media particle, and $s$ as surrounding soil.

Bioretention filter properties that demonstrated significant impact on flow volume and temperature under sensitivity analysis were further investigated to check that modeling bioretention filters using the underground tank element in MINUET was a valid method. Results confirmed that as filter media thickness increases, maximum temperature decreases, and the farther away the underdrain invert is to the bottom of the facility (more IWS), maximum temperature decreases. These results agree with existing findings indicating that the bioretention filter properties analyzed have thermal mitigation potential. Most properties remained constant for each retrofit, as listed in Table 6. The tank depth (diameter) accounted for the cumulative depths of the gravel and filter media layers, and represented the optimal media thickness. Particle diameter and fill fraction were calculated as the volume averaged media, and gravel particle size and fill volume computed from surface, media, and gravel storage and void ratios, respectively. Weighted averages of corresponding sand and loam values were calculated to determine media heat capacity and thermal diffusivity (Alnefaie and Abu-Hamdeh 2013; Farouki 1981). Outflow from the filter media component was controlled by a $0.142 \mathrm{~m}$ diameter orifice with an invert set at the facility bottom, not allowing water storage in the facility so that the BMP was modeled purely as a filter. Each facility released flow into the sewer network through a discharge pipe. Slope of each pipe was set at $0.0625 \mathrm{~m} / \mathrm{m}$ to ensure adequate hydraulic head through the facility. Based on existing facilities 
in the study watershed, the discharge pipe was assumed to be corrugated plastic, have a $0.305 \mathrm{~m}$ diameter, and have a length of $8 \mathrm{~m}$. The maximum tank inflow rate was defined as the 5-year peak flow from the respective DA calculated with the NRCS flow peak method (NRCS 1986), to ensure no overflowing. Excess flow was bypassed to the downstream discharge pipe element, as many bioretention filters are constructed to do in order to reduce overflow issues (VA DEQ 2013).

Table 6. Constant Properties of Bioretention Filter Retrofits

\begin{tabular}{|c|c|c|}
\hline Property & Value & Assumptions ${ }^{1}$ \\
\hline Depth/Diameter & $1.600 \mathrm{~m}$ & $\begin{array}{l}\text { Filter media: } 1.219 \mathrm{~m} \text {; } \\
\text { Gravel: } 0.381 \mathrm{~m}\end{array}$ \\
\hline $\begin{array}{l}\text { Initial/Bottom Elevation } \\
\text { Fill Fraction }\end{array}$ & $\begin{array}{c}670.560 \mathrm{~m} \\
0.652\end{array}$ & $\begin{array}{l}\text { Assumed arbitrary value } \\
\text { Void ratios: } \\
\text { Filter media: } 0.25 \text {; } \\
\text { Gravel: } 0.4\end{array}$ \\
\hline Media Particle Diameter & $0.003 \mathrm{~m}$ & $\begin{array}{l}\text { Filter media } \mathrm{D}_{\text {avg }}: 0.325 \mathrm{~mm} \\
\text { VDOT \#57 stone } \mathrm{D}_{50}: 12.7 \mathrm{~mm}(\mathrm{NRCS}) \\
\text { VDOT \#78 stone } \mathrm{D}_{50}: 9.5 \mathrm{~mm}(\mathrm{NRCS})\end{array}$ \\
\hline Facility Exfiltration Rate & $0 \mathrm{~m}^{3} / \mathrm{s}$ & Clay lining below facility restricts exfiltration \\
\hline Surface Land Use & Forest & Vegetation with high canopy shading \\
\hline Media Heat Capacity & $2.2 \times 10^{6} \mathrm{~J} / \mathrm{m}^{3}{ }^{\circ} \mathrm{C}$ & $80 \%$ sand; $20 \%$ loam \\
\hline Media Thermal Diffusivity & $1.5 \times 10^{-6} \mathrm{~m}^{2} / \mathrm{s}$ & $80 \%$ sand; $20 \%$ loam \\
\hline
\end{tabular}

${ }^{1}$ Assumptions from VA DEQ (2013) unless otherwise noted

The tank length was varied for each retrofit based on the design storage required, which was determined following Virginia design guidelines by calculating the required treatment volume $\left(T_{v}\right)$ (VA DCR 2013). Each tank length input into the model was calculated for a cylindrical tank retaining a storage volume equivalent to that of the prismatic bioretention filter represented. Increasing tank lengths increased the treatment capacity of the retrofit facilities.

\subsubsection{Scenario Analysis}

Model scenarios were simulated to evaluate impacts of retrofitting a watershed with bioretention filters on flow and temperature at the outlet. The metrics used to assess achievement of thermal mitigation goals were: the maximum event temperature $\left(T_{\max }\right)$, the event mean temperature $(E M T)$, and total heat export $(H)$. These metrics assess short term thermal impacts of individual storm events. EMT is a flow averaged temperature $\left({ }^{\circ} \mathrm{C}\right)$ (Wardynski et al. 2014): 


$$
E M T=\frac{\int_{0}^{D_{i}} T Q d t}{\int_{0}^{D_{i}} Q d t}
$$

where $T$ is instantaneous flow temperature $\left({ }^{\circ} \mathrm{C}\right), Q$ is instantaneous runoff rate $\left(\mathrm{m}^{3} / \mathrm{s}\right)$, and $D$ is the storm event duration (s).

Total heat export, $H(\mathrm{~J})$, is the integration of the instantaneous heat export, $h_{\exp }(\mathrm{J} / \mathrm{s})$, over the storm duration (Janke et al. 2009; Kieser et al. 2004; Long and Dymond 2013; Wardynski et al. 2014; Winston, Hunt, and Lord 2011):

$$
\begin{gathered}
h_{\text {exp }}=\rho_{w} C_{w} Q\left(T_{o}-T_{\text {ref }}\right) \\
H=\int_{0}^{D} h_{\text {exp }} d t
\end{gathered}
$$

where $\rho_{w}$ is the density of water $\left(\mathrm{kg} / \mathrm{m}^{3}\right), C_{w}$ is the specific heat of water $\left(\mathrm{J} / \mathrm{kg}^{\circ} \mathrm{C}\right), Q$ is instantaneous runoff rate $\left(\mathrm{m}^{3} / \mathrm{s}\right), T_{o}$ is instantaneous flow temperature $\left({ }^{\circ} \mathrm{C}\right), T_{r e f}$ is the reference temperature $\left({ }^{\circ} \mathrm{C}\right), D$ is the storm event duration (s), and $t$ is time (s). A reference temperature of $21^{\circ} \mathrm{C}$ was used so total heat export represents the thermal energy added to the stream by runoff above the acceptable standard. The $E M T$ threshold was also defined at $21^{\circ} \mathrm{C}$. The $T_{\max }$ threshold was set at $24^{\circ} \mathrm{C}$, the maximum survival temperature for rainbow trout (Brungs and Jones 1977), in order to make the goal more practical.

The design storms (Table 3) were simulated for every scenario. First, the two control scenarios were simulated and compared: existing condition model and future build out model. Further analysis involved retrofitting the control scenarios with bioretention filters. The existing condition model was retrofitted with 80 bioretention filters (Figure 5) and the future build out condition model with 82 (Figure 6). Since it is acceptable to aggregate bioretention cells for modeling purposes (Elliott, Trowsdale, and Wadhwa 2009), each modeled subbasin was treated with one retrofit even though alternate physical configurations may be necessary in reality. A retrofit was added at the outlet of each subbasin with over $10 \%$ impervious area, as this is the accepted minimum threshold before significant stream ecological degradation occurs (Walsh et al. 2005). Detention ponds with small drainage areas were replaced with bioretention filter retrofits in order to reduce runoff warming caused by flow impoundment. Drainage areas to existing 
underground storage facilities or bioretention filters were not retrofitted because those BMPs already provide thermal mitigation (Long and Dymond 2013; Natarajan and Davis 2010). For the first iteration, the retrofits were designed to treat the computed $T_{v}$. In subsequent iterations, treatment volumes were incrementally increased by a percentage of the computed treatment volume $\left(\% T_{v}\right)$.

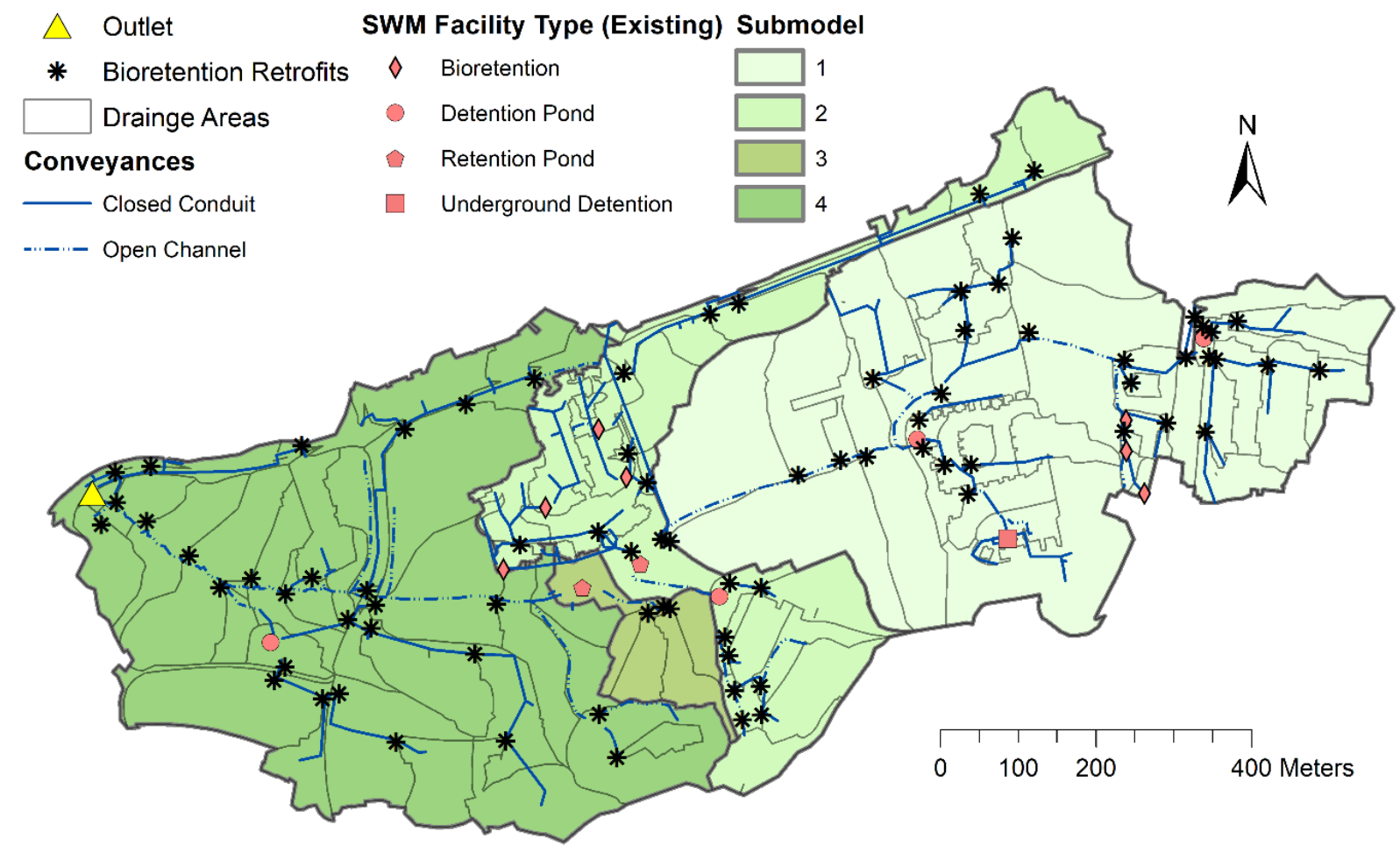

Figure 5. Proposed Locations of Bioretention Filter Retrofits for Existing Conditions 


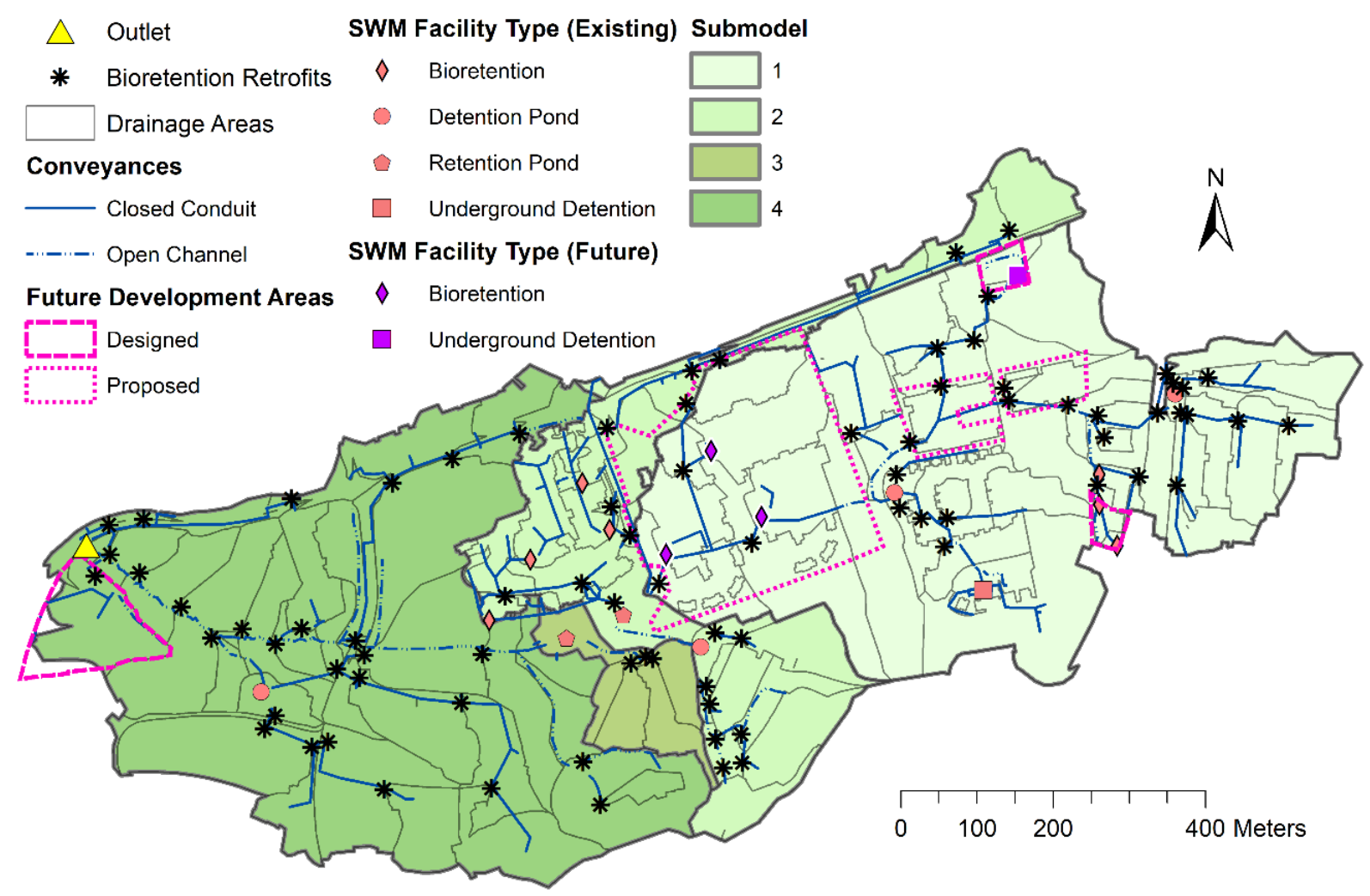

Figure 6. Proposed Locations of Bioretention Filter Retrofits for Future Build Out Conditions

When scenarios with retrofits were run, instability issues occurred where temperature calculations at certain tank elements experienced computational errors, preventing subsequent elements from routing. At least one instability issue occurred for every scenario iteration. One effective solution was adjusting maximum inflow values of the problematic tank elements until the instability was resolved. Sensitivity analysis had determined that maximum inflow was not a sensitive parameter, although the unstable elements seemed to have noticeable impacts on results. Although consistent adjustment of input parameters was attempted, maximum inflow values for problematic tank elements could not be kept constant among all iterations. However, values were maintained the same among all design storm simulations during each $\% T_{v}$ run.

\subsection{Results and Discussion}

\subsubsection{Calibration and Validation}

The uncalibrated model resulted in flow rates that were too high. Effective impervious area has been proven to be a highly sensitive property in a previous case study (Janke et al. 2013) and 
it varies based on storm intensity and duration. This parameter was adjusted to decrease flow rate by decreasing the proportion of connected impervious area in each subbasin. Since the storm events used had small rainfall depths (less than 1-year return periods), it was logical that effective impervious areas were calibrated to be small for the majority of the watershed. Additionally, runoff surfaces were adjusted to be rougher and soil saturated hydraulic conductivity values were increased to promote greater infiltration. The potential presence of karst in the watershed likely explains the need to use hydraulic conductivity values above the accepted range to compensate for unaccounted underground flow losses. Finally, a fraction of disconnected roof areas were excluded from each subbasin with the observation that many single family houses in the area have downspouts connected to french drains.

The flow related parameters also impacted temperature results. To finalize calibration of temperature, heat capacity and thermal diffusivity of asphalt were altered while maintaining the relationship among thermal diffusivity, heat capacity, and thermal conductivity (Bird, Stewart, and Lightfoot 2006):

$$
\alpha=\frac{k}{\rho c_{p}}
$$

where $\alpha$ is thermal diffusivity $\left(\mathrm{m}^{2} / \mathrm{s}\right), k$ is thermal conductivity $(\mathrm{W} / \mathrm{mK})$, and $\rho c_{p}$ is heat capacity $\left(\mathrm{J} / \mathrm{m}^{3} \mathrm{~K}\right)$. Pavement thickness also impacted runoff temperature and was decreased to account for the consideration of concrete sidewalks and miscellaneous paved areas included which are thinner than asphalt and its subgrade. Table 7 and Table 8 provide the final values of model parameters adjusted for the calibration of flow rate and temperature. 
Table 7. Calibrated Values of Parameters Used to Calibrate Flow Rate and Accepted Ranges

\begin{tabular}{|c|c|c|c|c|c|}
\hline Parameter & $\begin{array}{c}\text { Parameter } \\
\text { Characteristic }\end{array}$ & $\begin{array}{c}\text { Calibrated } \\
\text { Value }\end{array}$ & & $\begin{array}{l}\text { Accepted } \\
\text { Range }\end{array}$ & Source of Range \\
\hline \multirow{2}{*}{$\begin{array}{l}\text { Soil Saturated } \\
\text { Hydraulic } \\
\text { Conductivity } \\
(\mathrm{m} / \mathrm{s})\end{array}$} & B soil & $1.7 \times 10^{-5}$ & $\begin{array}{l}\text { Above } \\
\text { range }\end{array}$ & $\begin{array}{c}4.0 \times 10^{-6}- \\
1.0 \times 10^{-5}\end{array}$ & (NRCS 2009) \\
\hline & C soil & $4.8 \times 10^{-6}$ & $\begin{array}{l}\text { Above } \\
\text { range }\end{array}$ & $\begin{array}{l}4.0 \times 10^{-7}- \\
4.0 \times 10^{-6}\end{array}$ & (NRCS 2009) \\
\hline \multirow[t]{4}{*}{$\begin{array}{l}\text { Manning's n } \\
\text { Roughness }\end{array}$} & Grass & 0.28 & $\begin{array}{l}\text { Above } \\
\text { range }\end{array}$ & $0.10-0.25$ & (McCuen 2017) \\
\hline & Brush & 0.65 & $\begin{array}{l}\text { Above } \\
\text { range }\end{array}$ & $0.15-0.35$ & \\
\hline & Forest & 0.5 & In range & $0.1-0.5$ & \\
\hline & Asphalt & 0.03 & $\begin{array}{l}\text { Above } \\
\text { range }\end{array}$ & $\begin{array}{l}0.01- \\
0.018\end{array}$ & \\
\hline \multirow{4}{*}{$\begin{array}{c}\text { \% Initially } \\
\text { Assumed } \\
\text { Impervious } \\
\text { Area }\end{array}$} & Submodel 1 & $30 \%$ & & - & \\
\hline & Submodel 2 & $30 \%$ & & - & \\
\hline & Submodel 3 & $30 \%$ & & - & \\
\hline & Submodel 4 & $100 \%$ & & - & \\
\hline $\begin{array}{l}\text { Disconnected } \\
\text { Roof Area } \\
\text { Included }\end{array}$ & - & $\begin{array}{l}40 \% \text { of } \\
\text { roof area }\end{array}$ & & - & \\
\hline
\end{tabular}


Table 8. Calibrated Values of Parameters Used to Calibrate Temperature and Accepted Ranges

\begin{tabular}{|c|c|c|c|c|c|}
\hline Parameter & $\begin{array}{c}\text { Parameter } \\
\text { Characteristic }\end{array}$ & $\begin{array}{c}\text { Calibrated } \\
\text { Value }\end{array}$ & & $\begin{array}{l}\text { Accepted } \\
\text { Range }\end{array}$ & Source of Range \\
\hline $\begin{array}{c}\text { Heat } \\
\text { Capacity, } \\
\rho c_{p}\left(\mathrm{~J} / \mathrm{m}^{3} \mathrm{~K}\right)\end{array}$ & Asphalt & $1.0 \times 10^{6}$ & $\begin{array}{l}\text { Under } \\
\text { range }\end{array}$ & $\begin{array}{c}1.8 \times 10^{6}- \\
2.3 \times 10^{6}\end{array}$ & $\begin{array}{l}\text { (Hassn et al. 2016; } \\
\text { Kavianipour and Beck } \\
\text { 1977) }\end{array}$ \\
\hline $\begin{array}{c}\text { Thermal } \\
\text { Diffusivity, } \\
\alpha\left(\mathrm{m}^{2} / \mathrm{s}\right)\end{array}$ & Asphalt & $7.7 \times 10^{-7}$ & In range & $\begin{array}{c}4.4 \times 10^{-7}- \\
1.15 \times 10^{-6}\end{array}$ & $\begin{array}{l}\text { (Kavianipour and Beck } \\
\text { 1977; Luca and } \\
\text { Mrawira 2005) }\end{array}$ \\
\hline $\begin{array}{c}\text { Thermal } \\
\text { Conductivity, } \\
k(\mathrm{~W} / \mathrm{mK})\end{array}$ & Asphalt & 0.77 & $\begin{array}{l}\text { Under } \\
\text { range }\end{array}$ & $0.8-2.0$ & (FHWA 2019) \\
\hline Albedo & Asphalt & 0.10 & In range & $0.04-0.16$ & (FHWA 2019) \\
\hline $\begin{array}{l}\text { Thickness } \\
\text { (m) }\end{array}$ & Asphalt & 0.15 & In range & $\begin{array}{c}0.05 \mathrm{~m} \\
\text { pavement; } \\
0.1-0.15 \mathrm{~m} \\
\text { variable } \\
\text { subgrade }\end{array}$ & (Hein et al. 2017) \\
\hline
\end{tabular}

Goodness-of-fit results from calibration and validation are listed in Table 9. The validation simulations performed better than the calibration simulations in both discharge and temperature. Despite relatively low NSE values, the graphical fit of modeled results to observed results seem acceptable. Figure 7 provides selected simulation examples. In general, runoff hydrographs matched better than the thermographs. However, PBIAS and PEP values for temperature were consistently lower. During the events, all observed flow peaks were generated in the simulated hydrographs at similar peak times except for the August 7 storm (Figure 2b), where the last peak was missed entirely. The last peak likely occurred due to the upstream movement of the storm in the watershed, as no rainfall was recorded at that time. Precipitation occurred in the upstream part of the watershed later during the storm than the assumed uniform precipitation distribution modeled. This homogeneity assumption would be a significant source of error, especially for localized summer storms.

The simulated overall diurnal temperature patterns matched the observed profiles well, indicating that antecedent meteorological conditions were well represented by the model. The more jagged profiles during these time periods, most visible in the July 27 and August 7 storms, 
suggested strong sensitivity of MINUHET to one or more meteorological parameters such as solar radiation. Periods during rainfall were more volatile. While increases in temperature during rainfall were simulated around the observed time ranges, not all the fluctuations during that time were reflected. The modeled temperature peaks appear more as aggregated peaks of elevated temperatures. This may be a consequence of model simplification as more detailed modeling closer to the watershed outlet facilitates the simulation of nuanced output details (Janke et al. 2013). Also, the recession phase after each spike in temperature was significantly more abrupt in the simulated profiles than those observed. A possible explanation is that modeled elements lost heat to runoff quicker than actual conditions and did not retain enough energy to continue warming the water. This may have resulted from the lack of baseflow across the full downstream stretch of open channel. Moreover, Janke et al. (2013) noted that over prediction of flow rates from pervious areas resulted in under predicted temperatures, but that pattern was not consistently evident in the current results. This may be due to the storms having small rainfall depths, so runoff was mostly infiltrated through pervious areas. Furthermore, since stream temperature is impacted by runoff, error in runoff simulation also contributed to error in temperature simulation.

Table 9. Calibration and Validation Goodness-of-fit Results for Runoff Flow Rates and Temperatures

\begin{tabular}{cccccccc}
\hline \multirow{2}{*}{ Storm } & \multirow{2}{*}{ Use $^{1}$} & \multicolumn{3}{c}{ Runoff Flow Rate } & \multicolumn{3}{c}{ Temperature } \\
\cline { 3 - 7 } & & NSE & PBIAS (\%) & PEP (\%) & NSE & PBIAS (\%) & PEP (\%) \\
\hline June 19 & C & 0.310 & 9.4 & -13.2 & 0.691 & -0.2 & -7.0 to 13.6 \\
July 27 & C & 0.563 & -27.6 & -2.2 to 30.1 & 0.261 & -0.1 & 12.1 \\
August 7 & C & 0.422 & 33.6 & 3.8 to 12.0 & 0.207 & 1.3 & 0.1 \\
July 4 & V & 0.503 & -15.2 & 1.2 to 65.6 & 0.456 & -0.9 & 0.1 to -12.5 \\
July 31 & V & 0.915 & -21.6 & 7.5 & 0.595 & 1.1 & 2.9 \\
\hline
\end{tabular}

${ }^{1}$ Abbreviations: $\mathrm{C}=$ calibration, $\mathrm{V}=$ validation 

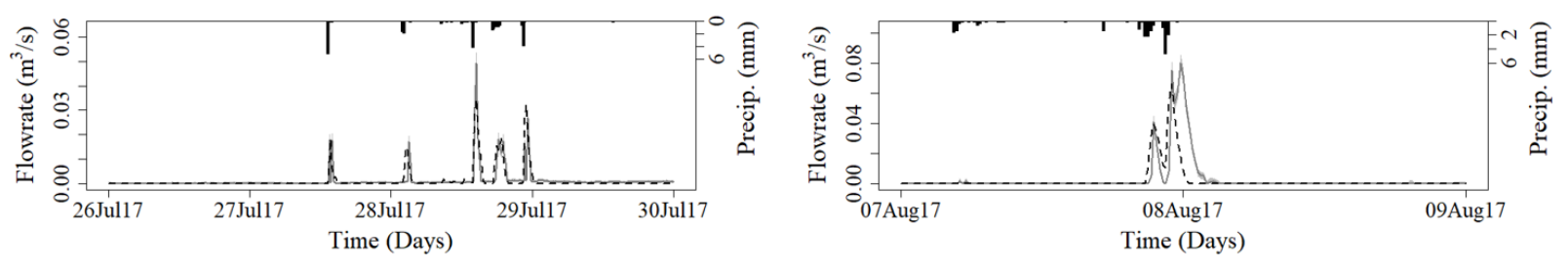

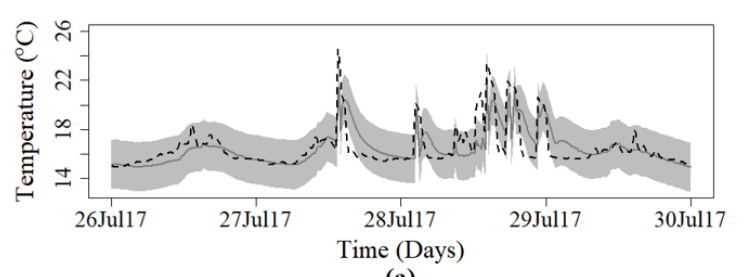

(a)

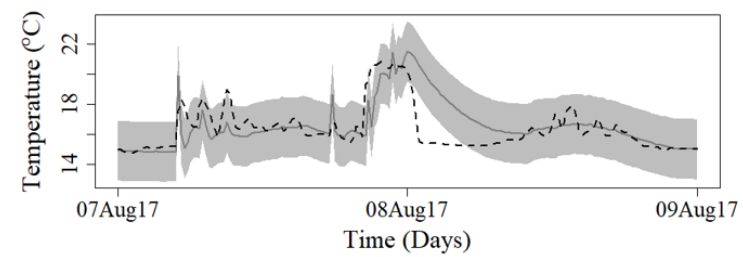

(b)
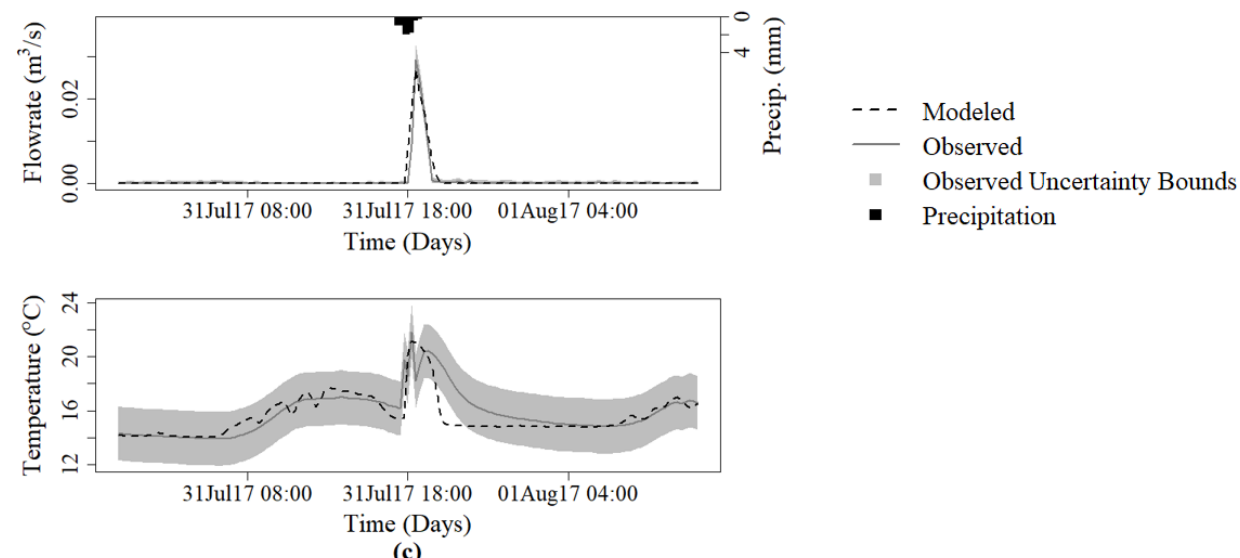

(c)

Figure 7. Discharge and Temperature Profiles of Select Calibration and Validation Simulations; Calibrated: (a) July 27, 2017 Storm, (b) August 7, 2017 Storm; Validated: (c) July 31, 2017 Storm

Additional potential sources of error and uncertainty likely affected calibration results. Study watershed data may have been influenced by ongoing construction in the watershed, which led to short term changes reflected in the observed data that were not reflected in the data used to build the model. Sensor data also had uncertainties. Observed temperature data had a rather large $\left(2^{\circ} \mathrm{C}\right)$ range of uncertainty, and most simulated values stayed within those upper and lower uncertainty bounds. Other error sources stemmed from model limitations. MINUHET is designed to model small scale watersheds and tends to be less accurate for larger watersheds (Ketabchy et al. 2018). There are errors from uniform subbasin property assumptions, which are inherent to a lumped model. Element assumptions such as trapezoidal channel cross sections and the lack of hydraulically relevant structural details affected flow. Also, bioretention filters were modeled with the underground tank element. Stability and simulation error issues arose that could only be 
resolved by adjusting input values, which introduced deviations from observed data. All these sources of error likely reduced the fit between observed and modeled results.

\subsubsection{Sensitivity Analysis}

The runoff calibration parameters analyzed for sensitivity were soil saturated hydraulic conductivity, surface roughness, percent connected impervious area, and percent included disconnected roof area. Temperature calibration parameters analyzed included the heat capacity, thermal diffusivity, thickness, and albedo of asphalt. Sensitivity analysis was also performed on select meteorological parameters: solar radiation, wind speed, cloud cover, and air temperature. The most sensitive parameters for runoff volume, in descending order, were: connected impervious area, B soil saturated hydraulic conductivity, and C soil saturated hydraulic conductivity. Asphalt roughness and disconnected roof area were more sensitive for the concentrated, high intensity storm (Figure 8a) than for the multi-burst, low intensity storm (Figure 8b). Certain meteorological parameters such as solar radiation, temperature, and wind speed had small, but noticeable relative sensitivities for runoff volume. These parameters are factors in evaporation, which is likely the process causing the sensitivity.

Air temperature was the most significant parameter impacting maximum stream temperature (Figure 8c,d). This agrees with previous MINUHET case studies which determined dew point temperature to be a highly sensitive parameter (Janke et al. 2013; Ketabchy et al. 2018) since air temperature is a factor of dew point temperature. Solar radiation, pavement thickness, and asphalt heat capacity were also sensitive parameters, although much less in comparison to air temperature (Figure 8c,d). Results emphasize the importance of having accurate air temperature and solar radiation measurements. Sensitivity analysis proved that certain flow parameters, including impervious area and soil hydraulic conductivity, also had significant impact on stream temperature, as observed during calibration. 


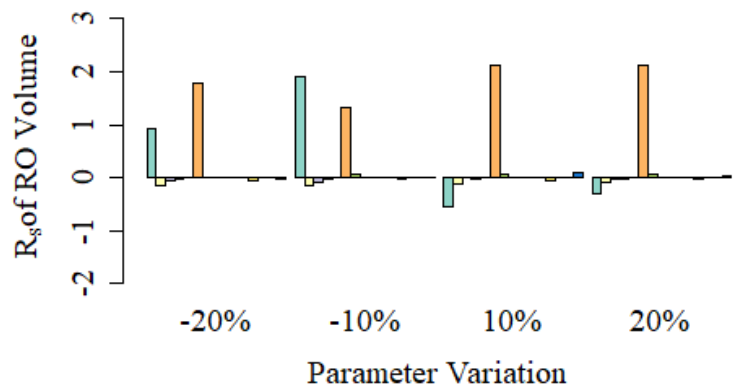

(a)

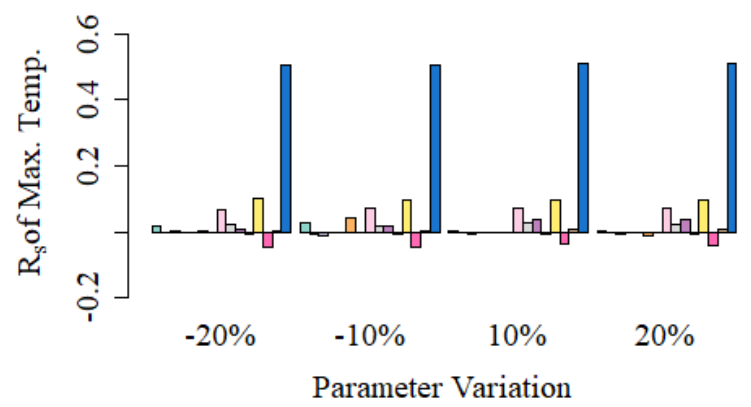

(c)

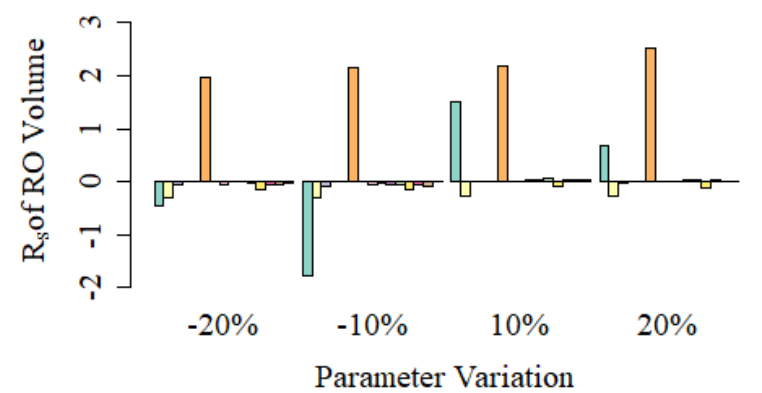

(b)

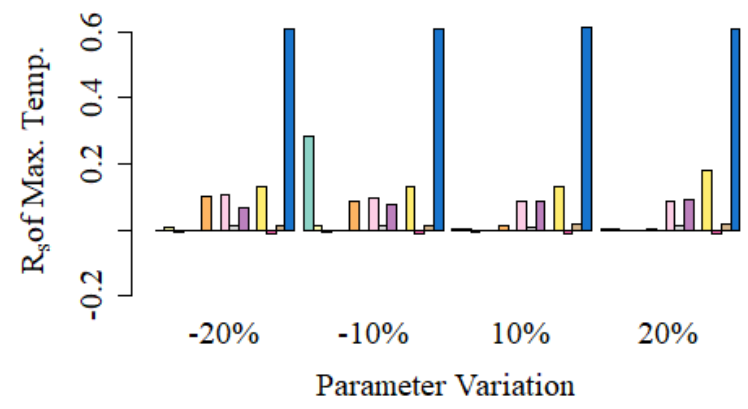

(d)

\footnotetext{
- Ksat (B soil) Ksat (C soil)

- Roughness (Asphalt)

- Roughness (Grass)

- Roughness (Brush)
}

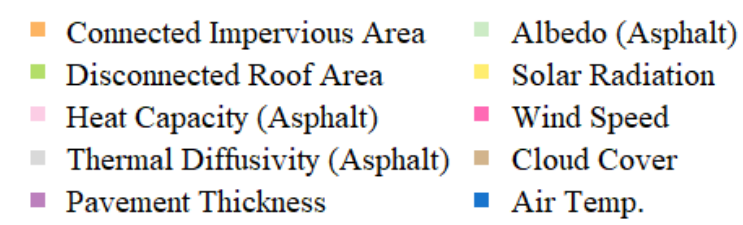

Figure 8. Relative Sensitivities of Runoff Volume and Max. Temperature to Model Parameters; Runoff Volume: (a) June 19, 2017 Storm, (b) July 27, 2017 Storm; Max. Temp.: (c) June 19, 2017 Storm, (d) July 27, 2017 Storm

Five bioretention filter facilities were used to conduct the sensitivity analysis of filter media thickness, particle size, heat capacity, thermal diffusivity, underdrain depth, and maximum inflow rate. Results are illustrated in Figure 9. Flow volume from the bioretention filters was most sensitive to media thickness and underdrain invert depth. These parameters were most sensitive for the bioretention filters with $31 \%$ and $66 \%$ impervious cover, and least for the more extreme impervious coverages. Media thickness showed a direct relationship to flow volume, but underdrain depth had an inverse relationship. Underdrain invert depth had minimal impact on maximum temperature. Filter media thickness was the most sensitive property for maximum temperature, followed by the media heat capacity. Both parameters are inversely related to maximum temperature, but as drainage area impervious coverage increased, media thickness got less sensitive, while heat capacity became more sensitive. Results suggested that media particle 
size, thermal diffusivity, and maximum inflow rate have negligible impact on both flow volume and temperature. Field experiments are necessary to confirm these findings.

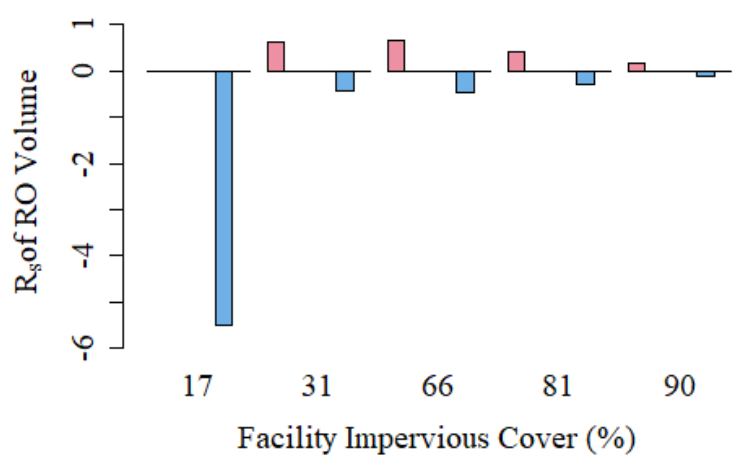

(a)

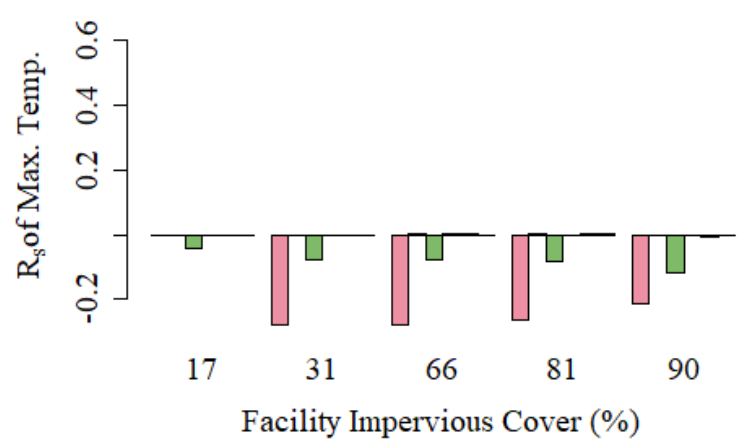

(c)

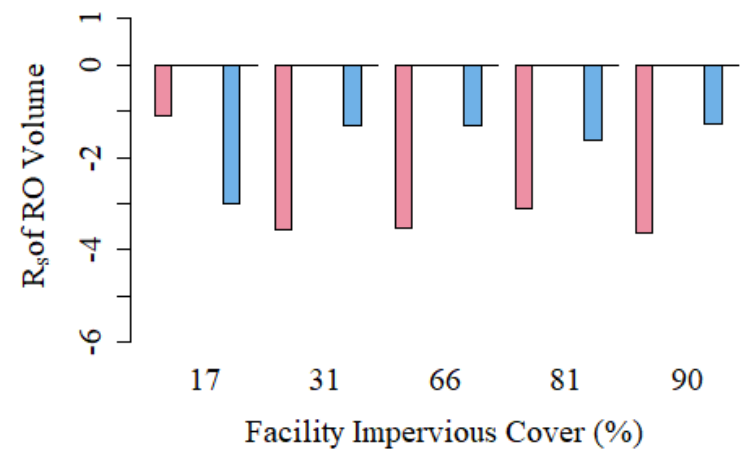

(b)

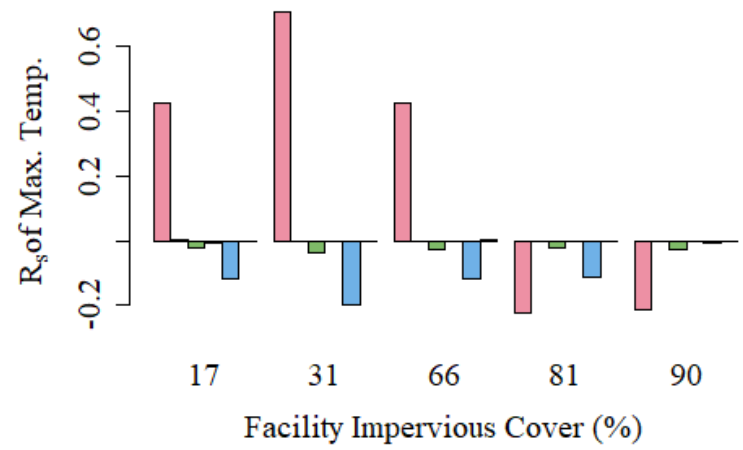

(d)

- Media Thickness $(\Delta 0.3 \mathrm{~m})$ Heat Capacity $(\Delta 20 \%) \quad$ Underdrain Depth $(\Delta 0.15 \mathrm{~m})$

- Media Size $(\Delta 33 \%) \quad$ Thermal Diffusivity $(\Delta 20 \%)$ Inflow Rate $(\Delta 20 \%)$

Figure 9. Relative Sensitivities of Runoff Volume and Max. Temperature to Bioretention Filter Properties; Runoff Volume: (a) June 19, 2017 Storm, (b) July 27, 2017 Storm;

Max. Temp.: (c) June 19, 2017 Storm, (d) July 27, 2017 Storm

\subsubsection{Scenario Comparison}

Design storms were simulated for the two control scenarios (Table 10). Runoff volumes and peak discharges of the future build out scenario were larger for all return periods, typical for increased development. Interestingly, EMT and $H$ values were generally lower for the future build out model, while $T_{\max }$ values were similar for both control scenarios. These outcomes may be attributed to a relatively small difference in development between scenarios, as impervious cover only increased by about $2 \%$ of the watershed area. Pavement related temperature increases may have been offset by the larger proportion of storm pipes added, roughly $15 \%$ more in total length, attesting to the significance of runoff cooling through underground pipes. However, intensifying 
piping of storm drainage networks is not a recommended thermal reduction practice because piping is associated with many symptoms of ecological degradation (Walsh et al. 2005). EMT decreased as return period increased, but $T_{\max }$ did not follow a similar trend. The highest $T_{\max }$ occurred during the 5-year storms. Both sets of watershed conditions yielded temperature metric values above the desired mitigation thresholds.

Table 10. Summary of Control Scenario Runoff Characteristics and Temperature Metrics

\begin{tabular}{ccccccc}
\hline $\begin{array}{c}\text { Scenario } \\
\text { Condition }\end{array}$ & $\begin{array}{c}\text { Storm } \\
\mathbf{T}_{\mathbf{R}} \\
(\mathbf{y r})\end{array}$ & $\begin{array}{c}\text { Runoff } \\
\text { Volume } \\
\left(\mathbf{m}^{\mathbf{3}}\right)\end{array}$ & $\begin{array}{c}\text { Runoff Peak } \\
\text { Discharge } \\
\left(\mathbf{m}^{\mathbf{3} / \mathbf{s})}\right.\end{array}$ & $\begin{array}{c}\text { Max. } \\
\text { Temp., } \\
\left({ }^{\circ} \mathbf{C}\right)\end{array}$ & $\begin{array}{c}\text { Event Mean } \\
\text { Temp., EMT } \\
\left({ }^{\circ} \mathbf{C}\right)\end{array}$ & $\begin{array}{c}\text { Total Heat } \\
\text { Export, H } \\
(\mathbf{M J})\end{array}$ \\
\hline \multirow{3}{*}{ Existing } & 1 & 1017 & 0.191 & 29.7 & 26.3 & 18.3 \\
& 2 & 1845 & 0.402 & 29.3 & 24.6 & 31.1 \\
\multirow{2}{*}{ Future } & 5 & 3847 & 0.887 & 30.1 & 22.3 & 29.4 \\
Build Out & 1 & 1420 & 0.366 & 29.7 & 24.3 & 22.4 \\
& 2 & 2254 & 0.646 & 29.2 & 22.9 & 23.2 \\
\hline
\end{tabular}

\subsubsection{Retrofit Implementation Analysis}

Figure 10 and Figure 11 illustrate the impacts of implementing bioretention filter retrofits across the entire watershed. Retrofit analysis results were somewhat unexpected and must be interpreted with consideration of model limitations. Attempts to resolve model instability issues led to unusual variabilities in the data, evident in Figure 11. 


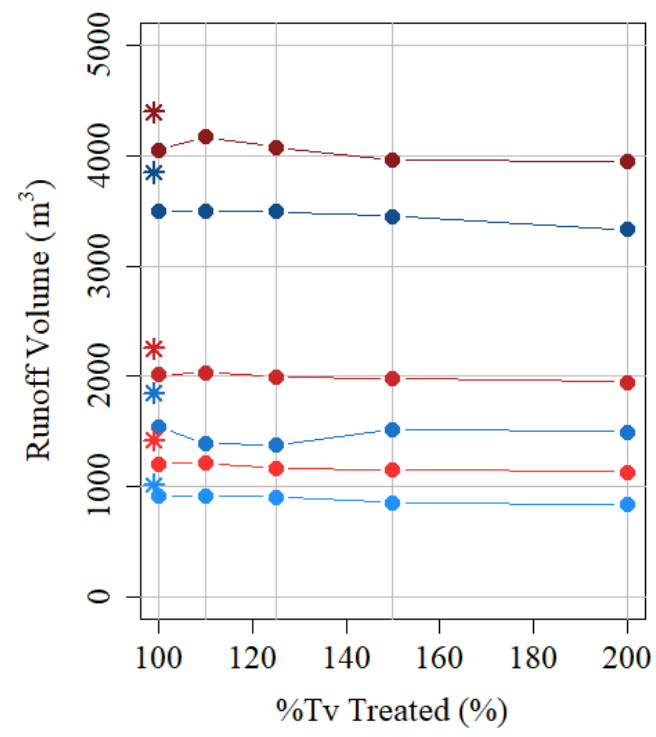

(a)

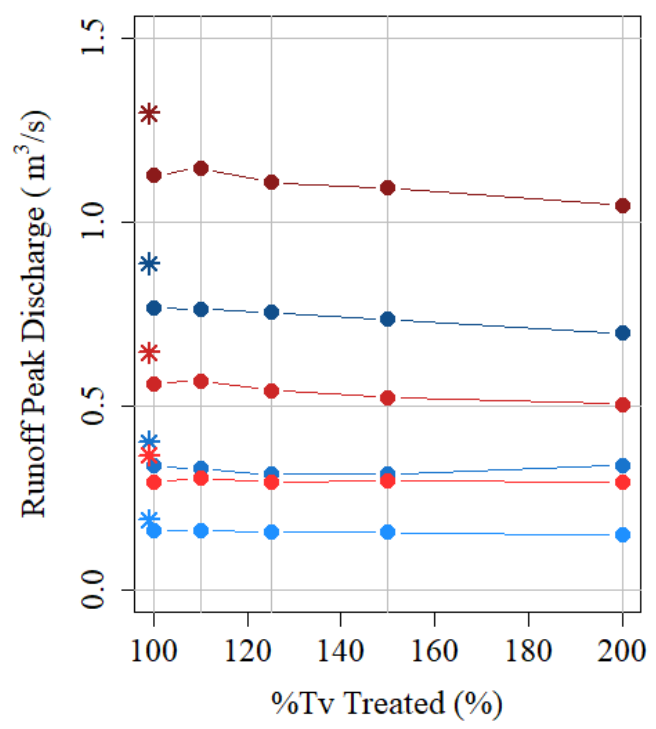

(b)

$$
\begin{aligned}
& \text { Existing Cond: } \longrightarrow \text { 1-yr } \mathrm{T}_{\mathrm{R}} \quad \longrightarrow 2 \text {-yr } \mathrm{T}_{\mathrm{R}} \quad \longrightarrow 5 \text {-yr } \mathrm{T}_{\mathrm{R}} \\
& \text { Future Cond.: }-1 \text {-yr } \mathrm{T}_{\mathrm{R}} \longrightarrow 2 \text {-yr } \mathrm{T}_{\mathrm{R}} \longrightarrow 5 \text {-yr } \mathrm{T}_{\mathrm{R}}
\end{aligned}
$$

Figure 10. Effects of Retrofit Analysis on Runoff Properties: (a) Volume, (b) Peak Discharge

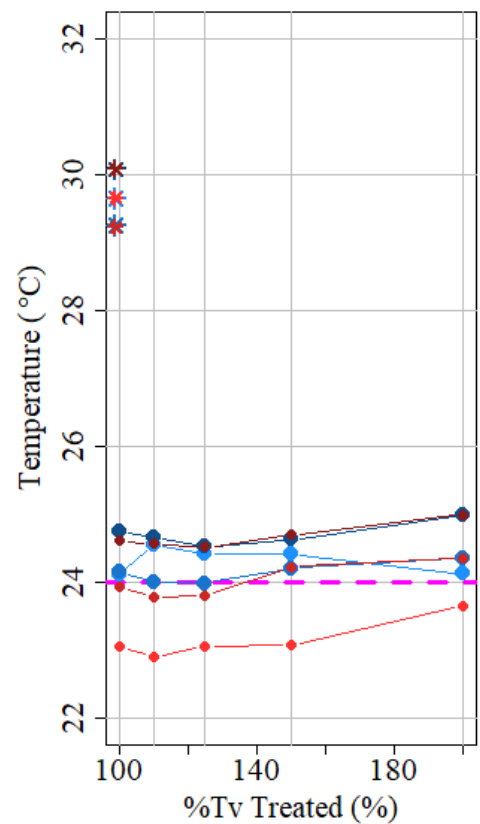

(a)

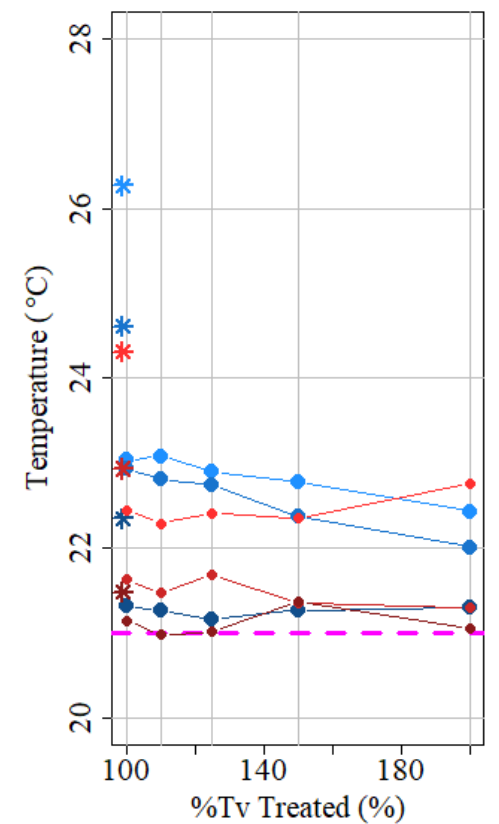

(b)

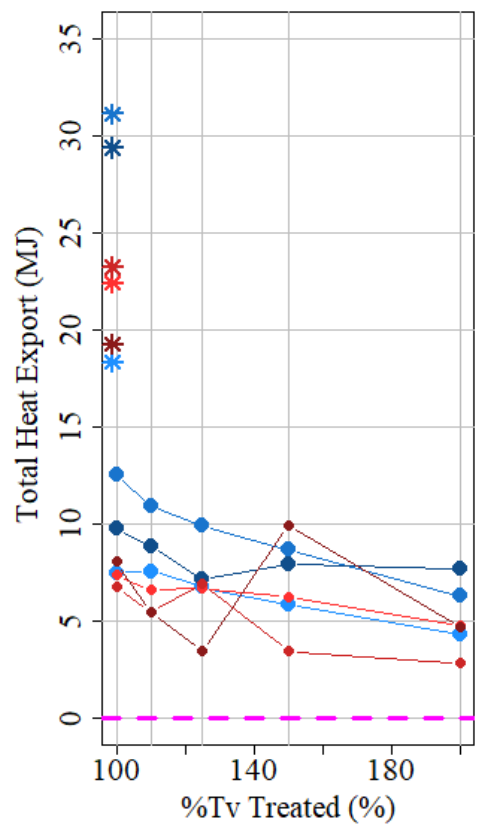

(c)

Existing Cond: $\rightarrow 1-\mathrm{yr} \mathrm{T}_{\mathrm{R}} \quad \longrightarrow 2$-yr $\mathrm{T}_{\mathrm{R}}$

Future Cond.: $\rightarrow 1$-yr $\mathrm{T}_{\mathrm{R}} \longrightarrow 2$-yr $\mathrm{T}_{\mathrm{R}}$

* Control (color by scenario)

Figure 11. Effect of Retrofit Analysis on Temperature Metrics: (a) Max. Temperature, (b) Event Mean Temperature, (c) Total Heat Export 
As expected, retrofits designed to treat $100 \%$ of $T_{v}$ decreased runoff volumes and peaks for all scenarios and storms. The retrofits significantly lowered flow temperatures, confirming the effectiveness of bioretention filters to reduce thermal pollution, even without exfiltration. Maximum temperatures decreased by at least $5^{\circ} \mathrm{C}$ across all simulated conditions. Initial retrofit of the future build out model reduced $T_{\max }$ values below the $24^{\circ} \mathrm{C}$ threshold during the 1-year and 2 -year storms. For most conditions however, initial $100 \% T_{v}$ retrofits were not enough to achieve thermal mitigation goals.

In general, thermal mitigation effectiveness of the retrofits improved as increasing $\% T_{v}$ amounts were treated. $T_{\max }$ of the future build out scenario was adequately mitigated for the 1-year storm by all treatment amounts studied, and for the 2-year storm by treatment less than $150 \% T_{v}$. $T_{\max }$ of the existing condition scenario was only sufficiently lowered for the 2-year storm by retrofits treating between $110 \%$ and $125 \%$ of $T_{v}$. In terms of $E M T$, larger $T_{R}$ storms produced lower values. No amount of treatment analyzed was adequate for meeting the EMT goal under existing watershed conditions. The future build out scenario under the 5-year storm produced EMT values less than $21^{\circ} \mathrm{C}$ with retrofits treating between $110 \%$ and $125 \% T_{v}$. Total heat export proved difficult to mitigate. While increasing retrofit treatment decreased $H$ values, the rate of $H$ decrease decayed as $\% T_{v}$ increased. Thus, retrofitting either scenario did not prevent heat export from surpassing the allowed threshold set by the reference temperature of $21^{\circ} \mathrm{C}$ and continued increase of $\% T_{v}$ would likely be futile. As runoff is strongly related to heat export, complete removal of runoff discharge would be necessary to prevent heat export to the outlet. Based on scenario analysis results, mitigation goals seem unlikely to be met with additional retrofit treatment, if not already achieved. Predictions from previous studies that bioretention filters are not adequate thermal mitigation methods were confirmed.

Results suggested that there is an equilibrium amount of treatment unique to each scenario, evidenced by the decline then increase in $T_{\max }$ and $E M T$ values over the increase of $\% T_{v}$ treated. The mechanics of equilibrium temperature are likely involved, where heat exchange is driven by temperature differentials (Edinger, Duttweiler, and Geyer 1968). After runoff temperatures equilibrated with filter media and surrounding ground temperatures, no more cooling in the BMPs occurred. Retained runoff would then be affected by heat from fresher runoff. 
For the situations that were adequately mitigated for thermal pollution by retrofits designed for up to $125 \% T_{v}$, implementation is feasible. In Virginia, higher level bioretention filter design standards for water quality require treatment of 125\% $T_{v}$ (VA DEQ 2013). Retrofits designed for treatment volumes greater than $125 \% T_{v}$ are less practical. As more facility surface area is needed for larger treatment volumes, construction becomes more challenging since buildable pervious areas are limited. Furthermore, more treatment is typically required in more impervious subbasins, which have less pervious land cover. The area requirements of bioretention filter 1-90 in Table 11 are examples.

Table 11. Required Bioretention Filter Surface Areas for Select Facilities

\begin{tabular}{cccccccc}
\hline \multirow{2}{*}{$\begin{array}{c}\text { Bioretention } \\
\text { Filter }\end{array}$} & $\begin{array}{c}\text { Total } \\
\text { DA }\left(\mathbf{m}^{\mathbf{2}}\right)\end{array}$ & $\begin{array}{c}\text { Pervious } \\
\text { DA }\left(\mathbf{m}^{\mathbf{2}}\right)\end{array}$ & \multicolumn{5}{c}{ Facility Surface Area Required as \% of Pervious DA } \\
\cline { 5 - 8 } & & & $\mathbf{1 0 0 \%} \boldsymbol{T}_{\boldsymbol{v}}$ & $\mathbf{1 1 0 \%} \boldsymbol{T}_{\boldsymbol{v}}$ & $\mathbf{1 2 5 \%} \boldsymbol{T}_{\boldsymbol{v}}$ & $\mathbf{1 5 0 \%} \boldsymbol{T}_{\boldsymbol{v}}$ & $\mathbf{2 0 0 \%} \boldsymbol{T}_{\boldsymbol{v}}$ \\
\hline $1-90$ & 3327 & 347 & 34.8 & 38.3 & 43.5 & 52.2 & 69.6 \\
$1-81$ & 9707 & 1892 & 17.2 & 18.9 & 21.5 & 25.8 & 34.4 \\
$1-66$ & 8352 & 2836 & 8.5 & 9.4 & 10.7 & 12.8 & 17.0 \\
$1-17$ & 21815 & 18185 & 1.0 & 1.1 & 1.2 & 1.5 & 2.0 \\
\hline
\end{tabular}

${ }^{1}$ Bioretention filter label convention: [submodel \#]-[\% impervious area]

\subsection{Conclusions}

A MINUHET model of a $0.8 \mathrm{~km}^{2}$ watershed was developed to analyze thermal impacts of additional development and bioretention filter retrofits for a range of summer design storms. This study concluded that watershed-wide bioretention filter retrofits were able to significantly reduce temperature spikes resulting from storm runoff for both existing development and future build out conditions. In general, temperature metric values decreased as the amount of treatment volume the BMPS were designed for increased. However, the treatment method was unable to adequately reduce thermal impacts to acceptable metric thresholds under most storm conditions. The few scenarios under which mitigation goals were accomplished occurred within feasible treatment volume ranges. Scenarios for which thermal pollution could not be adequately mitigated under the analyzed $\% T_{v}$ amounts are unlikely to be mitigated via bioretention filters. Therefore, the bioretention filter is not considered an effective thermal mitigation method for preventing thermal degradation in streams. 
Future work should analyze the effectiveness of other thermal mitigation practices at the watershed level, especially those which can actively remove large quantities of runoff, as well as methods which prolong the underground retention time of runoff. Runoff volume and peak decreases correlated with temperature decreases, so significant reduction of heat export would require hefty decreases in runoff volume. BMPs such as vegetated swales, rock cribs, or even underground detention facilities may be designed to have infiltrative capabilities and significant runoff storage, which would likely improve the BMPs' thermal mitigation. Results demonstrated the potency of pipe flow cooling, so practices which bring runoff below ground might also be effective thermal mitigation methods. As differences in development were demonstrated to impact stream temperatures, the effects of various development patterns and corresponding storm sewer networks should also be investigated. Development configurations that balance the thermal benefits of having reduced and disconnected impervious areas with the efficiencies of dense development may be valuable. Furthermore, more case studies at the watershed scale need to be done so that watershed characteristics can be analyzed for their impacts on the performance of thermal mitigation methods. In order to conduct high quality simulated experiments, the limitations of existing runoff temperature models must be addressed. With better understanding of how to implement valid methods, solutions that can successfully reduce thermal pollution below accepted thresholds may be developed to help restore stream health.

\section{Conclusion}

\subsection{Implications}

A runoff temperature model developed from existing conditions of a mid-sized watershed in Southwest Virginia was successfully calibrated and validated using MINUHET. Sensitivity analysis on model parameters revealed how influential each parameter was on simulated runoff volumes and maximum temperatures. Finally, bioretention basin retrofits were added to the models representing existing and future build out conditions in order to analyze the retrofits' thermal pollution reduction potentials. Results from this study confirmed the predictions of previous studies that runoff thermal pollution cannot be completely lowered down to goal threshold levels, even though implementation of the retrofits significantly decreased runoff temperatures and heat exports relative to the control scenarios. Scenarios during which temperature metrics did not reach 
target thresholds may never be successfully mitigated without significant runoff volume reductions, which bioretention filters cannot provide. Therefore, temperature mitigation practices which actively reduce runoff may be better methods.

The results from this study shed light on the difficulty of restoring thermally damaged aquatic ecosystems, especially those with strict temperature thresholds such as trout streams. Thermal pollution from runoff is a comprehensive issue dependent on weather, energy fluxes, and flow patterns. With the many factors involved, it is reasonable that the issue has not been proven simple to resolve, even with a combination of several thermal mitigation practices, as attempted by Ketabchy et al. (2019). Furthermore, with the increasing intensity of climate change, stormwater management as a thermal mitigation method may simply never be adequate to prevent stream temperature increases. Nonetheless, more studies on alternative mitigation methods are needed.

\subsection{Future Work}

Before further research into other thermal mitigation methods can continue, existing models should be improved or better models need to be developed. A runoff temperature model should be able to accurately account for the main types of infrastructure found in an urban watershed such as pipes, detention and retention ponds, open channels, and both pervious and impervious land surfaces. A model would also need the ability to model streamflow, as measurement of thermal impacts in a stream is beneficial, where mixing of different flow sources can provide more a realistic assessment (Wardynski et al. 2014).

In terms of MINUHET specifically, it is recommended that the limitations revealed in this study be addressed before application to other similar case studies. For many of the calibrated parameters, values outside of accepted ranges were necessary in order to have acceptable goodness-of-fit, suggesting that the model had difficulty accounting for some of the study watershed's characteristics. Due to the tedious manual data entry process, which increased the potential for data entry errors, and the numerous model simulation issues encountered, MINUHET was challenging to work with during this study. Undesired data adjustments had to be made to enable successful simulations, which likely impacted some of the results. Also, MINUHET does 
not have an element representing filtration devices such as bioretention filters and has been less accurate for larger watershed applications. These existing issues need to be resolved in future model versions.

Future work should evaluate the performance of other thermal mitigation methods at the watershed scale and determine whether those methods would be more successful at adequately reducing thermal pollution to acceptable levels. In particular, methods which can actively remove large volumes of runoff should be investigated, as runoff volume and peak decreases correspond with temperature decreases. Runoff reduction can be achieved through infiltration and storage, which BMPs such as vegetated swales, rock cribs, infiltrative bioretention basins, and underground detention facilities have the ability to do. Underground detention facilities can provide additional runoff cooling through pipe conduction mechanisms, and are not restricted by pervious area space availability.

Aside from SCMs, development patterns should also be analyzed for their effects on stream temperature. Results from this study indicated that different degrees of development and associated storm sewer network configurations influenced stream temperatures, enough to impact whether or not mitigation goals were met. Surprisingly, mitigation was more successful for the scenario with more development. This outcome should be further examined. One approach involves conducting more thermal mitigation case studies at the watershed level. Such case studies could then be compared to analyze how various watershed characteristics may impact the effectiveness of the thermal mitigation methods implemented. Perhaps one method would be more successful in a particular scenario than another.

BMPs are implemented as methods of managing stormwater quantity and quality with the goal to reduce environmental degradation of downstream waters caused by development. Since water temperature is a critical factor of ecological stream health, stormwater management should address thermal pollution as well. Therefore, with better understanding of how watersheds respond to mitigation methods thermally, holistic stormwater management solutions can be developed to help achieve the ultimate goal of preserving downstream aquatic ecosystems. 


\section{References}

Allen, D., W. Dietrich, P. Baker, F. Ligon, and B. Orr. 2007. "Development of a mechanistically based, basin-scale stream temperature model: applications to cumulative effects modeling." In Proceedings of the redwood region forest science symposium: What does the future hold? Gen. Tech. Rep. PSW-GTR-194, Albany, CA, 11-24. Pacific Southwest Research Station, Forest Service, US Department of Agriculture.

Alnefaie, K. A., and N. H. Abu-Hamdeh. 2013. "Specific Heat and Volumetric Heat Capacity of Some Saudian Soils as affected by Moisture and Density." In Proceedings of the 2013 International Conference on Mechanics, Fluids, Heat, Elasticity and Electromagnetic Fields, 139-143.

Arrington, K. E., J. M. Norman, A. Roa-Espinosa, and S. J. Ventura. 2004. "Implementing a Thermal Urban Runoff Model (TURM)." Journal of Water Management Modeling 12:427-458. doi: 10.14796/JWMM.R220-20.

ASCE. 1993. "Criteria for evaluation of watershed models." Journal of Irrigation and Drainage Engineering 119 (3):429-442.

Bird, R. B., W. E. Stewart, and E. N. Lightfoot. 2006. Transport Phenomena: Wiley.

Blacksburg. 2018. "Stormwater Data." http://tobdata.blacksburg.gov/TWM/.

Blacksburg. 2019. "Town of Blacksburg GIS Data." accessed Jul. 1, 2019. https://sites.google.com/vt.edu/townofblacksburggisdata/home.

Bogan, T., O. Mohseni, and H. G. Stefan. 2003. "Stream temperature-equilibrium temperature relationship." Water Resources Research 39 (9). doi: doi.org/10.1029/2003WR002034.

Booth, D. B., K. A. Kraseski, and C. R. Jackson. 2014. "Local-scale and watershed-scale determinants of summertime urban stream temperatures." Hydrological Processes 28:2427-2438. doi: 10.1002/hyp.9810.

Brown, L. E., and D. M. Hannah. 2007. "Alpine Stream Temperature Response to Storm Events." Journal of Hydrometeorology 8 (4):952-967.

Brown, R. A., and W. F. Hunt, III. 2010. "Impacts of media depth on effluent water quality and hydrologic performance of undersized bioretention cells." Journal of Irrigation and Drainage Engineering 137 (3):132-143. doi: https://doi.org/10.1061/(ASCE)IR.19434774.0000167.

Brown, R. A., R. W. Skaggs, and W. F. Hunt, III. 2013. "Calibration and validation of DRAINMOD to model bioretention hydrology." Journal of Hydrology 486 (2013):430442. doi: https://doi.org/10.1016/j.jhydrol.2013.02.017.

Brungs, W. S., and B. R. Jones. 1977. Temperature Criteria for Freshwater Fish: Protocols and Procedures. Duluth, MN: Environ. Research Lab, Ecological Resources Service, EPA, Office of Research and Development.

Campbell Scientific, Inc. 2020a. "034B-L Wind Set." Last Modified 2020, accessed Jan. 8, 2020. https://www.campbellsci.com/034b.

Campbell Scientific, Inc. 2020b. "CS215-L Digital Air Temperature and Relative Humidity Sensor." Last Modified 2020, accessed Jan. 8, 2020. https://www.campbellsci.com/cs215-1.

Campbell Scientific, Inc. 2020c. "CS300-L Pyranometer." Last Modified 2020, accessed Jan. 8 2020. https://www.campbellsci.com/cs300-pyranometer. 
Chapman, K., A. Wawiernia, and H. Kieweg. 2008. Types and Costs of Heat Mitigating Best Management Practices. Apple Valley, MN: Vermillion River Watershed Join Powers Organization.

Clark, J. 2017. "Temperature Dependence of the pH of pure Water." University of California Davis, Last Modified Jan. 20, 2017, accessed Mar. 1, 2019. https://chem.libretexts.org/Bookshelves/Physical_and_Theoretical_Chemistry_Textbook _Maps/Supplemental_Modules_(Physical_and_Theoretical_Chemistry)/Acids_and_Base s/Acids_and_Bases_in_Aqueous_Solutions/The_pH_Scale/Temperature_Dependence_of the $\mathrm{pH}$ of of pure Water.

Cockerill, K., W. P. Anderson, F. C. Harris, and K. Straka. 2017. "Hot, Salty Water: A Confluence of Issues in Managing Stormwater Runoff for Urban Streams." Journal of the American Water Resources Association (JAWRA) 53 (3):707-724. doi: 10.1111/17521688.12528.

Du, X., N. K. Shrestha, D. L. Ficklin, and J. Wang. 2018. "Incorporation of the equilibrium temperature approach in a Soil and Water Assessment Tool hydroclimatological stream temperature model." Hydrol. Earth Syst. Sci. 22 (4):2343-2357. doi: 10.5194/hess-222343-2018.

Dugdale, S. J., N. E. Bergeron, and A. St-Hilaire. 2013. "Temporal variability of thermal refuges and water temperature patterns in an Atlantic salmon river." Remote Sensing of Environment 136:358-373. doi: https://doi.org/10.1016/j.rse.2013.05.018.

Eaton, J. G., J. H. McCormick, B. E. Goodno, D. G. O'Brien, H. G. Stefany, M. Hondzo, and R. M. Scheller. 1995. "A Field Information-based System for Estimating Fish Temperature Tolerances." Fisheries 20 (4):10-18. doi: 10.1577/15488446(1995)020<0010:AFISFE>2.0.CO;2.

Edinger, J. E., D. W. Duttweiler, and J. C. Geyer. 1968. "The Response of Water Temperatures to Meteorological Conditions." Water Resources Research 4 (5):1137-1143.

Elliott, A. H., S. A. Trowsdale, and S. Wadhwa. 2009. "Effect of aggregation of on-site stormwater control devices in an urban catchment model." Journal of Hydrologic Engineering 14 (9):975-983. doi: https://doi.org/10.1061/(ASCE)HE.1943-5584.0000064.

EPA. 2009. "Stream Water Quality Model." U. S. Environmental Protection Agency, Last Modified Aug. 25, 2009, accessed Jan. 18, 2020. https://cfpub.epa.gov/si/si_public_record_Report.cfm?Lab=NERL\&dirEntryID=75862.

EPA. 2012. "Summaries of Water Pollution Reporting Categories." U. S. Environmental Protection Agency, accessed Jan. 18, 2020. https://watersgeo.epa.gov/ATTAINS/34PARENTATTAINSDESCRIPTIONS.pdf.

Farouki, O. T. 1981. Thermal Properties of Soils. CRREL Monograph 81-1. Hanover, NH: US Army Corps of Engineers. https://apps.dtic.mil/dtic/tr/fulltext/u2/a111734.pdf.

FHWA. 2019. "Pavement Thermal Performance And Contribution To Urban And Global Climate." Federal Highway Administration, accessed Jan. 14, 2020. https://www.fhwa.dot.gov/pavement/sustainability/articles/pavement_thermal.cfm.

Ficklin, D. L., Y. Luo, I. T. Stewart, and E. P. Maurer. 2012. "Development and application of a hydroclimatological stream temperature model within the Soil and Water Assessment Tool." Water Resources Research 48 (1). doi: https://doi.org/10.1029/2011WR011256.

Ford, D. E., and H. G. Stefan. 1980. "Thermal predictions using integral energy model." Journal of the Hydraulics Division 106 (1):39-55. 
Geankoplis, C. J., A. A. Hersel, and D. H. Lepek. 2018. Transport Processes and Separation Process Principles, Fifth Edition. Boston: Prentice Hall. O'Reilly Learning Platform.

Glose, A., L. K. Lautz, and E. A. Baker. 2017. "Stream heat budget modeling with HFLUX: Model development, evaluation, and applications across contrasting sites and seasons." Environmental modelling \& software 92:213-228. doi: https://doi.org/10.1016/j.envsoft.2017.02.021.

Gronbeck, C. 2009. "SunPosition Output." https://susdesign.com/sunposition/index.php.

Haq, R., and W. James. 2002. "Thermal enrichment of stream temperature by urban storm waters." In Global Solutions for Urban Drainage, 1-11.

Hassn, A., Andrea C., Andrew D., and Alvaro G. 2016. "Thermal properties of asphalt pavements under dry and wet conditions." Materials and Design 91 (2016):432-439. doi: dx.doi.org/10.1016/j.matdes.2015.11.116.

Hathaway, J. M., R. J. Winston, R. A. Brown, W. F. Hunt, and D. T. McCarthy. 2016. "Temperature dynamics of stormwater runoff in Australia and the USA." Science of the Total Environment 559:141-150. doi: http://dx.doi.org/10.1016/j.scitotenv.2016.03.155.

Hein, D., S. Rao, S. Tayabji, and H. Lee. 2017. Bases and Subbases for Concrete Pavements. FHWA-HIF-16-005. Washington DC: Federal Highway Administration. https://rosap.ntl.bts.gov/view/dot/38477.

Herb, W. 2008. Analysis of the effect of stormwater runoff volume regulations on thermal loading to the Vermillion River, Report 520. Minneapolis, MN: St. Anthony Falls Laboratory, University of Minnesota. http://hdl.handle.net/11299/115343.

Herb, W., B. Janke, O. Mohseni, and H. Stefan. 2010a. MINUHET (Minnesota Urban Heat Export Tool) User Manual, Report 530. Minneapolis, MN: St. Anthony Falls Laboratory, University of Minnesota. http://hdl.handle.net/11299/115556.

Herb, W., B. Janke, O. Mohseni, and H. Stefan. 2010b. MINUHET (Minnesota Urban Heat Export Tool): A software tool for the analysis of stream thermal loading by urban stormwater runoff, Report 526. Minneapolis, MN: St. Anthony Falls Lab, University of Minnesota. http://hdl.handle.net/11299/117645.

Herb, W., O. Mohseni, and H. Stefan. 2007. Heat Export and Runoff Temperature Analysis for Rainfall Event Selection, Report 483. Minneapolis, MN: St. Anthony Falls Lab, University of Minnesota. http://hdl.handle.net/11299/113688.

Herb, W. R., B. Janke, O. Mohseni, and H. G. Stefan. 2006a. An Analytic Model for Runoff and Runoff Temperature from a Paved Surface, Report 484. Minneapolis, MN: St. Anthony Fall Lab, University of Minnesota. http://hdl.handle.net/11299/113690.

Herb, W. R., B. Janke, O. Mohseni, and H. G. Stefan. 2008. "Ground surface temperature simulation for different land covers." Journal of Hydrology 356 (3-4):327-343. doi: https://doi.org/10.1016/j.jhydrol.2008.04.020.

Herb, W. R., B. Janke, O. Mohseni, and H. G. Stefan. 2009. "Runoff temperature model for paved surfaces." Journal of Hydrologic Engineering 14 (10):1146-1155. doi: https://doi.org/10.1061/(ASCE)HE.1943-5584.0000108.

Herb, W. R., O. Mohseni, and H. G. Stefan. 2009. "Simulation of Temperature Mitigation by a Stormwater Detention Pond." JAWRA Journal of the American Water Resources Association 45 (5):1164-1178. doi: https://doi.org/10.1111/j.1752-1688.2009.00354.x.

Herb, W. R., M. Weiss, O. Mohseni, and H. G. Stefan. 2006b. Hydrothermal Simulation of a Stormwater Detention Pond or Infiltration Basin, Report 479. Minneapolis, MN: St. Anthony Falls Laboratory, University of Minnesota. http://hdl.handle.net/11299/113685. 
Hondzo, M., and H. G. Stefan. 1993. "Lake water temperature simulation model." Journal of Hydraulic Engineering 119 (11):1251-1273. doi: https://doi.org/10.1061/(ASCE)07339429(1993)119:11(1251).

Honsberg, C., and S. Bowden. 2019. "Photovoltaics Education Website." https://www.pveducation.org/.

Hunt, W. F., A. P. Davis, and R. G. Traver. 2012. "Meeting Hydrologic and Water Quality Goals through Targeted Bioretention Design." Journal of Environmental Engineering 138 (6):698-707. doi: https://doi.org/10.1061/(ASCE)EE.1943-7870.0000504.

James, W., and B. Verspagen. 1997. "Thermal enrichment of stormwater by urban pavement." Advances in Modeling the management of Stormwater impacts 5:155-177.

James, W., and J. Xie. 1999. "Modeling thermal enrichment of streams due to solar heating of local urban stormwater." Journal of Water Management Modeling.

Janke, B. D. , W. R. Herb, O. Mohseni, and H. G. Stefan. 2013. "Case Study of Simulation of Heat Export by Rainfall Runoff from a Small Urban Watershed Using MINUHET." Journal of Hydrologic Engineering 18 (8):995-1006. doi: https://doi.org/10.1061/(ASCE)HE.1943-5584.0000696.

Janke, B. D., W. R. Herb, O. Mohseni, and H. G. Stefan. 2009. "Simulation of heat export by rainfall-runoff from a paved surface." Journal of Hydrology 365:195-212. doi: 10.1016/j.jhydrol.2008.11.019.

Jones, M. P, and W. F. Hunt. 2007. Stormwater BMPs for trout waters: coldwater stream design guidance for stormwater wetlands, wet ponds, and bioretention, Urban Waterways. NC: North Carolina Cooperative Extension. http://digital.ncdcr.gov/cdm/ref/collection/p16062coll9/id/230562.

Jones, M. P. , W. F. Hunt, and R. J. Winston. 2012. "Effect of Urban Catchment Composition on Runoff Temperature." Journal of Environmental Engineering 138 (12):1231-1236. doi: 10.1061/(ASCE)EE.1943-7870.0000577.

Jones, M. P., and W. F. Hunt. 2009. "Bioretention impact on runoff temperature in trout sensitive waters." Journal of Environmental Engineering 135 (8):577-585. doi: https://doi.org/10.1061/(ASCE)EE.1943-7870.0000022.

Jones, M. P., and W. F. Hunt. 2010. "Effect of Storm-Water Wetlands and Wet Ponds on Runoff Temperature in Trout Sensitive Waters." Journal of Irrigation \& Drainage Engineering 136 (9):656-661. doi: 10.1061/(ASCE)IR.1943-4774.0000227.

Kavianipour, A., and J. V. Beck. 1977. "Thermal Property Estimation Utilizing the LaPlace Transform with Application to Asphaltic Pavement." International Journal of Heat and Mass Transfer 20:259-267. doi: https://doi.org/10.1016/0017-9310(77)90212-5.

Ketabchy, M., D. J. Sample, T. Wynn-Thompson, and M. N. Yazdi. 2018. "Thermal evaluation of urbanization using a hybrid approach." Journal of Environmental Management 226:457-475. doi: https://doi.org/10.1016/j.jenvman.2018.08.016.

Ketabchy, M., D. J. Sample, T. Wynn-Thompson, and M. N. Yazdi. 2019. "Simulation of watershed-scale practices for mitigating stream thermal pollution due to urbanization." Science of the Total Environment 671 (2019):215-231. doi: https://doi.org/10.1016/j.scitotenv.2019.03.248.

Kieser, M. S., J. A. Spoelstra, A. F. Fang, W. James, and Y. Li. 2004. Stormwater thermal enrichment in urban watersheds: Water Environment Research Foundation. 
Kinouchi, T., H. Yagi, and M. Miyamoto. 2007. "Increase in stream temperature related to anthropogenic heat input from urban wastewater." Journal of Hydrology 335 (1):78-88. doi: https://doi.org/10.1016/j.jhydrol.2006.11.002.

Klein, R. D. 1979. "Urbanization and Stream Quality Impairment." Journal of the American Water Resources Association (JAWRA) 15 (4):948-963. doi: 10.1111/j.17521688.1979.tb01074.x.

Laanaya, F., A. St-Hilaire, and E. Gloaguen. 2017. "Water temperature modelling: comparison between the generalized additive model, logistic, residuals regression and linear regression models." Hydrological sciences journal 62 (7):1078-1093. doi: https://doi.org/10.1080/02626667.2016.1246799.

Land Design Technologies, LLC. 2019. "Storm QC v2.2 Software." https://landdesigntech.com/products/\#.

LeBlanc, R. T., R. D. Brown, and J. E. FitzGibbon. 1997. "Modeling the Effects of Land Use Change on the Water Temperature in Unregulated Urban Streams." Journal of Environmental Management 49 (4):445-469. doi: https://doi.org/10.1006/jema.1996.0106.

Li, H., L. J. Sharkey, W. F. Hunt, and A. P. Davis. 2009. "Mitigation of impervious surface hydrology using bioretention in North Carolina and Maryland." Journal of Hydrologic Engineering 14 (4):407-415. doi: https://doi.org/10.1061/(ASCE)10840699(2009)14:4(407).

Li, M., B. Dvorak, and C. Y. Sung. 2010. "Bioretention, low impact development, and stormwater management." Urban Ecosystem Ecology:413-430.

Long, D. L., and R. L. Dymond. 2013. "Thermal Pollution Mitigation in Cold Water Stream Watersheds Using Bioretention." Journal of the American Water Resources Association (JAWRA) 50 (4):977-987. doi: 10.1111/jawr.12152.

Luca, J., and D. Mrawira. 2005. "New Measurement of Thermal Properties of Superpave Asphalt Concrete." Journal of Materials in Civil Engineering 17 (1):72-79. doi: 10.1061/(ASCE)0899-1561(2005)17:1(72).

Martin, C. J. , C. C. Hodges, and R. L. Dymond. 2019. "Geospatial Method to Map Potential Risk of Stormwater Thermal Pollution." Journal of the American Water Resources Association (JAWRA) 55 (2):515-522. doi: https://doi.org/10.1111/1752-1688.12732.

Mayer, T. D. 2012. "Controls of summer stream temperature in the Pacific Northwest." Journal of Hydrology 475:323-335. doi: http://dx.doi.org/10.1016/j.jhydrol.2012.10.012.

McCuen, R. H. 1973. "The role of sensitivity analysis in hydrologic modeling." Journal of Hydrology 18 (1):37-53. doi: https://doi.org/10.1016/0022-1694(73)90024-3.

McCuen, R. H. 2017. Hydrologic Analysis and Design. 4 ed. Hoboken, NJ: Pearson Higher Education, Inc.

Mohseni, O., H. G. Stefan, and T. R. Erickson. 1998. "A nonlinear regression model for weekly stream temperatures." Water Resources Research 34 (10):2685-2692. doi: https://doi.org/10.1029/98WR01877.

Moriasi, D. N., J. G. Arnold, M.W. Van Liew, R.L. Binger, R.D. Harmel, and T.L. Veith. 2007. "Model Evaluation Guidelines for Systematic Quantification of Accuracy in Watershed Simulations." Transactions of the ASABE 50 (3):885-900. doi: 10.13031/2013.23153.

Morrill, J. C., R. C. Bales, and M. H. Conklin. 2005. "Estimating stream temperature from air temperature: implications for future water quality." Journal of Environmental 
Engineering 131 (1):139-146. doi: https://doi.org/10.1061/(ASCE)0733-

9372(2005)131:1(139).

Nash, J. E., and J. V. Sutcliffe. 1970. "River flow forecasting through conceptual models part IA discussion of principles." Journal of hydrology 10 (3):282-290. doi: https://doi.org/10.1016/0022-1694(70)90255-6.

Natarajan, P., and A. P. Davis. 2010. "Thermal Reduction by an Underground Storm-Water Detention System." Journal of Environmental Engineering 136 (5):520-526. doi: https://doi.org/10.1061/(ASCE)EE.1943-7870.0000172.

National Research Council. 2009. Urban Stormwater Management in the United States. Washington, DC: The National Academies Press.

Nelson, K. C., and M. A. Palmer. 2007. "Stream Temperature Surges Under Urbanization and Climate Change: Data, Models, and Responses." Journal of the American Water Resources Association (JAWRA) 43 (2):440-452. doi: 10.1111/j.17521688.2007.00034.x.

NOAA. 2017. "NOAA Atlas 14 Point Precipitation Frequency Estimates: VA." NOAA, Last Modified April 21, 2017, accessed Nov. 19, 2019. https://hdsc.nws.noaa.gov/hdsc/pfds/pfds_map_cont.html.

NOAA. 2019. "Local Climatological Data CSV, Station WBAN: 53881." National Centers for Environmental Information (NCEI), accessed July 8, 2019. https://www.ncdc.noaa.gov/cdo-web/datasets/LCD/stations/WBAN:53881/detail.

NRCS. 1986. Urban Hydrology for Small Watersheds: TR-55: U. S. Department of Agriculture.

NRCS. 2009. "Ch. 7: Hydrologic Soil Groups." In Part 630 Hydrology: National Engineering Handbook. U. S. Department of Agriculture.

NRCS. n.d. "Stone Size Schedule." Natural Resources Conservation Service, accessed Aug. 24, 2019. https://www.dcr.virginia.gov/soil-and-water/document/des-dt-stone-size.pdf.

Ophardt, C. 2015. "Temperature Effects on Solubility." University of California Davis, Last Modified Jan. 4, 2015, accessed Mar. 1, 2019. https://chem.libretexts.org/Bookshelves/Physical_and_Theoretical_Chemistry_Textbook _Maps/Supplemental_Modules_(Physical_and_Theoretical_Chemistry)/Acids_and_Base s/Acids_and_Bases_in_Aqueous_Solutions/The_pH_Scale/Temperature_Dependence_of the_pH_of_pure Water.

Picksley, W., and A. Deletic. 1999. "The Thermal Enrichment of Storm Runoff from Paved Areas - a Statistical Analysis." Journal of Water Management Modeling. doi: 10.14796/JWMM.R204-07.

Pluhowski, E. J. 1970. "Urbanization and its effect on the temperature of the streams on Long Island, New York". U.S. Geological Survey Professional Paper 627-D. http://pubs.er.usgs.gov/publication/pp627D.

Risley, J. C., E. A. Roehl, Jr., and P. A. Conrads. 2003. "Estimating Water Temperatures in Small Streams in Western Oregon using Neural Network Models". Portland, OR: U.S. Geological Survey Water-Resources Investigations Report 02-4218. https://pubs.usgs.gov/wri/wri024218/.

Roa-Espinosa, A., T. B. Wilson, J. M. Norman, and K. Johnson. 2003. "Predicting the impact of urban development on stream temperature using a thermal urban runoff model (TURM)." National Conference on Urban Stormwater: Enhancing Programs at the Local Level, February, 17-20. 
Sabouri, F., B. Gharabaghi, A. A. Mahboubi, and E. A. McBean. 2013. "Impervious surfaces and sewer pipe effects on stormwater runoff temperature." Journal of Hydrology 502:10-17. doi: http://dx.doi.org/10.1016/j.jhydrol.2013.08.016.

Selbig, W. R. 2015. "Simulating the effect of climate change on stream temperature in the Trout Lake Watershed, Wisconsin." Science of The Total Environment 521-522:11-18. doi: https://doi.org/10.1016/j.scitotenv.2015.03.072.

Somers, K. A., E. S. Bernhardt, J. B. Grace, B. A. Hassett, E. B. Sudduth, S. Wang, and D. L. Urban. 2013. "Streams in the urban heat island: spatial and temporal variability in temperature." Freshwater Science 32 (1):309-326. doi: 10.1899/12-046.1.

St-Hilaire, A., M. Boucher, F. Chebana, S. Ouellet-Proulx, Q. X. Zhou, S. Larabi, S. J. Dugdale, and M. Latraverse. 2015. "Breathing a new life to an older model: The CEQUEAU tool for flow and water temperature simulations and forecasting." In Proceedings of the 22nd Canadian Hydrotechnical Conference. Montreal, QC, Canada.

Steel, E. A., T. J. Beechie, C. E. Torgersen, and A. H. Fullerton. 2017. "Envisioning, Quantifying, and Managing Thermal Regimes on River Networks." BioScience 67 (6):506-522. doi: 10.1093/biosci/bix047.

StREAM Lab. 2019. "StREAM Lab Meteorological Data." Department of Biological Systems Engineering, Virginia Tech. https://www.bse.vt.edu/research/facilities/StREAM_Lab.html.

Teledyne Isco, Inc. 2009. 2150 Area Velocity Flow Module and Sensor: Installation and Operation Guide: Teledyne Isco, Inc.

Texas Electronics, Inc. n.d. TR-525 Series Rainfall Sensors User's Manual: Texas Electronics, Inc.

Thompson, A., T. Wilson, J. Norman, A. Gemechu, and A. Roa-Espinosa. 2008. "Modeling the effect of summertime heating on urban runoff temperature." Journal of the American Water Resources Association (JAWRA) 44:1548-1563. doi: https://doi.org/10.1111/j.1752-1688.2008.00259.x.

VA DCR. 2013. Virginia Stormwater Management Handbook. 2013 Draft. Richmond, VA: VA Department of Conservation and Recreation. https://www.swbmp.vwrrc.vt.edu/references-tools/2013-draft-handbook/.

VA DCR. 2020. "Virginia Hydrologic Unit Explorer." VA Department of Conservation and Recreation. http://consapps.dcr.virginia.gov/htdocs/maps/HUExplorer.htm.

VA DEQ. 2013. "Specification No. 9: Bioretention (v2.0 Draft)." In Virginia DEQ Stormwater Design Specification. Virginia Stormwater BMP Clearinghouse: VA Department of Environmental Quality. https://www.swbmp.vwrrc.vt.edu/wpcontent/uploads/2017/11/BMP-Spec-No-9_BIORETENTION_v1-9_03012011.pdf.

VA DEQ. 2018. "Fact Sheets for Impaired (Category 4 or 5) Waters in 2018." In Draft 2018 305(b)/303(d) Water Quality Assessment Integrated Report. VA Department of Environmental Quality. https://www.deq.virginia.gov/Programs/Water/WaterQualityInformationTMDLs/WaterQ ualityAssessments/2018305(b)303(d)IntegratedReport.aspx.

VA DGIF. 2020. "Virginia Trout Fishing." VA Department of Game and Inland Fisheries, accessed May 30, 2019. https://dgifvirginia.maps.arcgis.com/apps/webappviewer/index.html?id=441ed456c8664166bb735b $\underline{1 \mathrm{db} 6024 \mathrm{e} 48}$. 
Van Buren, M. A., W. E. Watt, J. Marsalek, and B. C. Anderson. 2000. "Thermal enhancement of stormwater runoff by paved surfaces." Water research 34 (4):1359-1371.

Virginia Citizen Water Quality Monitoring Program. 2007. "Chapter 11: Temperature." In Virginia Citizen Water Quality Monitoring Program Methods Manual. VA: Virginia Department of Environmental Quality. https://www.deq.virginia.gov/Portals/0/DEQ/Water/WaterQualityMonitoring/CitizenMon itoring/Citmon_Manual.pdf.

Walker, J. S. 1989. "Nuclear Power and the Environment: The Atomic Energy Commission and Thermal Pollution, 1965-1971." Technology and Culture 30 (4):964-992. doi: $10.2307 / 3106199$.

Walsh, C. J., A. H. Roy, J. W. Feminella, P. D. Cottingham, P. M. Groffman, and R. P. Morgan. 2005. "The urban stream syndrome: current knowledge and the search for a cure." Journal of the North American Benthological Society 24 (3):706-723. doi: https://doi.org/10.1899/04-028.1.

Wardynski, B. J., R. J. Winston, D. E. Line, and W. F. Hunt. 2014. "Metrics for assessing thermal performance of stormwater control measures." Ecological Engineering 71:551562. doi: http://dx.doi.org/10.1016/j.ecoleng.2014.07.068.

Watson, E. C., and H. Chang. 2017. "Relation Between Stream Temperature and Landscape Characteristics Using Distance Weighted Metrics." Water Resources Management 32 (3):1167-1192. doi: https://doi.org/10.1007/s11269-017-1861-9.

Webster, K. 2011. "In Hot Water: Temperature TMDLs in the Pacific Northwest." Thesis, Tufts University, 2011. ProQuest Dissertations Publishing.

Winston, R. J., W. F. Hunt, and W. G. Lord. 2011. "Thermal mitigation of urban storm water by level spreader-vegetative filter strips." Journal of Environmental Engineering 137 (8):707-716. doi: https://doi.org/10.1061/(ASCE)EE.1943-7870.0000367. 


\section{Appendices}

\section{Appendix A - MINUHET Model Details}

\section{A.1 Input Data}

Table A1. Existing Condition Scenario Bioretention Filter Information

\begin{tabular}{|c|c|c|c|c|}
\hline $\begin{array}{c}\text { Bioretention } \\
\text { Filter }\end{array}$ & $\begin{array}{l}\text { DA } \\
\left(\mathbf{m}^{2}\right)\end{array}$ & $\begin{array}{l}\mathbf{T}_{\mathbf{v}} \\
\left(\mathbf{m}^{3}\right)\end{array}$ & $\begin{array}{c}\text { Length } \\
\text { (m) }\end{array}$ & $\begin{array}{l}\text { Equivalent SA } \\
\qquad\left(\mathbf{m}^{2}\right)\end{array}$ \\
\hline $1-10$ & 19732 & 113 & 161 & 185 \\
\hline $1-17$ & 21815 & 110 & 158 & 181 \\
\hline $1-23$ & 29045 & 203 & 291 & 333 \\
\hline $1-24 a$ & 6563 & 57 & 82 & 94 \\
\hline $1-24 b$ & 4970 & 44 & 64 & 73 \\
\hline $1-27$ & 28213 & 282 & 403 & 462 \\
\hline $1-28$ & 6285 & 58 & 83 & 95 \\
\hline $1-31$ & 1005 & 11 & 16 & 18 \\
\hline $1-33$ & 27088 & 306 & 437 & 502 \\
\hline $1-37 a$ & 16091 & 189 & 271 & 311 \\
\hline $1-37 b$ & 10197 & 112 & 160 & 184 \\
\hline $1-40$ & 5579 & 69 & 98 & 113 \\
\hline $1-42$ & 5385 & 68 & 98 & 112 \\
\hline $1-45$ & 2122 & 28 & 40 & 45 \\
\hline $1-48$ & 10165 & 141 & 201 & 231 \\
\hline $1-49$ & 8594 & 122 & 174 & 200 \\
\hline $1-50$ & 1452 & 9 & 13 & 15 \\
\hline $1-53$ & 1106 & 17 & 24 & 27 \\
\hline $1-54$ & 12574 & 187 & 268 & 307 \\
\hline $1-58$ & 8586 & 138 & 197 & 226 \\
\hline $1-59 a$ & 5257 & 84 & 120 & 137 \\
\hline $1-59 b$ & 654 & 11 & 15 & 18 \\
\hline $1-60$ & 5976 & 99 & 141 & 162 \\
\hline $1-62$ & 1210 & 20 & 29 & 33 \\
\hline $1-66$ & 8352 & 147 & 211 & 242 \\
\hline $1-68 a$ & 5239 & 94 & 135 & 155 \\
\hline $1-68 b$ & 4514 & 81 & 116 & 133 \\
\hline $1-72$ & 597 & 11 & 16 & 18 \\
\hline $1-78 a$ & 4489 & 89 & 128 & 147 \\
\hline $1-78 b$ & 2047 & 41 & 58 & 67 \\
\hline $1-81$ & 9707 & 198 & 283 & 325 \\
\hline $1-83$ & 5920 & 124 & 177 & 203 \\
\hline $1-90$ & 3327 & 74 & 105 & 121 \\
\hline $1-100$ & 1006 & 24 & 35 & 40 \\
\hline $2-20$ & 3710 & 31 & 44 & 50 \\
\hline $2-23$ & 1727 & 13 & 18 & 21 \\
\hline
\end{tabular}




\begin{tabular}{|c|c|c|c|c|}
\hline $2-32 a$ & 8500 & 87 & 125 & 143 \\
\hline $2-32 b$ & 8866 & 97 & 139 & 159 \\
\hline $2-32 c$ & 2931 & 30 & 42 & 49 \\
\hline $2-33$ & 5531 & 54 & 77 & 88 \\
\hline $2-36$ & 5682 & 68 & 97 & 111 \\
\hline $2-41 \mathrm{a}$ & 10782 & 124 & 177 & 203 \\
\hline $2-41 b$ & 6927 & 87 & 124 & 143 \\
\hline $2-42$ & 6798 & 79 & 114 & 130 \\
\hline $2-52$ & 10638 & 158 & 226 & 259 \\
\hline $2-53$ & 8983 & 126 & 180 & 207 \\
\hline $2-56$ & 775 & 12 & 18 & 20 \\
\hline $2-57 a$ & 8083 & 130 & 185 & 212 \\
\hline $2-57 b$ & 5522 & 87 & 125 & 143 \\
\hline $2-60$ & 4400 & 72 & 104 & 119 \\
\hline $2-61$ & 9670 & 161 & 230 & 264 \\
\hline $2-62$ & 5436 & 88 & 126 & 144 \\
\hline $2-63$ & 1362 & 23 & 33 & 38 \\
\hline $2-65$ & 5929 & 103 & 147 & 168 \\
\hline $2-67$ & 5145 & 91 & 130 & 149 \\
\hline $2-68$ & 2510 & 45 & 65 & 75 \\
\hline $3-30$ & 7490 & 69 & 99 & 114 \\
\hline $3-56$ & 5769 & 90 & 128 & 147 \\
\hline $3-68$ & 5120 & 92 & 131 & 151 \\
\hline 4-10a & 11600 & 61 & 87 & 100 \\
\hline $4-10 b$ & 19022 & 92 & 132 & 151 \\
\hline $4-11$ & 11419 & 65 & 93 & 107 \\
\hline $4-12 a$ & 7908 & 59 & 84 & 96 \\
\hline $4-14$ & 3852 & 25 & 36 & 41 \\
\hline $4-16$ & 22281 & 160 & 229 & 262 \\
\hline $4-18 a$ & 3457 & 25 & 35 & 41 \\
\hline $4-18 b$ & 9366 & 76 & 109 & 125 \\
\hline $4-20$ & 5554 & 39 & 55 & 63 \\
\hline $4-27$ & 8281 & 82 & 117 & 134 \\
\hline $4-28$ & 13403 & 130 & 185 & 213 \\
\hline $4-30$ & 20208 & 200 & 286 & 328 \\
\hline 4-32a & 13401 & 140 & 200 & 229 \\
\hline $4-32 b$ & 10530 & 112 & 160 & 183 \\
\hline $4-34$ & 18713 & 207 & 295 & 339 \\
\hline $4-37$ & 4001 & 49 & 70 & 81 \\
\hline 4-38a & 18584 & 223 & 319 & 366 \\
\hline $4-38 b$ & 9849 & 123 & 176 & 202 \\
\hline $4-40$ & 9140 & 113 & 162 & 186 \\
\hline $4-41$ & 3547 & 45 & 64 & 74 \\
\hline $4-43$ & 8247 & 111 & 159 & 182 \\
\hline
\end{tabular}




$\begin{array}{ccccc}4-46 & 5732 & 76 & 109 & 125 \\ 4-56 & 5059 & 80 & 114 & 131 \\ 4-61 & 3722 & 62 & 89 & 102 \\ 4-64 & 2756 & 48 & 68 & 78 \\ 4-68 & 2637 & 47 & 67 & 77 \\ 4-69 & 2185 & 50 & 133 & 65 \\ 4-90 & 4164 & 93 & \end{array}$

Table A2. Future Build Out Scenario Bioretention Filter Information

\begin{tabular}{|c|c|c|c|c|}
\hline $\begin{array}{l}\text { Bioretention } \\
\text { Filter }\end{array}$ & $\begin{array}{l}\text { DA } \\
\left(\mathbf{m}^{2}\right)\end{array}$ & $\begin{array}{c}\mathbf{T}_{\mathbf{v}} \\
\left(\mathbf{m}^{3}\right)\end{array}$ & $\begin{array}{c}\text { Input Length } \\
\text { (m) }\end{array}$ & $\begin{array}{c}\text { Equivalent SA } \\
\left(\mathbf{m}^{2}\right)\end{array}$ \\
\hline $1-10$ & 16617 & 88 & 126 & 145 \\
\hline $1-19$ & 6471 & 51 & 73 & 84 \\
\hline $1-23$ & 21711 & 169 & 241 & 277 \\
\hline $1-24$ & 4970 & 44 & 64 & 73 \\
\hline $1-28$ & 6285 & 58 & 83 & 95 \\
\hline $1-36$ & 16201 & 187 & 267 & 307 \\
\hline $1-37$ & 10473 & 121 & 173 & 199 \\
\hline $1-40 \mathrm{a}$ & 5579 & 69 & 98 & 113 \\
\hline $1-40 c$ & 4369 & 54 & 77 & 88 \\
\hline $1-42$ & 5385 & 68 & 98 & 112 \\
\hline $1-44$ & 14064 & 187 & 268 & 307 \\
\hline $1-48$ & 10165 & 141 & 201 & 231 \\
\hline $1-49$ & 8594 & 122 & 174 & 200 \\
\hline $1-50 a$ & 1452 & 9 & 13 & 15 \\
\hline $1-50 \mathrm{~b}$ & 624 & 9 & 13 & 15 \\
\hline $1-54 a$ & 12574 & 187 & 268 & 307 \\
\hline $1-54 b$ & 7642 & 116 & 166 & 191 \\
\hline $1-56$ & 11937 & 187 & 268 & 307 \\
\hline $1-57$ & 11688 & 186 & 265 & 304 \\
\hline $1-58$ & 8586 & 138 & 197 & 226 \\
\hline $1-59 a$ & 5257 & 84 & 120 & 137 \\
\hline $1-59 b$ & 654 & 11 & 15 & 18 \\
\hline $1-60$ & 5976 & 99 & 141 & 162 \\
\hline $1-62$ & 1210 & 20 & 29 & 33 \\
\hline $1-66$ & 8352 & 147 & 211 & 242 \\
\hline $1-67$ & 8305 & 147 & 210 & 242 \\
\hline $1-68 a$ & 5239 & 94 & 135 & 155 \\
\hline $1-68 b$ & 4514 & 81 & 116 & 133 \\
\hline $1-69 a$ & 8804 & 159 & 228 & 262 \\
\hline $1-69 b$ & 3997 & 72 & 103 & 119 \\
\hline $1-69 c$ & 1487 & 27 & 38 & 44 \\
\hline
\end{tabular}




\begin{tabular}{|c|c|c|c|c|}
\hline $1-72$ & 597 & 113 & 161 & 185 \\
\hline $1-78 a$ & 4489 & 89 & 128 & 147 \\
\hline $1-78 b$ & 2047 & 41 & 58 & 67 \\
\hline $1-81$ & 9707 & 198 & 283 & 325 \\
\hline $1-83$ & 5920 & 124 & 177 & 203 \\
\hline $1-90$ & 3327 & 74 & 105 & 121 \\
\hline $1-100$ & 1006 & 24 & 35 & 40 \\
\hline $2-20$ & 3710 & 31 & 44 & 50 \\
\hline $2-23 a$ & 1727 & 13 & 18 & 21 \\
\hline $2-23 b$ & 7834 & 73 & 105 & 120 \\
\hline $2-32 a$ & 8500 & 87 & 125 & 143 \\
\hline $2-32 b$ & 2931 & 30 & 42 & 49 \\
\hline $2-33$ & 5531 & 54 & 77 & 88 \\
\hline $2-36$ & 5682 & 68 & 97 & 111 \\
\hline $2-41 a$ & 10782 & 124 & 177 & 203 \\
\hline $2-41 b$ & 6927 & 87 & 124 & 143 \\
\hline $2-42$ & 6798 & 79 & 114 & 130 \\
\hline $2-51$ & 5243 & 76 & 109 & 125 \\
\hline $2-53$ & 8983 & 126 & 180 & 207 \\
\hline $2-56$ & 775 & 12 & 18 & 20 \\
\hline $2-57 a$ & 8083 & 130 & 185 & 212 \\
\hline $2-57 b$ & 5522 & 87 & 125 & 143 \\
\hline $2-60$ & 4400 & 72 & 104 & 119 \\
\hline $2-61$ & 9670 & 161 & 230 & 264 \\
\hline $2-62$ & 5436 & 88 & 126 & 144 \\
\hline $2-63$ & 1362 & 23 & 33 & 38 \\
\hline $2-66$ & 5544 & 97 & 138 & 158 \\
\hline $2-67$ & 5145 & 91 & 130 & 149 \\
\hline $2-68$ & 2510 & 45 & 65 & 75 \\
\hline $3-30$ & 7490 & 69 & 99 & 114 \\
\hline $3-56$ & 5769 & 90 & 128 & 147 \\
\hline $3-68$ & 5120 & 92 & 131 & 151 \\
\hline $4-10 a$ & 19022 & 92 & 132 & 151 \\
\hline $4-10 b$ & 9836 & 51 & 73 & 83 \\
\hline $4-11$ & 11419 & 65 & 93 & 107 \\
\hline $4-14$ & 3852 & 25 & 36 & 41 \\
\hline $4-16$ & 22103 & 161 & 231 & 265 \\
\hline $4-18 a$ & 3457 & 25 & 35 & 41 \\
\hline $4-18 b$ & 9366 & 76 & 109 & 125 \\
\hline $4-20 a$ & 5554 & 39 & 55 & 63 \\
\hline $4-20 b$ & 14200 & 123 & 177 & 203 \\
\hline $4-27$ & 8281 & 82 & 117 & 134 \\
\hline $4-28$ & 13403 & 130 & 185 & 213 \\
\hline $4-30$ & 20208 & 200 & 286 & 328 \\
\hline
\end{tabular}




\begin{tabular}{ccccc}
$4-32 \mathrm{a}$ & 13401 & 140 & 200 & 229 \\
$4-32 \mathrm{~b}$ & 10530 & 112 & 160 & 183 \\
$4-34$ & 18713 & 207 & 295 & 339 \\
$4-37$ & 4001 & 223 & 70 & 81 \\
$4-38 \mathrm{a}$ & 18584 & 123 & 319 & 366 \\
$4-38 \mathrm{~b}$ & 9849 & 113 & 176 & 202 \\
$4-40$ & 9140 & 45 & 162 & 186 \\
$4-41$ & 3547 & 111 & 65 & 74 \\
$4-43$ & 8247 & 76 & 159 & 182 \\
$4-46$ & 5732 & 80 & 109 & 125 \\
$4-56$ & 5059 & 62 & 114 & 131 \\
$4-61$ & 3722 & 48 & 89 & 102 \\
$4-64$ & 2756 & 47 & 68 & 78 \\
$4-68$ & 2637 & 40 & 67 & 77 \\
$4-69$ & 2185 & 93 & 57 & 65 \\
$4-90$ & 4164 & & 133 & 153 \\
\hline
\end{tabular}

\section{A.2 Model Simplification}

Detailed and simplified model versions of the study watershed were compared to verify the validity of simplifying the runoff and temperature models of MINUHET. Two storm events, a concentrated, high intensity storm (June 19, 2017) and a multi-burst, low intensity storm (July 27, 2017), were simulated to highlight any differences in results caused by varying storm characteristics, but the varied storm characteristics did not result in obvious differences between each model version's performances. Small sections of the full model with various defining characteristics were investigated, as summarized in Table A3. Table A4 lists the comparison results evaluated with the Nash Sutcliffe Efficiency Coefficient (NSE) (Nash and Sutcliffe 1970), percent bias (PBIAS) (ASCE 1993; Moriasi et al. 2007), or percent error in volume for flow rate, and percent error in peak (PEP) (ASCE 1993). Most sections analyzed produced well matching flow rate and temperature results (NSE>0.8, PBIAS and PEP < $<10 \%$ ). In general, model simplification effected temperature outputs more than flow rate outputs. Simplification of the full watershed model resulted in very small differences between the detailed and simplified model (NSE>0.99). Temperature PBIAS and peak errors of the full model flow rate were all less than or equal to $\pm 1.0 \%$. However, volume and peak errors for flow rate were more substantial. Overall consideration of the comparison results determined that use of the simplified watershed model was acceptable for this study. 
Table A3. Summary of Notable Characteristics of Individual Model Sections Analyzed to Verify Model Simplification

\begin{tabular}{clcccc}
\hline $\begin{array}{c}\text { Model } \\
\text { Section }\end{array}$ & $\begin{array}{c}\text { Defining } \\
\text { Characteristics }\end{array}$ & $\begin{array}{c}\text { Subbasin } \\
\text { Simplification }\end{array}$ & $\begin{array}{c}\text { Pipe } \\
\text { Simplification } \\
\text { (m) }\end{array}$ & $\begin{array}{c}\text { Number of } \\
\text { SWM } \\
\text { Facilities }\end{array}$ & Land Use \\
\hline 1 & $\begin{array}{l}\text { Most simplified } \\
\text { section; drains to } \\
\text { detention pond }\end{array}$ & 9 to 2 & 8 to 3 & 1 & $\begin{array}{c}\text { Low density } \\
\text { residential (single } \\
\text { family homes) } \\
\text { High density }\end{array}$ \\
\hline $\begin{array}{l}\text { Very dense } \\
\text { development; } \\
\text { bioretention filters; } \\
\text { significant } \\
\text { simplification of } \\
\text { small subbasins }\end{array}$ & 67 to 11 & 36 to 14 & 4 & $\begin{array}{c}\text { residential (multi- } \\
\text { resident units) }\end{array}$ \\
3 & $\begin{array}{l}\text { Highly impervious } \\
\text { roadway; long, } \\
\text { linear subbasin areas } \\
\text { and pipes }\end{array}$ & 17 to 3 & 16 to 7 & 0 & $\begin{array}{c}\text { Roadway } \\
\text { Both pipe and open } \\
\text { channel flowpath; } \\
\text { drains to detention } \\
\text { pond }\end{array}$ \\
$\begin{array}{l}\text { Open channel } \\
\text { network; lots of } \\
\text { pervious area }\end{array}$ & 8 to 5 & 4 to 4 & 1 & $\begin{array}{c}\text { Medium density } \\
\text { residential } \\
\text { (townhomes) }\end{array}$ \\
\hline 5 & 36 to 19 & 49 to 40 & 2 & $\begin{array}{l}\text { Riparian area and } \\
\text { open space; some } \\
\text { low density } \\
\text { residential }\end{array}$ \\
\hline
\end{tabular}

Table A4. Goodness-of-fit Comparison between Detailed and Simplified Models and Sections

\begin{tabular}{cccccccc}
\hline \multirow{2}{*}{$\begin{array}{c}\text { Output } \\
\text { Property }\end{array}$} & \multirow{2}{*}{$\begin{array}{c}\text { Model } \\
\text { Section }\end{array}$} & $\begin{array}{c}\text { June 19 } \\
\text { Storm }\end{array}$ & $\begin{array}{c}\text { July 27 } \\
\text { Storm }\end{array}$ & $\begin{array}{c}\text { June 19 } \\
\text { Storm }\end{array}$ & $\begin{array}{c}\text { July 27 } \\
\text { Storm }\end{array}$ & $\begin{array}{c}\text { June 19 } \\
\text { Storm }\end{array}$ & $\begin{array}{c}\text { July 27 } \\
\text { Storm }\end{array}$ \\
\hline Runoff & Full Model & 0.993 & 0.998 & 6.3 & 0.6 & 10.4 & -1.0 \\
Flow Rate & 1 & 0.935 & 0.997 & 17.8 & -1.8 & 26.3 & -5.5 \\
& 2 & 0.995 & 0.974 & -6.3 & -12.3 & -6.5 & -12.0 \\
& 3 & 1.000 & 1.000 & 0.2 & 0.1 & -0.3 & 3.8 \\
& 4 & 0.901 & 0.966 & -3.6 & -9.0 & 0.6 & -13.6 \\
& 5 & 0.886 & 0.928 & -6.7 & -2.9 & 15.9 & 9.7 \\
\hline Temperature & Full Model & 0.996 & 0.998 & 0.0 & 0.0 & 0.9 & -0.4 \\
& 1 & 0.600 & 0.934 & -0.6 & -0.7 & -1.7 & -2.8 \\
& 2 & 0.820 & 0.906 & -0.5 & 0.2 & 0.1 & -0.6 \\
& 3 & 0.905 & 0.986 & -0.4 & -0.4 & -0.6 & -0.5 \\
& 4 & 0.970 & 0.956 & 0.0 & -0.1 & -1.2 & 0.5 \\
& 5 & 0.995 & 0.999 & 0.0 & 0.0 & 0.0 & 0.0 \\
\hline
\end{tabular}




\section{A.3 Submodel Routing}

The watershed was divided into submodels. Division of the submodels were restricted by program requirements. An upstream submodel must directly flow into the immediately downstream model in order to be connected. So the submodels were divided based on inflow and outflow through the two retention ponds intersecting the main channel of the watershed's storm sewer network. Each pond had to serve as a submodel outlet in order to properly run the pond program DOS shell.

To obtain output results at the point of interest, the watershed outlet, the 4 submodels were routed together with stand-alone DOS shells of MINUHET's routing and pond programs in the following steps, as illustrated in Figure A1:

1. Run Submodel 1, Submodel 2, Submodel 3, and Submodel 4

2. Add Submodel 1 output results to Submodel 2

3. Run Pond Program at Retention Pond 1

4. Run Routing Program at Weir between Retention Pond 1 and Retention Pond 2

5. Add routed output results to Submodel 3

6. Run Pond Program at Retention Pond 2

7. Add routed output results to Submodel 4

8. Run Routing Program at Watershed Outlet

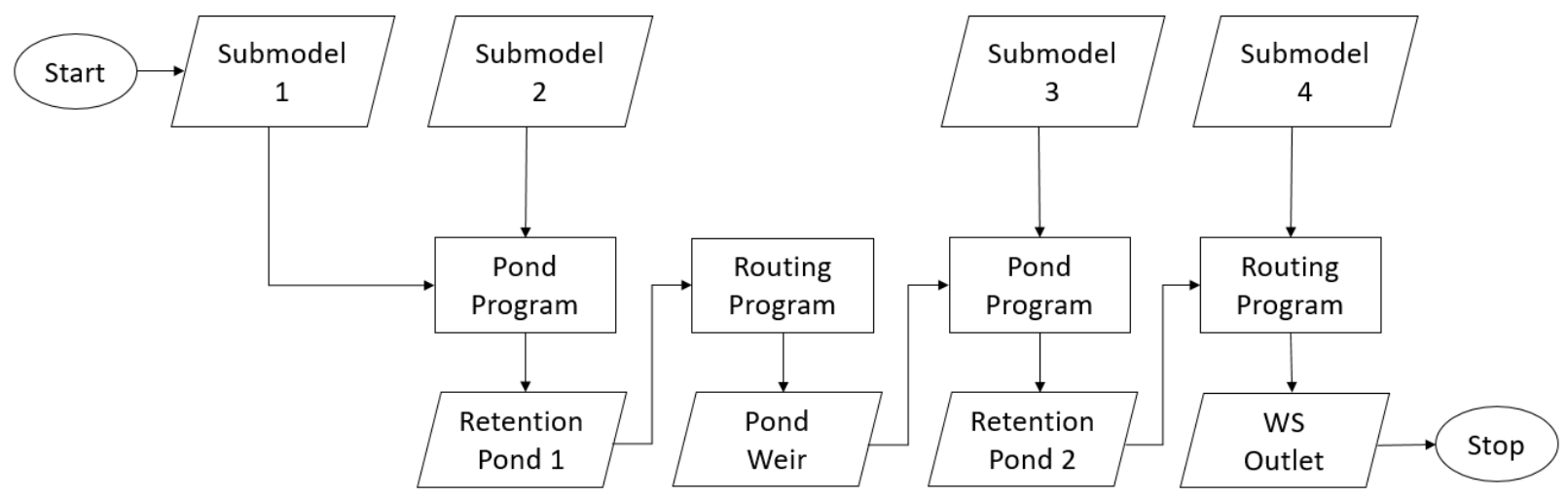

Figure A1. Schematic of the Process Used to Route Submodels Together to Obtain Output at the Watershed Outlet Point 


\section{A.4 Simulation Instabilities of Bioretention Filter Facilities}

Table A5. Inconsistent Input Values of Max. Qin Adjusted for Iterations to Resolve Instability of Bioretention Filters which Experienced Issues

\begin{tabular}{|c|c|c|c|c|c|c|}
\hline \multirow{2}{*}{ Model } & \multirow{2}{*}{ Facility } & \multicolumn{5}{|c|}{ Max. $Q_{\text {in }}$ Values Input $\left(\mathrm{m}^{3} / \mathrm{s}\right)$} \\
\hline & & $100 \% T_{v}$ & $110 \% \mathrm{~T}_{\mathrm{v}}$ & $125 \% \mathrm{~T}_{\mathrm{v}}$ & $150 \% \mathrm{~T}_{\mathrm{v}}$ & $200 \% \mathrm{~T}_{\mathrm{v}}$ \\
\hline Existing & $1-60$ & 0.028 & 0.028 & 0.028 & 0.02 & 0.028 \\
\hline \multirow[t]{16}{*}{ Condition } & $1-83$ & 0.055 & 0.055 & 0.055 & 0.05 & 0.055 \\
\hline & $2-32 b$ & 0.010 & 0.010 & 0.010 & 0.004 & 0.010 \\
\hline & $2-52$ & 0.029 & 0.029 & 0.035 & 0.035 & 0.035 \\
\hline & $2-65$ & 0.032 & 0.032 & 0.032 & 0.035 & 0.032 \\
\hline & $4-10 b$ & 0.010 & 0.010 & 0.010 & 0.010 & 0.015 \\
\hline & $4-27$ & 0.021 & 0.021 & 0.021 & 0.021 & 0.03 \\
\hline & $4-28$ & 0.030 & 0.03 & 0.03 & 0.035 & 0.03 \\
\hline & $4-32 a$ & 0.015 & 0.015 & 0.015 & 0.016 & 0.015 \\
\hline & $4-32 b$ & 0.030 & 0.03 & 0.03 & 0.035 & 0.03 \\
\hline & $4-34$ & 0.018 & 0.022 & 0.022 & 0.022 & 0.022 \\
\hline & $4-38 b$ & 0.020 & 0.03 & 0.058 & 0.06 & 0.058 \\
\hline & $4-40$ & 0.028 & 0.028 & 0.028 & 0.028 & 0.029 \\
\hline & $4-43$ & 0.045 & 0.045 & 0.045 & 0.055 & 0.045 \\
\hline & $4-46$ & 0.012 & 0.012 & 0.012 & 0.012 & 0.02 \\
\hline & $4-48$ & 0.040 & 0.040 & 0.040 & 0.035 & 0.040 \\
\hline & $4-90$ & 0.041 & 0.041 & 0.041 & 0.041 & 0.055 \\
\hline Future Build & $1-37$ & 0.013 & 0.013 & 0.013 & 0.005 & 0.013 \\
\hline \multirow[t]{18}{*}{ Out } & $1-48$ & 0.026 & 1.026 & 2.026 & 0.030 & 2.026 \\
\hline & $1-54 a$ & 0.075 & 0.025 & 0.025 & 0.025 & 0.025 \\
\hline & $1-60$ & 0.028 & 0.028 & 0.028 & 0.020 & 0.028 \\
\hline & $1-83$ & 0.055 & 0.055 & 0.055 & 0.050 & 0.055 \\
\hline & $2-41 a$ & 0.020 & 0.020 & 0.020 & 0.010 & 0.020 \\
\hline & $2-51$ & 0.080 & 0.080 & 0.080 & 0.080 & 0.035 \\
\hline & $2-66$ & 0.027 & 0.027 & 0.027 & 0.029 & 0.027 \\
\hline & $4-10 a$ & 0.010 & 0.010 & 0.010 & 0.010 & 0.015 \\
\hline & $4-27$ & 0.021 & 0.021 & 0.021 & 0.021 & 0.030 \\
\hline & $4-28$ & 0.030 & 1.030 & 2.030 & 0.035 & 2.030 \\
\hline & $4-32 a$ & 0.011 & 0.013 & 0.011 & 0.010 & 0.011 \\
\hline & $4-32 b$ & 0.030 & 0.030 & 0.030 & 0.035 & 0.030 \\
\hline & $4-34$ & 0.018 & 0.022 & 0.022 & 0.022 & 0.022 \\
\hline & $4-38 b$ & 0.020 & 0.030 & 0.040 & 0.060 & 0.058 \\
\hline & $4-40$ & 0.028 & 0.028 & 0.028 & 0.028 & 0.029 \\
\hline & $4-43$ & 0.045 & 0.045 & 0.045 & 0.055 & 0.045 \\
\hline & $4-46$ & 0.012 & 0.012 & 0.012 & 0.012 & 0.020 \\
\hline & $4-90$ & 0.041 & 0.041 & 0.041 & 0.041 & 0.060 \\
\hline
\end{tabular}




\section{Appendix B - Calibration and Validation Results}

\section{B.1 Calibration and Validation Figures Not Included in Research Paper}
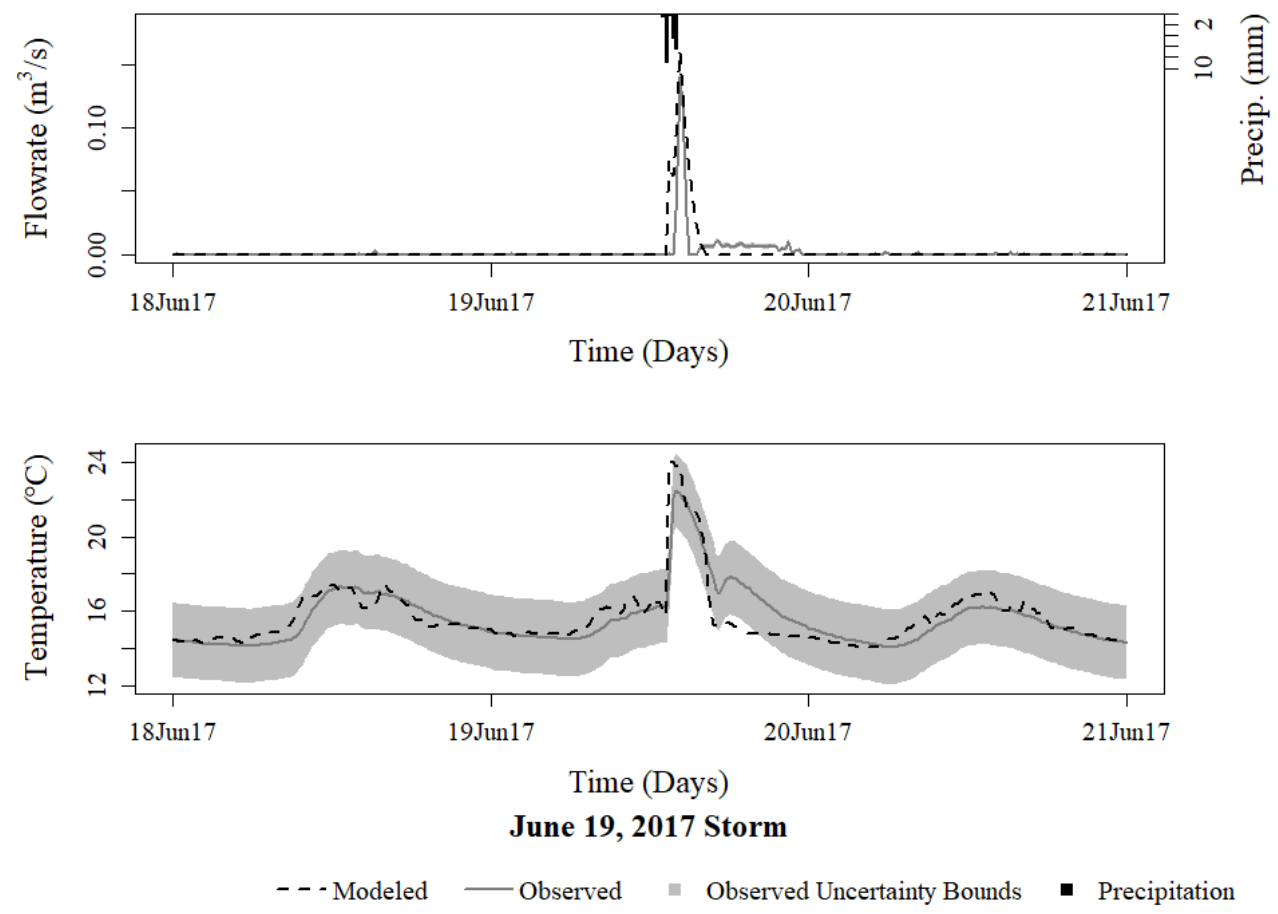

Figure A2. Discharge and Temperature Profile of Calibrated June 19, 2017 Storm
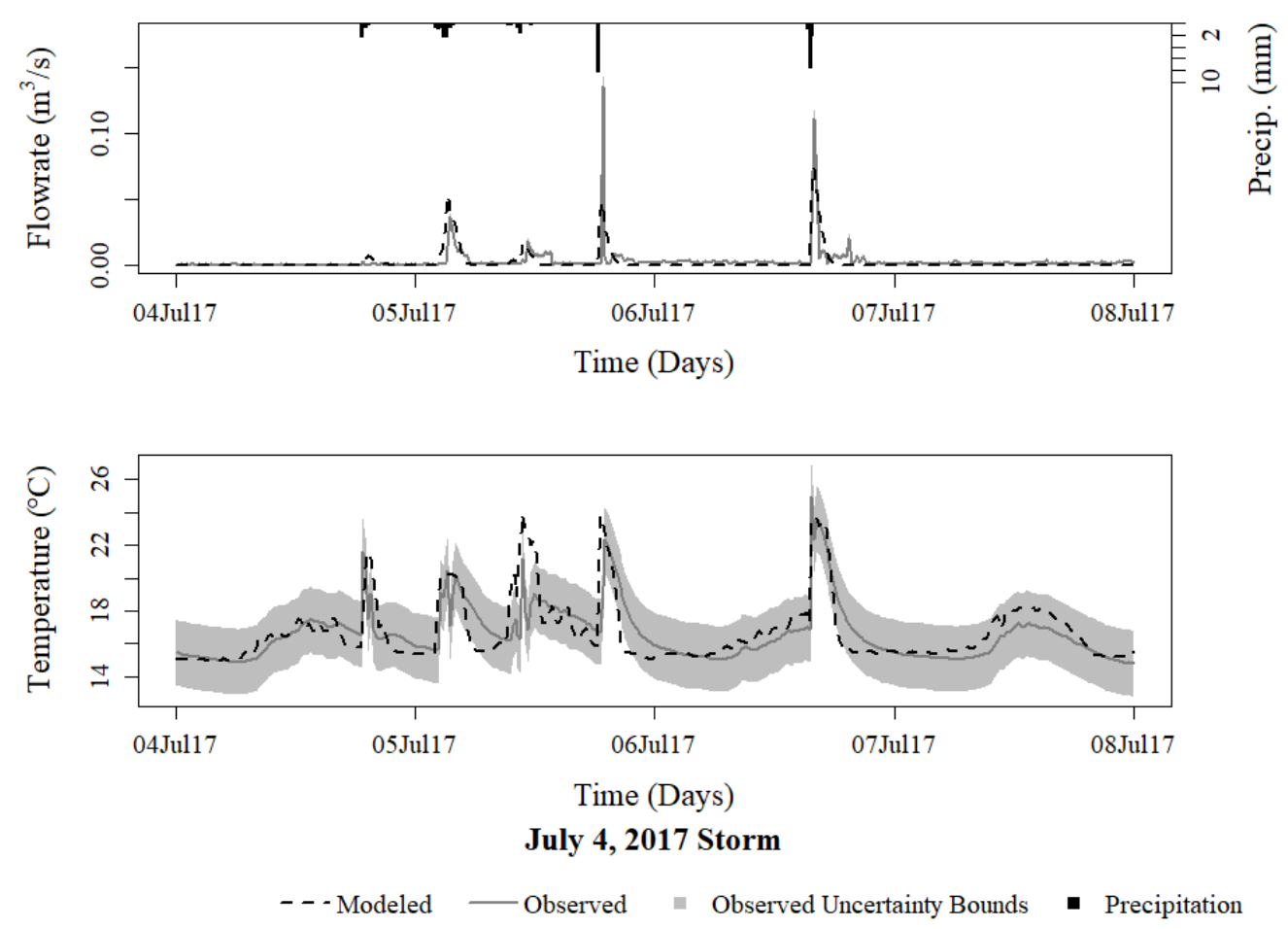

Figure A3. Discharge and Temperature Profile of Validated July 4, 2017 Storm 


\section{B.2 Additional Storms Simulated by Model}

Table A6. Goodness-of-fit Results for Runoff Flow Rates and Temperatures of Additional Storms Simulated

\begin{tabular}{ccccccc}
\hline \multirow{2}{*}{ Storm } & \multicolumn{3}{c}{ Runoff Flow Rate } & \multicolumn{3}{c}{ Temperature } \\
\cline { 2 - 7 } & NSE & PBIAS (\%) & PEP (\%) & NSE & PBIAS (\%) & PEP (\%) \\
\hline June 4, 2017 & 0.349 & -23.2 & -13.2 & 0.308 & -2.0 & 0.3 to -6.97 \\
July 24, 2017 & 0.060 & -160.4 & -0.7 & 0.521 & 1.1 & 2.8 to 3.9 \\
Aug. 4, 2017 & -0.880 & -97.2 & -18.6 & 0.524 & 1.1 & -2.7 to 22.8 \\
Aug. 13, 2017 & 0.175 & -33.0 & 24.0 & 0.701 & 0.5 & 0.6 to -1.3 \\
\hline
\end{tabular}

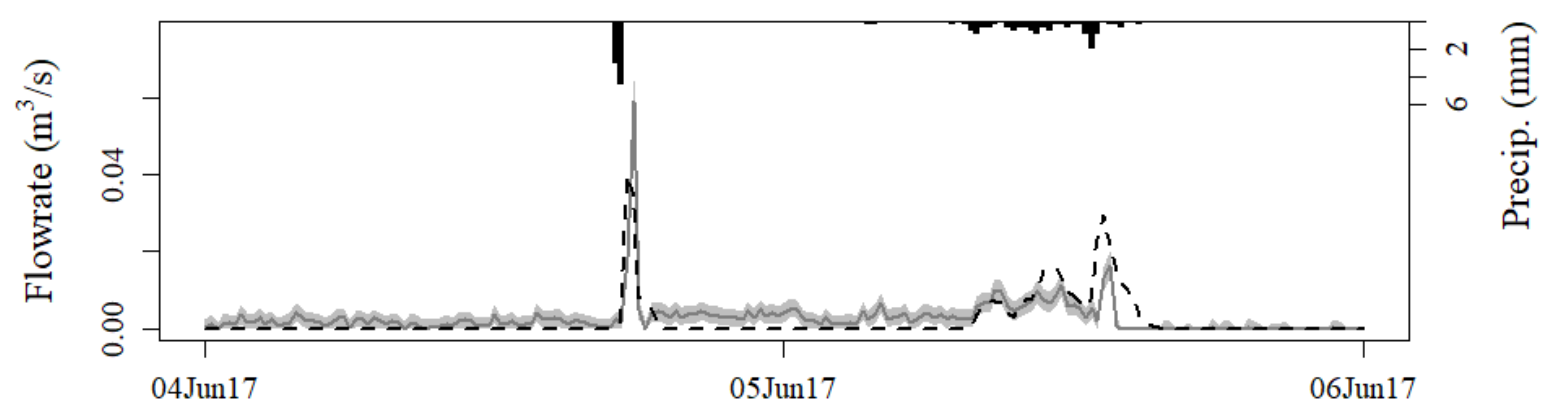

Time (Days)

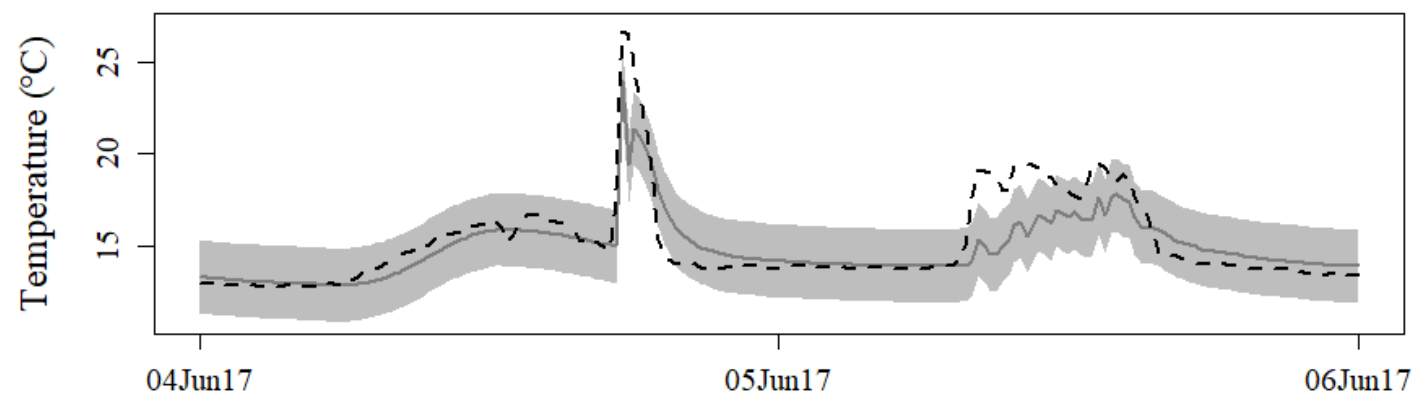

Time (Days)

June 4, 2017 Storm

- - Modeled - Observed - Observed Uncertainty Bounds - Precipitation

Figure A4. Discharge and Temperature Profile of June 4, 2017 Storm 


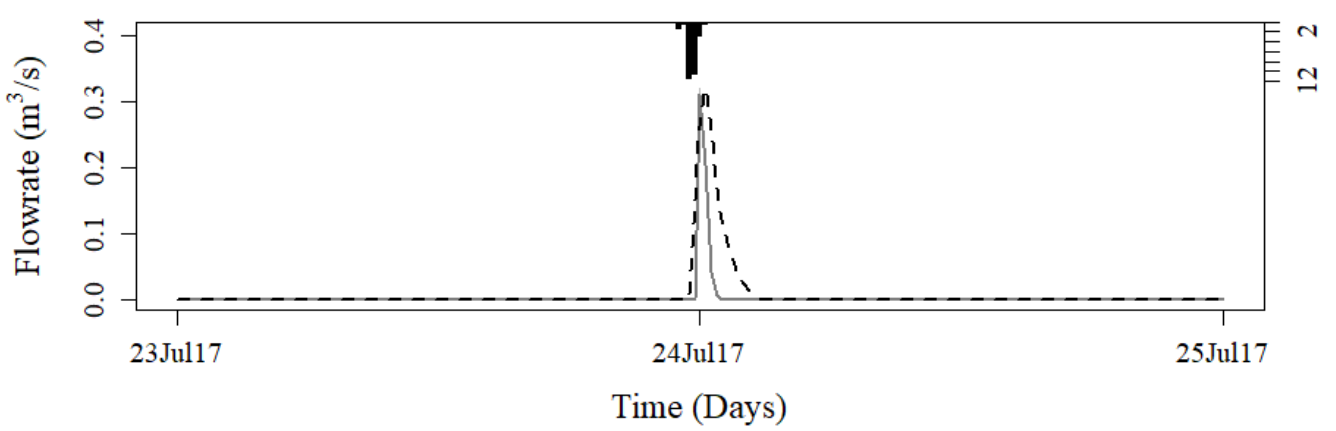

国
它
D.

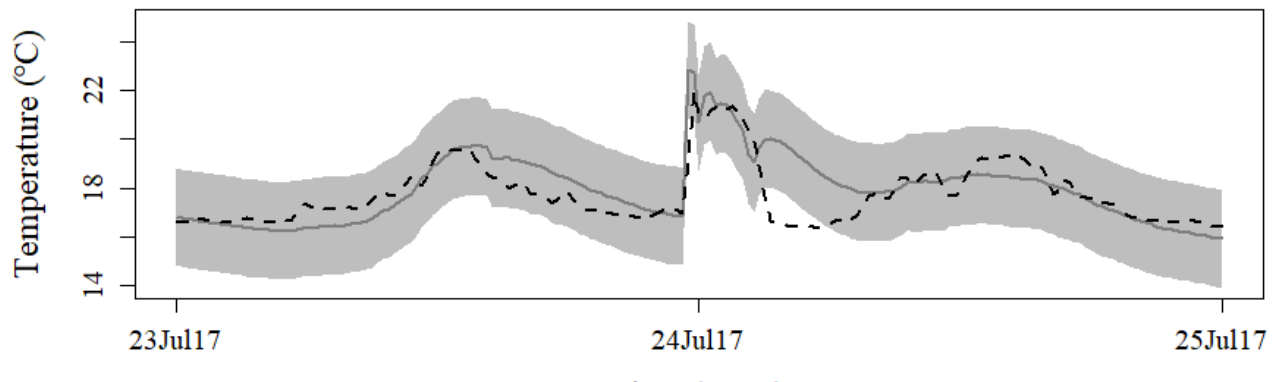

Time (Days)

July 24, 2017 Storm

- - Modeled - Observed Observed Uncertainty Bounds - Precipitation

Figure A5. Discharge and Temperature Profile of July 24, 2017 Storm
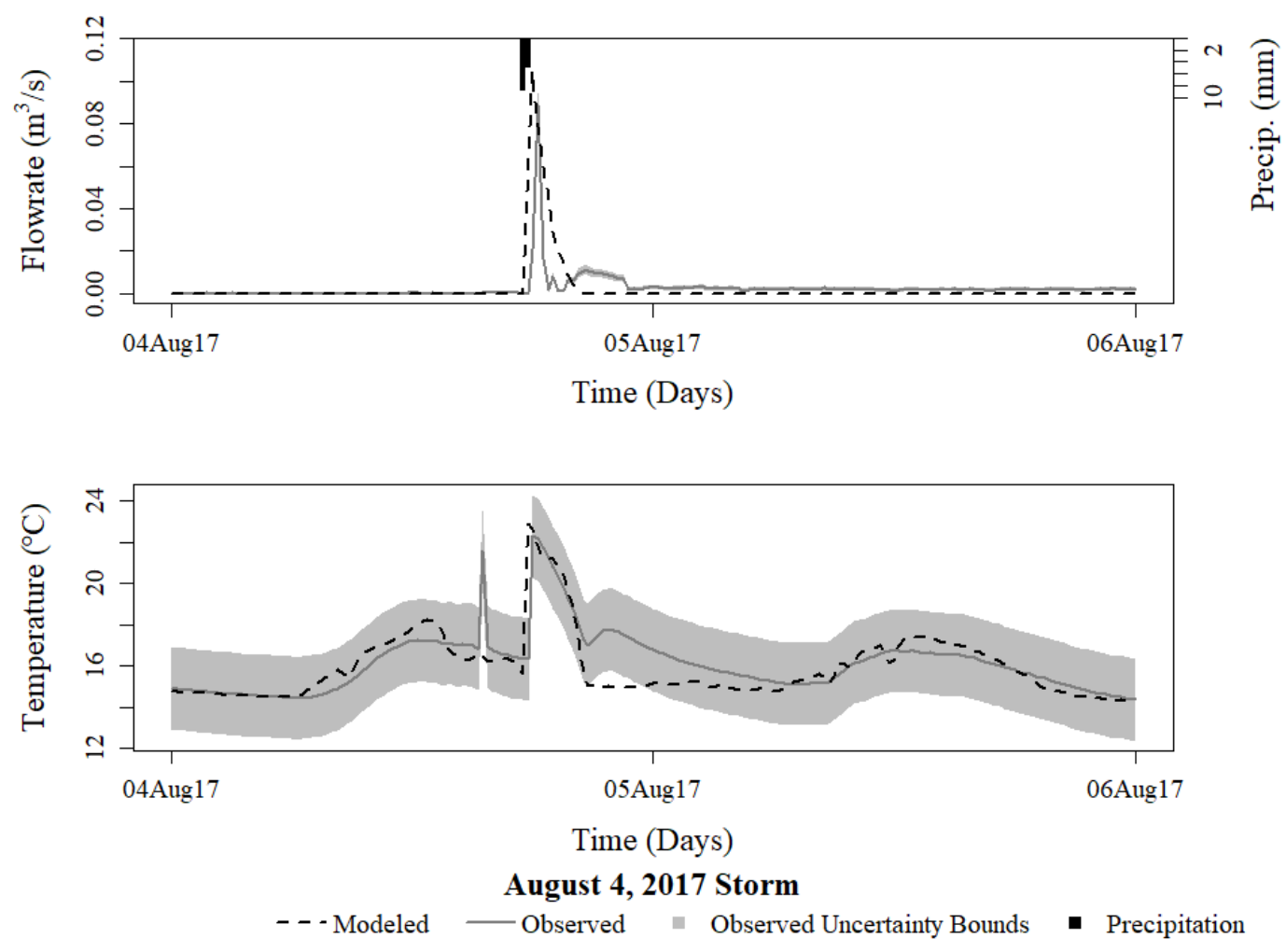

Figure A6. Discharge and Temperature Profile of August 4, 2017 Storm 

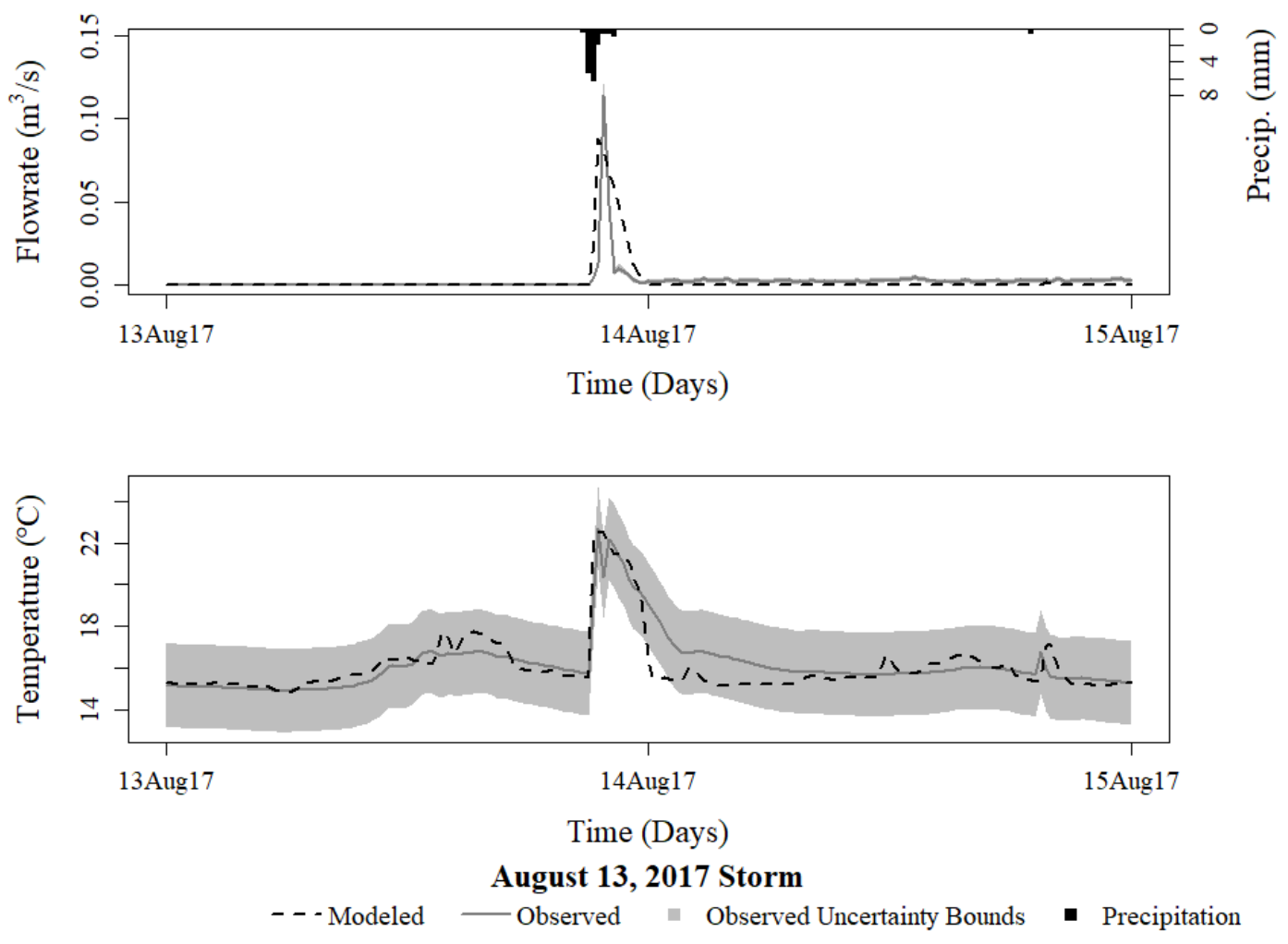

Figure A7. Discharge and Temperature Profile of August 13, 2017 Storm 


\section{Appendix C - Supplemental Results}

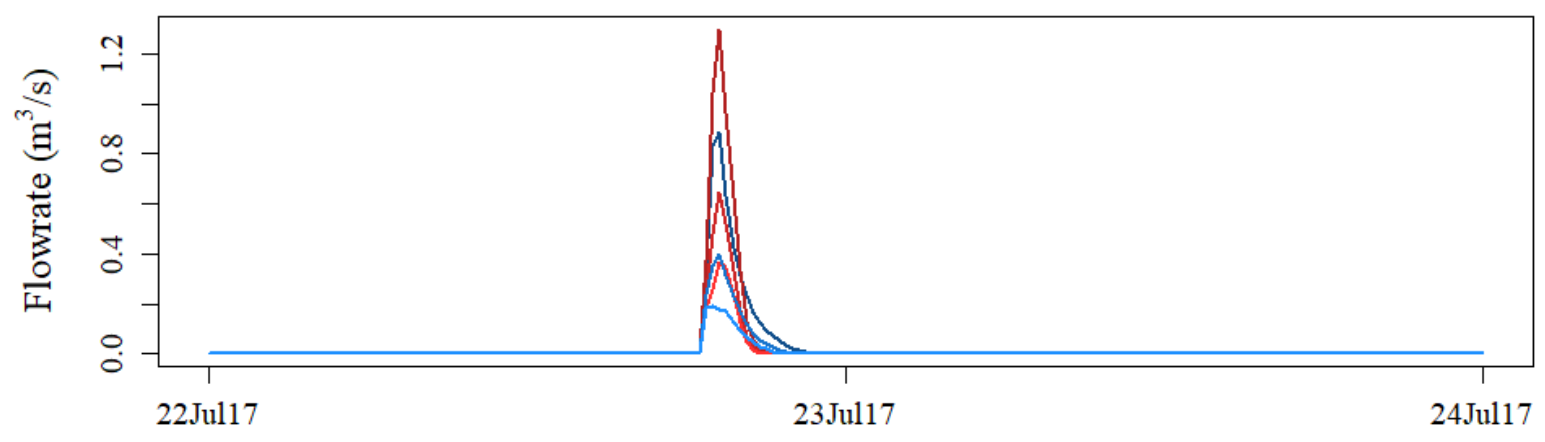

Time (Days)

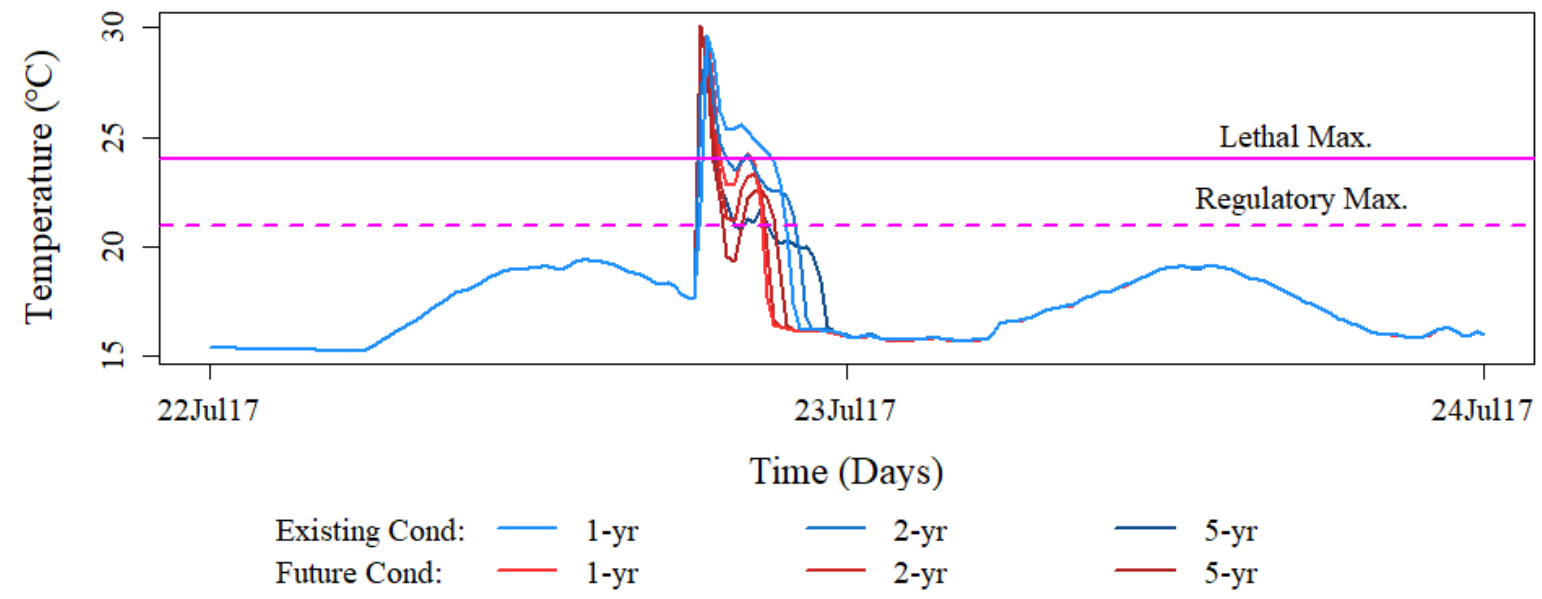

Figure A8. Comparison of Runoff Hydrographs and Thermographs between Existing Condition and Future Development Control Scenarios for Design Storms 
Table A7. Numerical Results from Simulations of \% $\mathrm{T}_{\mathrm{V}}$ Iterations

\begin{tabular}{|c|c|c|c|c|c|c|c|}
\hline $\begin{array}{c}\text { Storm } \\
T_{R}\end{array}$ & Scenario & Iteration & $\begin{array}{c}\text { RO Volume } \\
\left(\mathrm{m}^{3}\right)\end{array}$ & $\begin{array}{c}\text { RO Q Qeak } \\
\left(\mathrm{m}^{3} / \mathrm{s}\right)\end{array}$ & $\mathbf{T}_{\max }\left({ }^{\circ} \mathbf{C}\right)$ & $\operatorname{EMT}\left({ }^{\circ} \mathbf{C}\right)$ & H (MJ) \\
\hline \multirow[t]{6}{*}{$1-y r$} & Existing & Control & 1017 & 0.191 & 29.7 & 26.3 & 18.3 \\
\hline & Dev. & $100 \% \mathrm{TV}$ & 914 & 0.160 & 24.1 & 23.0 & 7.47 \\
\hline & & $110 \% \mathrm{TV}$ & 921 & 0.162 & 24.6 & 23.1 & 7.55 \\
\hline & & $125 \% \mathrm{Tv}$ & 908 & 0.158 & 24.4 & 22.9 & 6.72 \\
\hline & & $150 \% \mathrm{TV}$ & 859 & 0.157 & 24.4 & 22.8 & 5.79 \\
\hline & & $100 \% \mathrm{Tv}$ & 838 & 0.151 & 24.1 & 22.4 & 4.31 \\
\hline \multirow[t]{6}{*}{$1-y r$} & Future & Control & 1420 & 0.366 & 29.7 & 24.3 & 22.4 \\
\hline & Dev. & $100 \% \mathrm{Tv}$ & 1208 & 0.293 & 23.1 & 22.4 & 7.36 \\
\hline & & $110 \% \mathrm{Tv}$ & 1217 & 0.304 & 22.9 & 22.3 & 6.57 \\
\hline & & $125 \% \mathrm{Tv}$ & 1166 & 0.294 & 23.1 & 22.4 & 6.68 \\
\hline & & $150 \% \mathrm{Tv}$ & 1155 & 0.296 & 23.1 & 22.3 & 6.20 \\
\hline & & $100 \% \mathrm{Tv}$ & 1134 & 0.295 & 23.7 & 22.8 & 4.75 \\
\hline \multirow[t]{6}{*}{$2-y r$} & Existing & Control & 1845 & 0.402 & 29.3 & 24.6 & 31.1 \\
\hline & Dev. & $100 \% \mathrm{Tv}$ & 1542 & 0.338 & 24.2 & 22.9 & 12.5 \\
\hline & & $110 \% \mathrm{Tv}$ & 1389 & 0.330 & 24.0 & 22.8 & 10.9 \\
\hline & & $125 \% \mathrm{Tv}$ & 1382 & 0.315 & 24.0 & 22.7 & 9.87 \\
\hline & & $150 \% \mathrm{Tv}$ & 1519 & 0.315 & 24.2 & 22.4 & 8.65 \\
\hline & & $100 \% \mathrm{Tv}$ & 1497 & 0.340 & 24.4 & 22.0 & 6.24 \\
\hline \multirow[t]{6}{*}{$2-y r$} & Future & Control & 2254 & 0.646 & 29.2 & 22.9 & 23.2 \\
\hline & Dev. & $100 \% \mathrm{Tv}$ & 2013 & 0.561 & 23.9 & 21.6 & 6.72 \\
\hline & & $110 \% \mathrm{Tv}$ & 2035 & 0.570 & 23.8 & 21.5 & 5.44 \\
\hline & & $125 \% \mathrm{Tv}$ & 1994 & 0.542 & 23.8 & 21.7 & 6.88 \\
\hline & & $150 \% \mathrm{Tv}$ & 1983 & 0.523 & 24.2 & 21.3 & 3.42 \\
\hline & & $100 \% \mathrm{TV}$ & 1948 & 0.505 & 24.4 & 21.3 & 2.82 \\
\hline \multirow[t]{6}{*}{$5-y r$} & Existing & Control & 3847 & 0.887 & 30.1 & 22.3 & 29.4 \\
\hline & Dev. & $100 \% \mathrm{Tv}$ & 3496 & 0.765 & 24.7 & 21.3 & 9.76 \\
\hline & & $110 \% \mathrm{Tv}$ & 3497 & 0.765 & 24.7 & 21.3 & 8.85 \\
\hline & & $125 \% \mathrm{TV}$ & 3494 & 0.755 & 24.5 & 21.2 & 7.09 \\
\hline & & $150 \% \mathrm{TV}$ & 3450 & 0.736 & 24.6 & 21.3 & 7.92 \\
\hline & & $100 \% \mathrm{TV}$ & 3328 & 0.698 & 25.0 & 21.3 & 7.69 \\
\hline \multirow[t]{6}{*}{$5-y r$} & Future & Control & 4392 & 1.296 & 30.1 & 21.5 & 19.2 \\
\hline & Dev. & $100 \% \mathrm{Tv}$ & 4051 & 1.128 & 24.6 & 21.1 & 8.02 \\
\hline & & $110 \% \mathrm{Tv}$ & 4169 & 1.146 & 24.6 & 21.0 & 5.40 \\
\hline & & $125 \% \mathrm{Tv}$ & 4072 & 1.108 & 24.5 & 21.0 & 3.43 \\
\hline & & $150 \% \mathrm{TV}$ & 3959 & 1.093 & 24.7 & 21.4 & 9.94 \\
\hline & & $100 \% \mathrm{TV}$ & 3948 & 1.044 & 25.0 & 21.1 & 4.63 \\
\hline
\end{tabular}




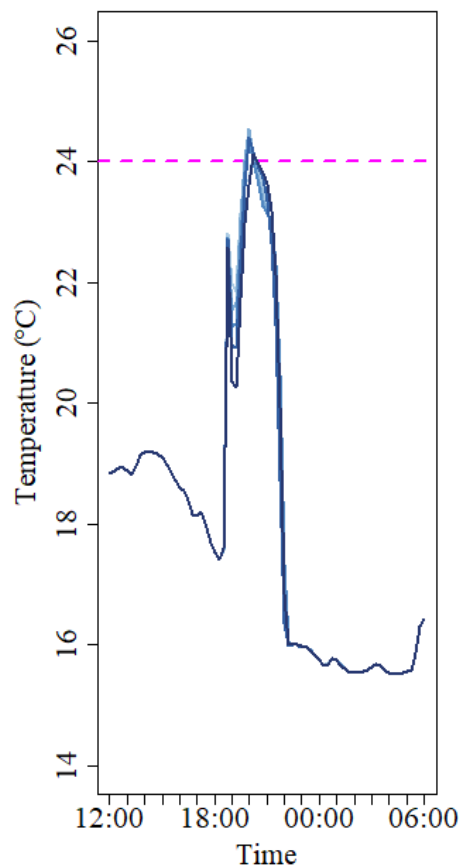

(a) 1 -yr $\mathrm{T}_{\mathrm{R}}$

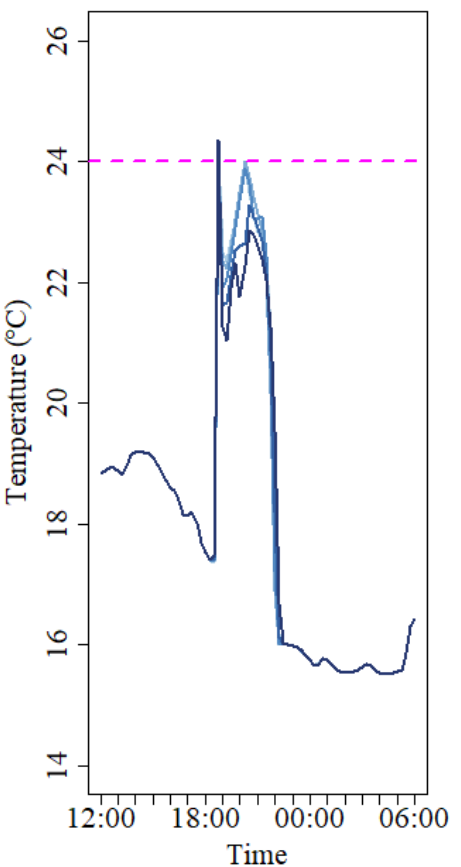

(a) $2-y r T_{R}$

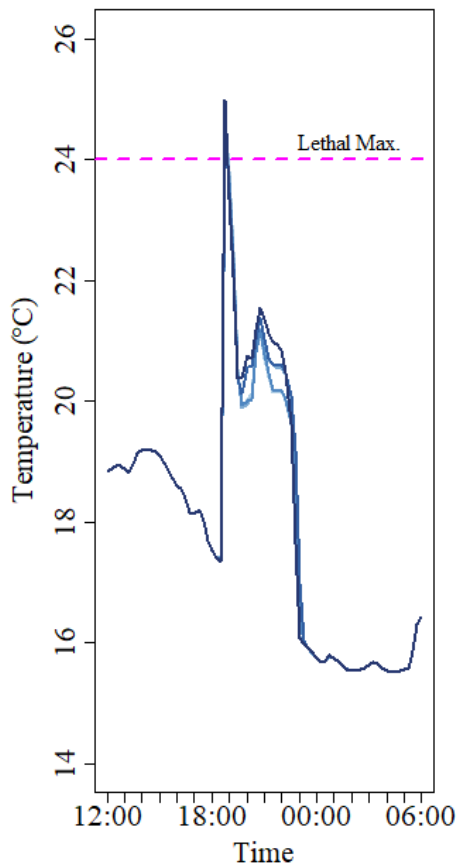

(a) 5 -yr $\mathrm{T}_{\mathrm{R}}$

$100 \% \mathrm{~T}_{\mathrm{V}}$

$110 \% \mathrm{~T}_{\mathrm{V}}$

$125 \% \mathrm{~T}_{\mathrm{V}}$

$150 \% \mathrm{~T}_{\mathrm{V}}$

$200 \% \mathrm{~T}_{\mathrm{V}}$

Figure A9. Simulated Thermographs of Existing Condition Scenario for $\% \mathrm{~T}_{\mathrm{v}}$ Iterations for (a) 1-year $\mathrm{T}_{\mathrm{R}}$, (b) 2-year $\mathrm{T}_{\mathrm{R}}$, and (c) 5-year $\mathrm{T}_{\mathrm{R}}$

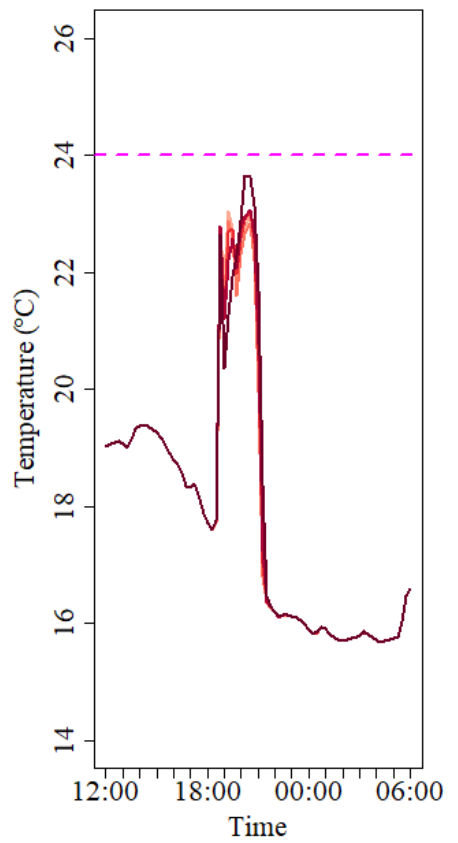

(a) 1 -yr $T_{R}$

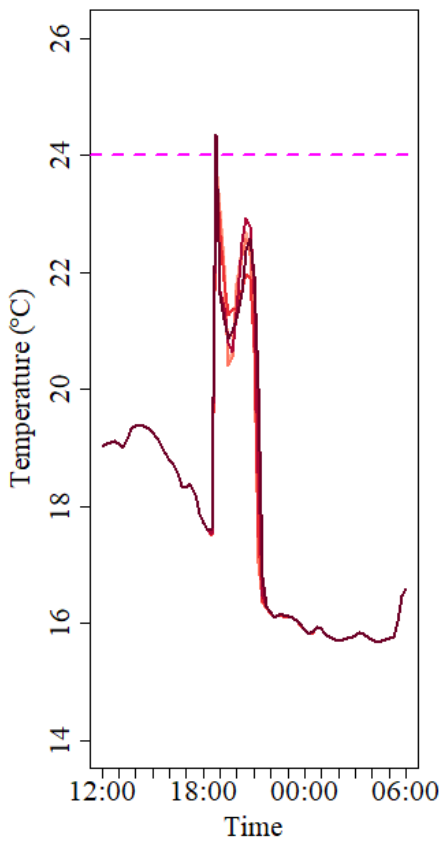

(b) 2 -yr $\mathrm{T}_{\mathrm{R}}$

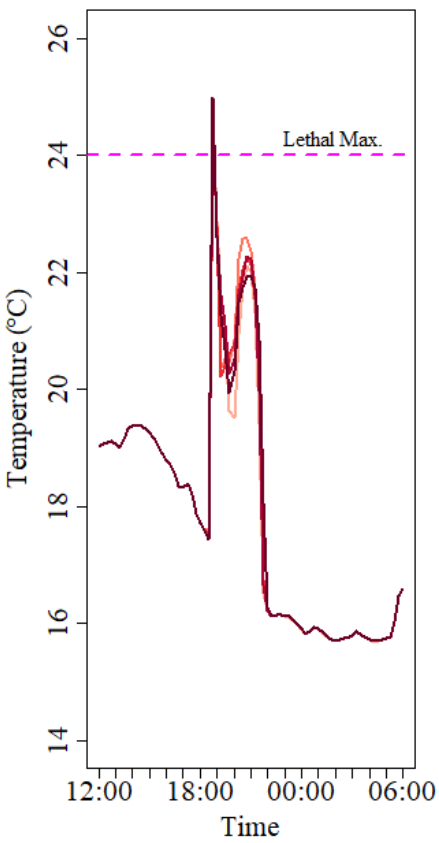

(c) 5 -yr $\mathrm{T}_{\mathrm{R}}$

Figure A10. Simulated Thermographs of Future Development Scenario for $\% \mathrm{~T}_{\mathrm{v}}$ Iterations for (a) 1-year $T_{R}$, (b) 2-year $T_{R}$, and (c) 5-year $T_{R}$ 


\section{Appendix D - Design Storm Input Files}

Table A8. Partial Sample of Design Storm Meteorological Data Input for 1-year Storm, Starting 24 Hours before Storm (Rainfall Depth Varies for other Return Periods)

\begin{tabular}{|c|c|c|c|c|c|c|}
\hline Time & $\begin{array}{c}\text { Air Temp. } \\
\left({ }^{\circ} \mathrm{C}\right)\end{array}$ & $\begin{array}{l}\text { RH } \\
(\%)\end{array}$ & $\begin{array}{c}\text { Solar Radiation } \\
(\mathrm{W} / \mathrm{m} 2)\end{array}$ & $\begin{array}{c}\text { Wind Speed } \\
(\mathbf{m} / \mathbf{s})\end{array}$ & $\begin{array}{l}\text { Rainfal } \\
1(\mathbf{c m})\end{array}$ & $\begin{array}{c}\text { Cloud Cover } \\
\text { Fraction }\end{array}$ \\
\hline $7 / 21 / 2017$ 18:00 & 30.06 & 55.74 & 305.06 & 1.96 & 0 & 0.45 \\
\hline $7 / 21 / 2017$ 18:15 & 29.69 & 57.735 & 257.08 & 1.60 & 0 & 0.45 \\
\hline $7 / 21 / 2017$ 18:30 & 29.32 & 59.73 & 208.46 & 1.24 & 0 & 0.45 \\
\hline 7/21/2017 18:45 & 29.26 & 60.795 & 159.32 & 0.62 & 0 & 0.225 \\
\hline 7/21/2017 19:00 & 29.2 & 61.86 & 109.78 & 0.00 & 0 & 0 \\
\hline $7 / 21 / 2017$ 19:15 & 27.835 & 68.665 & 59.96 & 0.18 & 0 & 0 \\
\hline $7 / 21 / 2017$ 19:30 & 26.47 & 75.47 & 10.00 & 0.36 & 0 & 0 \\
\hline $7 / 21 / 2017$ 19:45 & 25.395 & 78.635 & 0 & 0.76 & 0 & 0 \\
\hline 7/21/2017 20:00 & 24.32 & 81.8 & 0 & 1.16 & 0 & 0 \\
\hline $7 / 21 / 2017$ 20:15 & 23.985 & 82.35 & 0 & 1.24 & 0 & 0 \\
\hline $7 / 21 / 2017$ 20:30 & 23.65 & 82.9 & 0 & 1.32 & 0 & 0 \\
\hline $7 / 21 / 2017$ 20:45 & 22.86 & 86.6 & 0 & 0.84 & 0 & 0 \\
\hline 7/21/2017 21:00 & 22.07 & 90.3 & 0 & 0.36 & 0 & 0 \\
\hline $7 / 21 / 2017$ 21:15 & 21.615 & 92.3 & 0 & 0.18 & 0 & 0 \\
\hline $7 / 21 / 201721: 30$ & 21.16 & 94.3 & 0 & 0.00 & 0 & 0 \\
\hline $7 / 21 / 2017$ 21:45 & 21.025 & 95.05 & 0 & 0.22 & 0 & 0 \\
\hline 7/21/2017 22:00 & 20.89 & 95.8 & 0 & 0.44 & 0 & 0 \\
\hline $7 / 21 / 2017$ 22:15 & 20.39 & 96.95 & 0 & 0.22 & 0 & 0 \\
\hline $7 / 21 / 201722: 30$ & 19.89 & 98.1 & 0 & 0.00 & 0 & 0 \\
\hline $7 / 21 / 2017$ 22:45 & 19.685 & 98.65 & 0 & 0.00 & 0 & 0 \\
\hline 7/21/2017 23:00 & 19.48 & 99.2 & 0 & 0.00 & 0 & 0 \\
\hline $7 / 21 / 2017$ 23:15 & 19.39 & 99.6 & 0 & 0.26 & 0 & 0 \\
\hline $7 / 21 / 2017$ 23:30 & 19.3 & 100 & 0 & 0.52 & 0 & 0 \\
\hline $7 / 21 / 2017$ 23:45 & 19.1 & 100 & 0 & 0.26 & 0 & 0 \\
\hline 7/22/2017 0:00 & 18.9 & 100 & 0 & 0.00 & 0 & 0 \\
\hline $7 / 22 / 20170: 15$ & 18.93 & 100 & 0 & 0.46 & 0 & 0 \\
\hline $7 / 22 / 20170: 30$ & 18.96 & 100 & 0 & 0.92 & 0 & 0 \\
\hline $7 / 22 / 20170: 45$ & 18.58 & 100 & 0 & 0.46 & 0 & 0 \\
\hline $7 / 22 / 2017$ 1:00 & 18.2 & 100 & 0 & 0.00 & 0 & 0 \\
\hline 7/22/2017 1:15 & 18.345 & 100 & 0 & 0.00 & 0 & 0 \\
\hline $7 / 22 / 20171: 30$ & 18.49 & 100 & 0 & 0.00 & 0 & 0 \\
\hline $7 / 22 / 20171: 45$ & 18.23 & 100 & 0 & 0.00 & 0 & 0 \\
\hline $7 / 22 / 20172: 00$ & 17.97 & 100 & 0 & 0.00 & 0 & 0 \\
\hline $7 / 22 / 20172: 15$ & 18.15 & 100 & 0 & 0.00 & 0 & 0 \\
\hline $7 / 22 / 20172: 30$ & 18.33 & 100 & 0 & 0.00 & 0 & 0 \\
\hline $7 / 22 / 20172: 45$ & 18.165 & 100 & 0 & 0.00 & 0 & 0 \\
\hline $7 / 22 / 20173: 00$ & 18 & 100 & 0 & 0.00 & 0 & 0 \\
\hline $7 / 22 / 20173: 15$ & 17.88 & 100 & 0 & 0.00 & 0 & 0 \\
\hline $7 / 22 / 20173: 30$ & 17.76 & 100 & $\begin{array}{c}0 \\
77\end{array}$ & 0.00 & 0 & 0 \\
\hline
\end{tabular}




\begin{tabular}{|c|c|c|c|c|c|c|}
\hline $7 / 22 / 20173: 45$ & 17.6 & 100 & 0 & 0.00 & 0 & 0 \\
\hline 7/22/2017 4:00 & 17.44 & 100 & 0 & 0.00 & 0 & 0 \\
\hline $7 / 22 / 20174: 15$ & 17.405 & 100 & 0 & 0.00 & 0 & 0 \\
\hline 7/22/2017 4:30 & 17.37 & 100 & 0 & 0.00 & 0 & 0 \\
\hline 7/22/2017 4:45 & 17.335 & 100 & 0 & 0.00 & 0 & 0 \\
\hline 7/22/2017 5:00 & 17.3 & 100 & 0 & 0.00 & 0 & 0 \\
\hline $7 / 22 / 20175: 15$ & 17.045 & 100 & 0 & 0.00 & 0 & 0 \\
\hline $7 / 22 / 20175: 30$ & 16.79 & 100 & 20.00 & 0.00 & 0 & 0 \\
\hline $7 / 22 / 20175: 45$ & 17.025 & 100 & 69.94 & 0.00 & 0 & 0 \\
\hline 7/22/2017 6:00 & 17.26 & 100 & 119.71 & 0.00 & 0 & 0 \\
\hline $7 / 22 / 20176: 15$ & 17.985 & 100 & 169.18 & 0.00 & 0 & 0 \\
\hline $7 / 22 / 20176: 30$ & 18.71 & 100 & 218.23 & 0.00 & 0 & 0 \\
\hline $7 / 22 / 20176: 45$ & 19.52 & 100 & 266.73 & 0.30 & 0 & 0 \\
\hline 7/22/2017 7:00 & 20.33 & 100 & 314.57 & 0.60 & 0 & 0 \\
\hline $7 / 22 / 2017$ 7:15 & 21.155 & 100 & 361.62 & 0.30 & 0 & 0 \\
\hline 7/22/2017 7:30 & 21.98 & 100 & 407.76 & 0.00 & 0 & 0 \\
\hline $7 / 22 / 2017$ 7:45 & 23.28 & 94.4 & 452.89 & 0.26 & 0 & 0 \\
\hline 7/22/2017 8:00 & 24.58 & 88.8 & 496.88 & 0.52 & 0 & 0 \\
\hline $7 / 22 / 20178: 15$ & 25.005 & 86.7 & 548.02 & 0.56 & 0 & 0 \\
\hline $7 / 22 / 20178: 30$ & 25.43 & 84.6 & 589.14 & 0.60 & 0 & 0 \\
\hline $7 / 22 / 20178: 45$ & 26.035 & 82.65 & 628.79 & 1.24 & 0 & 0 \\
\hline 7/22/2017 9:00 & 26.64 & 80.7 & 666.87 & 1.88 & 0 & 0 \\
\hline 7/22/2017 9:15 & 27.115 & 78.655 & 703.28 & 1.16 & 0 & 0 \\
\hline 7/22/2017 9:30 & 27.59 & 76.61 & 744.64 & 0.44 & 0 & 0 \\
\hline 7/22/2017 9:45 & 28.155 & 74.585 & 777.07 & 0.80 & 0 & 0 \\
\hline 7/22/2017 10:00 & 28.72 & 72.56 & 807.56 & 1.16 & 0 & 0 \\
\hline $7 / 22 / 2017$ 10:15 & 28.97 & 70.195 & 836.03 & 1.80 & 0 & 0 \\
\hline 7/22/2017 10:30 & 29.22 & 67.83 & 857.30 & 2.44 & 0 & 0 \\
\hline $7 / 22 / 2017$ 10:45 & 29.71 & 65.67 & 881.96 & 2.56 & 0 & 0 \\
\hline 7/22/2017 11:00 & 30.2 & 63.51 & 900.10 & 2.68 & 0 & 0 \\
\hline $7 / 22 / 2017$ 11:15 & 30.57 & 60.655 & 916.80 & 2.12 & 0 & 0 \\
\hline $7 / 22 / 2017$ 11:30 & 30.94 & 57.8 & 932.04 & 1.56 & 0 & 0 \\
\hline 7/22/2017 11:45 & 30.955 & 60.53 & 942.49 & 1.56 & 0 & 0 \\
\hline 7/22/2017 12:00 & 30.97 & 63.26 & 948.98 & 1.56 & 0 & 0 \\
\hline $7 / 22 / 2017$ 12:15 & 30.755 & 61.84 & 955.10 & 1.84 & 0 & 0 \\
\hline 7/22/2017 12:30 & 30.54 & 60.42 & 955.10 & 2.12 & 0 & 0 \\
\hline 7/22/2017 12:45 & 28.64 & 69.995 & 955.10 & 2.04 & 0 & 0.225 \\
\hline 7/22/2017 13:00 & 26.74 & 79.57 & 948.98 & 1.96 & 0 & 0.45 \\
\hline 7/22/2017 13:15 & 28.79 & 72.875 & 939.10 & 2.12 & 0 & 0.725 \\
\hline 7/22/2017 13:30 & 30.84 & 66.18 & 928.37 & 2.28 & 0 & 0.8 \\
\hline 7/22/2017 13:45 & 31.55 & 61.36 & 912.76 & 2.36 & 0 & 0.8 \\
\hline 7/22/2017 14:00 & 32.26 & 56.54 & 895.70 & 2.44 & 0 & 0.8 \\
\hline $7 / 22 / 201714: 15$ & 32.335 & 54.25 & 877.20 & 2.92 & 0 & 0.8 \\
\hline $7 / 22 / 2017$ 14:30 & 32.41 & 51.96 & 852.11 & 3.40 & 0 & 0.8 \\
\hline
\end{tabular}




\begin{tabular}{|c|c|c|c|c|c|c|}
\hline 7/22/2017 14:45 & 32.66 & 51.38 & 824.89 & 3.00 & 0 & 0.8 \\
\hline 7/22/2017 15:00 & 32.91 & 50.8 & 795.60 & 2.60 & 0 & 0.8 \\
\hline 7/22/2017 15:15 & 33.02 & 49.26 & 764.33 & 2.20 & 0 & 0.8 \\
\hline 7/22/2017 15:30 & 33.13 & 47.72 & 731.15 & 1.80 & 0 & 0.8 \\
\hline 7/22/2017 15:45 & 32.985 & 47.72 & 696.14 & 1.96 & 0 & 0.8 \\
\hline 7/22/2017 16:00 & 32.84 & 47.72 & 659.38 & 2.12 & 0 & 1 \\
\hline $7 / 22 / 2017$ 16:15 & 32.595 & 50.675 & 620.99 & 1.28 & 0 & 1 \\
\hline 7/22/2017 16:30 & 32.35 & 53.63 & 572.87 & 0.44 & 0 & 1 \\
\hline 7/22/2017 16:45 & 32.525 & 51.22 & 531.19 & 2.04 & 0 & 1 \\
\hline 7/22/2017 17:00 & 32.7 & 48.81 & 488.18 & 3.64 & 0 & 1 \\
\hline 7/22/2017 17:15 & 32.18 & 52.58 & 443.95 & 2.20 & 0 & 1 \\
\hline 7/22/2017 17:30 & 31.66 & 56.35 & 398.61 & 0.76 & 0 & 1 \\
\hline 7/22/2017 17:45 & 31.39 & 55.965 & 352.27 & 1.36 & 0 & 1 \\
\hline 7/22/2017 18:00 & 31.12 & 55.58 & 295.52 & 1.96 & 0 & 1 \\
\hline 7/22/2017 18:15 & 31.075 & 55.73 & 247.40 & 1.88 & 0.34 & 1 \\
\hline 7/22/2017 18:30 & 31.03 & 55.88 & 198.67 & 1.80 & 1.34 & 1 \\
\hline 7/22/2017 18:45 & 30.655 & 55.935 & 149.44 & 1.80 & 0.69 & 1 \\
\hline 7/22/2017 19:00 & 30.28 & 55.99 & 99.83 & 1.80 & 0.20 & 1 \\
\hline 7/22/2017 19:15 & 29.72 & 57.925 & 59.96 & 1.16 & 0 & 1 \\
\hline 7/22/2017 19:30 & 29.16 & 59.86 & 10.00 & 0.52 & 0 & 1 \\
\hline 7/22/2017 19:45 & 28.515 & 65.545 & 0 & 0.96 & 0 & 1 \\
\hline 7/22/2017 20:00 & 27.87 & 71.23 & 0 & 1.40 & 0 & 1 \\
\hline $7 / 22 / 201720: 15$ & 27.505 & 72.59 & 0 & 0.70 & 0 & 1 \\
\hline 7/22/2017 20:30 & 27.14 & 73.95 & 0 & 0.00 & 0 & 1 \\
\hline 7/22/2017 20:45 & 27.445 & 71.53 & 0 & 0.22 & 0 & 1 \\
\hline 7/22/2017 21:00 & 27.75 & 69.11 & 0 & 0.44 & 0 & 0.9 \\
\hline $7 / 22 / 201721: 15$ & 27.5 & 70.815 & 0 & 0.68 & 0 & 0.8 \\
\hline 7/22/2017 21:30 & 27.25 & 72.52 & 0 & 0.92 & 0 & 0.45 \\
\hline 7/22/2017 21:45 & 26.955 & 73.515 & 0 & 1.04 & 0 & 0.225 \\
\hline 7/22/2017 22:00 & 26.66 & 74.51 & 0 & 1.16 & 0 & 0 \\
\hline $7 / 22 / 201722: 15$ & 26.28 & 75.885 & 0 & 1.08 & 0 & 0.45 \\
\hline 7/22/2017 22:30 & 25.9 & 77.26 & 0 & 1.00 & 0 & 0.45 \\
\hline 7/22/2017 22:45 & 25.7 & 78 & 0 & 1.08 & 0 & 0.45 \\
\hline 7/22/2017 23:00 & 25.5 & 78.74 & 0 & 1.16 & 0 & 0.45 \\
\hline 7/22/2017 23:15 & 24.705 & 82.17 & 0 & 1.00 & 0 & 0.45 \\
\hline 7/22/2017 23:30 & 23.91 & 85.6 & 0 & 0.84 & 0 & 0.45 \\
\hline 7/22/2017 23:45 & 23.42 & 88 & 0 & 0.42 & 0 & 0.45 \\
\hline 7/23/2017 0:00 & 22.93 & 90.4 & 0 & 0.00 & 0 & 0.45 \\
\hline $7 / 23 / 20170: 15$ & 23.93 & 85.9 & 0 & 0.30 & 0 & 0.45 \\
\hline $7 / 23 / 20170: 30$ & 24.93 & 81.4 & 0 & 0.60 & 0 & 0.45 \\
\hline 7/23/2017 0:45 & 24.825 & 82 & 0 & 0.52 & 0 & 0.225 \\
\hline 7/23/2017 1:00 & 24.72 & 82.6 & 0 & 0.44 & 0 & 0 \\
\hline $7 / 23 / 2017$ 1:15 & 24.37 & 84.2 & 0 & 0.22 & 0 & 0 \\
\hline $7 / 23 / 2017$ 1:30 & 24.02 & 85.8 & 0 & 0.00 & 0 & 0 \\
\hline
\end{tabular}




\begin{tabular}{|c|c|c|c|c|c|c|}
\hline $7 / 23 / 2017$ 1:45 & 23.835 & 86.85 & 0 & 0.18 & 0 & 0 \\
\hline 7/23/2017 2:00 & 23.65 & 87.9 & 0 & 0.36 & 0 & 0 \\
\hline $7 / 23 / 20172: 15$ & 23.765 & 87.55 & 0 & 0.52 & 0 & 0 \\
\hline $7 / 23 / 20172: 30$ & 23.88 & 87.2 & 0 & 0.68 & 0 & 0 \\
\hline $7 / 23 / 20172: 45$ & 24.32 & 85.55 & 0 & 0.88 & 0 & 0 \\
\hline 7/23/2017 3:00 & 24.76 & 83.9 & 0 & 1.08 & 0 & 0 \\
\hline 7/23/2017 3:15 & 24.505 & 84.95 & 0 & 0.72 & 0 & 0 \\
\hline 7/23/2017 3:30 & 24.25 & 86 & 0 & 0.36 & 0 & 0 \\
\hline 7/23/2017 3:45 & 24.115 & 86.45 & 0 & 0.18 & 0 & 0 \\
\hline 7/23/2017 4:00 & 23.98 & 86.9 & 0 & 0.00 & 0 & 0 \\
\hline 7/23/2017 4:15 & 23.845 & 87.65 & 0 & 0.30 & 0 & 0 \\
\hline 7/23/2017 4:30 & 23.71 & 88.4 & 0 & 0.60 & 0 & 0 \\
\hline 7/23/2017 4:45 & 23.485 & 89.6 & 0 & 0.76 & 0 & 0 \\
\hline 7/23/2017 5:00 & 23.26 & 90.8 & 0 & 0.92 & 0 & 0 \\
\hline $7 / 23 / 20175: 15$ & 24.205 & 85.5 & 0 & 3.12 & 0 & 0.45 \\
\hline 7/23/2017 5:30 & 25.15 & 80.2 & 20.00 & 5.32 & 0 & 0.8 \\
\hline $7 / 23 / 20175: 45$ & 24.97 & 80.55 & 69.94 & 3.52 & 0 & 0.9 \\
\hline 7/23/2017 6:00 & 24.79 & 80.9 & 119.71 & 1.72 & 0 & 1 \\
\hline $7 / 23 / 20176: 15$ & 24.415 & 80.5 & 159.32 & 2.68 & 0 & 0.8 \\
\hline 7/23/2017 6:30 & 24.04 & 80.1 & 208.46 & 3.64 & 0 & 0.45 \\
\hline $7 / 23 / 20176: 45$ & 23.445 & 79.875 & 257.08 & 3.84 & 0 & 0.625 \\
\hline 7/23/2017 7:00 & 22.85 & 79.65 & 314.57 & 4.04 & 0 & 0.8 \\
\hline $7 / 23 / 2017$ 7:15 & 22.835 & 79.235 & 361.62 & 3.36 & 0 & 1 \\
\hline 7/23/2017 7:30 & 22.82 & 78.82 & 407.76 & 2.68 & 0 & 1 \\
\hline 7/23/2017 7:45 & 23.005 & 80.16 & 452.89 & 2.04 & 0 & 0.725 \\
\hline 7/23/2017 8:00 & 23.19 & 81.5 & 496.88 & 1.40 & 0 & 0.45 \\
\hline $7 / 23 / 20178: 15$ & 23.24 & 80.135 & 539.63 & 2.84 & 0 & 0 \\
\hline $7 / 23 / 20178: 30$ & 23.29 & 78.77 & 589.14 & 4.28 & 0 & 0 \\
\hline 7/23/2017 8:45 & 23.59 & 78.03 & 628.79 & 2.88 & 0 & 0.225 \\
\hline 7/23/2017 9:00 & 23.89 & 77.29 & 666.87 & 1.48 & 0 & 0.45 \\
\hline 7/23/2017 9:15 & 24.145 & 76.935 & 703.28 & 1.28 & 0 & 0.45 \\
\hline 7/23/2017 9:30 & 24.4 & 76.58 & 737.93 & 1.08 & 0 & 0 \\
\hline 7/23/2017 9:45 & 24.98 & 73.99 & 770.74 & 1.04 & 0 & 0 \\
\hline 7/23/2017 10:00 & 25.56 & 71.4 & 801.62 & 1.00 & 0 & 0 \\
\hline 7/23/2017 10:15 & 25.79 & 69.285 & 830.50 & 1.72 & 0 & 0 \\
\hline 7/23/2017 10:30 & 26.02 & 67.17 & 857.30 & 2.44 & 0 & 0 \\
\hline 7/23/2017 10:45 & 26.535 & 67.91 & 881.96 & 2.48 & 0 & 0 \\
\hline 7/23/2017 11:00 & 27.05 & 68.65 & 900.10 & 2.52 & 0 & 0 \\
\hline 7/23/2017 11:15 & 27.935 & 63.62 & 916.80 & 3.24 & 0 & 0 \\
\hline $7 / 23 / 2017$ 11:30 & 28.82 & 58.59 & 932.04 & 3.96 & 0 & 0 \\
\hline 7/23/2017 11:45 & 29.805 & 58.405 & 942.49 & 2.76 & 0 & 0 \\
\hline 7/23/2017 12:00 & 30.79 & 58.22 & 948.98 & 1.56 & 0 & 0 \\
\hline $7 / 23 / 2017$ 12:15 & 30.265 & 55.89 & 952.09 & 1.60 & 0 & 0.45 \\
\hline 7/23/2017 12:30 & 29.74 & 53.56 & 955.10 & 1.64 & 0 & 0.45 \\
\hline
\end{tabular}




\begin{tabular}{|c|c|c|c|c|c|c|}
\hline 7/23/2017 12:45 & 29.71 & 53.7 & 952.09 & 2.16 & 0 & 0.225 \\
\hline 7/23/2017 13:00 & 29.68 & 53.84 & 948.98 & 2.68 & 0 & 0 \\
\hline $7 / 23 / 2017$ 13:15 & 29.69 & 53.315 & 939.10 & 3.04 & 0 & 0.45 \\
\hline 7/23/2017 13:30 & 29.7 & 52.79 & 928.37 & 3.40 & 0 & 0.45 \\
\hline 7/23/2017 13:45 & 29.69 & 51.855 & 912.76 & 3.56 & 0 & 0.45 \\
\hline 7/23/2017 14:00 & 29.68 & 50.92 & 895.70 & 3.72 & 0 & 0.45 \\
\hline $7 / 23 / 2017$ 14:15 & 29.59 & 51.57 & 872.36 & 2.88 & 0 & 0.45 \\
\hline 7/23/2017 14:30 & 29.5 & 52.22 & 852.11 & 2.04 & 0 & 0.45 \\
\hline 7/23/2017 14:45 & 29.4 & 52.655 & 824.89 & 1.80 & 0 & 0.225 \\
\hline 7/23/2017 15:00 & 29.3 & 53.09 & 795.60 & 1.56 & 0 & 0 \\
\hline 7/23/2017 15:15 & 29.3 & 52.445 & 764.33 & 2.00 & 0 & 0.45 \\
\hline 7/23/2017 15:30 & 29.3 & 51.8 & 731.15 & 2.44 & 0 & 0.45 \\
\hline 7/23/2017 15:45 & 28.84 & 53.585 & 696.14 & 2.44 & 0 & 0.225 \\
\hline 7/23/2017 16:00 & 28.38 & 55.37 & 659.38 & 2.44 & 0 & 0 \\
\hline $7 / 23 / 2017$ 16:15 & 28.43 & 55.425 & 613.12 & 2.36 & 0 & 0 \\
\hline 7/23/2017 16:30 & 28.48 & 55.48 & 572.87 & 2.28 & 0 & 0 \\
\hline 7/23/2017 16:45 & 28.155 & 56.8 & 531.19 & 1.60 & 0 & 0 \\
\hline 7/23/2017 17:00 & 27.83 & 58.12 & 488.18 & 0.92 & 0 & 0 \\
\hline 7/23/2017 17:15 & 28.34 & 55.095 & 443.95 & 1.36 & 0 & 0 \\
\hline 7/23/2017 17:30 & 28.85 & 52.07 & 389.42 & 1.80 & 0 & 0 \\
\hline 7/23/2017 17:45 & 28.925 & 50.84 & 342.90 & 1.36 & 0 & 0 \\
\hline 7/23/2017 18:00 & 29 & 49.61 & 295.52 & 0.92 & 0 & 0 \\
\hline $7 / 23 / 2017$ 18:15 & 28.395 & 50.875 & 247.40 & 0.46 & 0 & 0 \\
\hline 7/23/2017 18:30 & 27.79 & 52.14 & 198.67 & 0.00 & 0 & 0.45 \\
\hline 7/23/2017 18:45 & 26.705 & 61.15 & 149.44 & 0.00 & 0 & 0.725 \\
\hline 7/23/2017 19:00 & 25.62 & 70.16 & 99.83 & 0.00 & 0 & 1 \\
\hline 7/23/2017 19:15 & 25.23 & 72.23 & 49.98 & 0.22 & 0 & 1 \\
\hline 7/23/2017 19:30 & 24.84 & 74.3 & 10.00 & 0.44 & 0 & 1 \\
\hline 7/23/2017 19:45 & 24.375 & 76.6 & 0 & 0.22 & 0 & 1 \\
\hline 7/23/2017 20:00 & 23.91 & 78.9 & 0 & 0.00 & 0 & 1 \\
\hline $7 / 23 / 201720: 15$ & 23.56 & 81.2 & 0 & 0.00 & 0 & 1 \\
\hline 7/23/2017 20:30 & 23.21 & 83.5 & 0 & 0.00 & 0 & 1 \\
\hline 7/23/2017 20:45 & 22.45 & 85.45 & 0 & 0.22 & 0 & 0.9 \\
\hline 7/23/2017 21:00 & 21.69 & 87.4 & 0 & 0.44 & 0 & 0.8 \\
\hline $7 / 23 / 201721: 15$ & 21.87 & 87.2 & 0 & 0.52 & 0 & 0.8 \\
\hline 7/23/2017 21:30 & 22.05 & 87 & 0 & 0.60 & 0 & 1 \\
\hline 7/23/2017 21:45 & 23.405 & 80.935 & 0 & 1.88 & 0 & 0.9 \\
\hline 7/23/2017 22:00 & 24.76 & 74.87 & 0 & 3.16 & 0 & 0.8 \\
\hline $7 / 23 / 201722: 15$ & 24.455 & 78.535 & 0 & 3.08 & 0 & 1 \\
\hline 7/23/2017 22:30 & 24.15 & 82.2 & 0 & 3.00 & 0 & 1 \\
\hline 7/23/2017 22:45 & 23.14 & 89.6 & 0 & 1.50 & 0 & 1 \\
\hline 7/23/2017 23:00 & 22.13 & 97 & 0 & 0.00 & 0 & 1 \\
\hline $7 / 23 / 201723: 15$ & 21.44 & 98 & 0 & 2.30 & 0 & 1 \\
\hline 7/23/2017 23:30 & 20.75 & 99 & 0 & 4.60 & 0 & 1 \\
\hline
\end{tabular}


$7 / 23 / 201723: 45$

7/24/2017 0:00
20.17

19.59
99.5

100
2.72

0.84
0

0
1

1 